\title{
CHARACTERISTICS OF LIGHTNING AT AND IN THE VICINITY OF THE CN TOWER
}

\author{
by \\ Vicki Todorovski \\ BASc, University of Windsor, 2004 \\ A thesis \\ presented to Ryerson University \\ in partial fulfillment of the \\ requirement for the degree of \\ Master of Applied Science \\ in the Program of \\ Electrical and Computer Engineering
}

Toronto, Ontario, Canada, 2007

(C) Vicki Todorovski, 2007 


\section{Author's Declaration}

I hereby declare that I am the sole author of this thesis.

I authorize Ryerson University to lend this thesis to other institutions or individuals for the sole purpose of scholarly research.

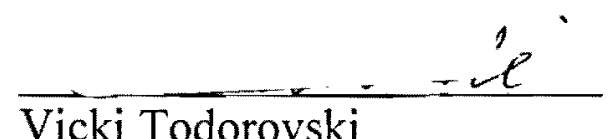

I further authorize Ryerson University to reproduce this thesis by photocopying or by other means, in total or in part, at the request of other institutions or individuals for the sole purpose of scholarly research.

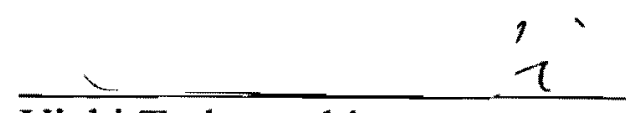

Vicki Todorovski 


\section{Instructions for Borrowers}

Ryerson University requires the signatures of all persons using or photocopying this thesis. Please sign below, and give address and date.

\begin{tabular}{|c|c|c|c|}
\hline Name & Signature & Address & Date \\
\hline & & & \\
\hline & & & \\
\hline & & & \\
\hline & & & \\
\hline & & & \\
\hline & & & \\
\hline & & & \\
\hline & & & \\
\hline & & & \\
\hline & & & \\
\hline & & & \\
\hline & & & \\
\hline & & & \\
\hline & & & \\
\hline & & & \\
\hline & & & \\
\hline & & & \\
\hline & & & \\
\hline & & & \\
\hline & & & \\
\hline & & & \\
\hline & & & \\
\hline & & & \\
\hline & & & \\
\hline & & & \\
\hline & & & \\
\hline
\end{tabular}




\begin{abstract} Tower

CVicki Todorovski 2007

Master of Applied Science

Department of Electrical and Computer Engineering

Ryerson University
\end{abstract}

Characteristics of Lightning Strikes at and in the Vicinity of the $\mathrm{CN}$

The CN Tower has been the center of tourism in Toronto since it first opened to the public on June 26, 1976. It is the world's tallest manmade freestanding structure as well as Canada's most recognizable icon standing at a height of 553 meters. However, like everything else, there could be a down side to this incredible structure. Does it attract more lightning; potentially putting the surrounding area in its vicinity in harm's way, or does it provide lightning protection to this area? Although, extensive analysis have been performed concerning the characteristics of lightning strikes to the $\mathrm{CN}$ Tower, not much attention has been given to the characteristics of lightning strikes in the vicinity of the tower or the influence the tower has on the lightning environment around it. This thesis is believed to be the first to fill such a gap and tries to answer these questions. Using the 2005 North American Lightning Detection Network data for the area of up to $100 \mathrm{~km}$ from the tower, an extensive investigation of lightning activities in the vicinity of the tower is presented here. A comparison between the characteristics of $\mathrm{CN}$ Tower strikes and the characteristics of strikes occurring in its vicinity is also presented. Furthermore, the parameters of the lightning electromagnetic pulse (LEMP) generated by a strike to the tower are compared with those generated by a non-CN Tower strike. A substantial increase in the $\mathrm{CN}$ Tower LEMP peak in comparison with that resulting from non-CN Tower LEMP has been found. Therefore, electronic and communication systems located in the vicinity of a very tall structure must be specially protected from the lightning-generated electromagnetic pulse. 


\section{Acknowledgements}

First and foremost, I would like to sincerely thank my parents Lily and George Todorovski for their everlasting love, understanding, moral and financial support throughout my studies towards my BASc and MASc degrees in Electrical and Computer Engineering. I thank you both with all my heart. Also I would like to say thanks and the best of luck to my younger brother, Danny Todorovski who is graduating with a degree in Computer Science.

My heartfelt thanks goes out to all my closest friends, GL, JT, MC, for their continuing friendship, guidance and support that they have provided me during my studies, particularly my best friend David Onichuk, for his constant encouragement, knowledge and support throughout my studies. I have learned so much from you about electrical and computer systems which would not have been possible without your patience, guidance and support. Thank you for, first, giving me the opportunity to not only work with you during my BASc studies but also to volunteer though the organization that you were managing to provide computer systems and expertise to members of the community free of charge and second, for all your unending help and support during my MASc journey.

I would also like to give my sincerest thanks to my thesis supervisor, Dr. Ali M. Hussein for his advice and guidance throughout my MASc research. His professionalism, knowledge and expertise will never be forgotten. I will always value the research discussions that we had over the last few years.

I would also like to thank Chief Scientist Ken Cummins of Vaisala Inc. for providing me with the North American Lightning Detection Network data and for answering any questions I had at the beginning of this work.

I would further like to thank Mariusz Milewski, PhD student in Electrical and Computer Engineering at Ryerson University, for his assistance and support.

Finally, I would like to express my gratitude to Professor Emeritus Wasyl Janischewskyj of University of Toronto for pioneering the CN Tower lightning research in 1978. 


\section{Contents}

List of Tables

List of Figures

1 Introduction

2 Lightning Phenomenon

2.1 What is Lightning and how does it Happen?

2.2 Lightning Terminology

2.3 Importance of Measuring the Lightning Current

3 Tracking Lightning at the CN Tower

3.1 Flash Trajectory

3.2 Lightning Current Derivative

3.3 Lightning Electromagnetic Pulse.....

4 North American Lightning Detection Network

4.1 Magnetic Field Direction Finding ............................................... 24

4.2 Time-of-Arrival Technique ........................................................ 24

4.3 NALDN: Observations and Findings for North America ........................... 25

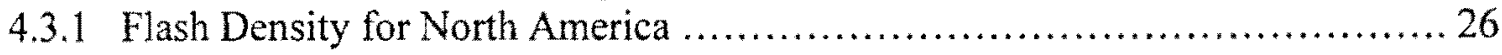

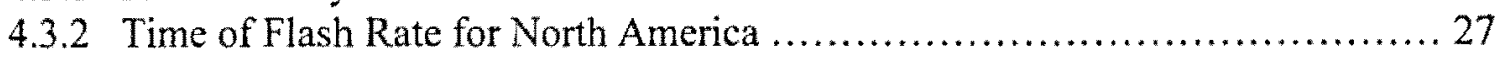

4.3.3 Peak Current for North America ........................................... 28

4.3.4 Flash Multiplicity for North America ..................................... 28

5 Flash Characteristics $\quad \mathbf{3 0}$

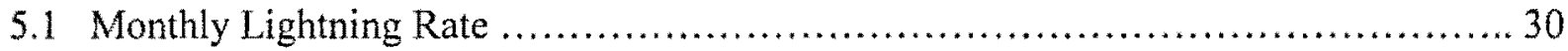

5.2 Diumal Distribution of Flashes ...................................................... 31

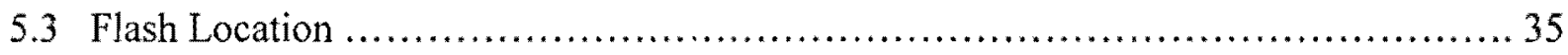

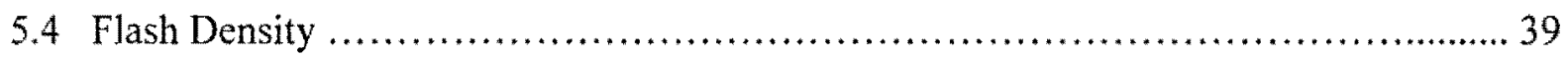

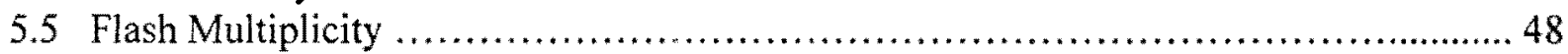

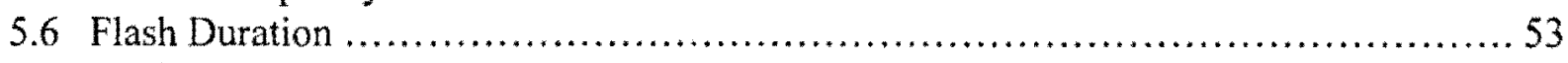

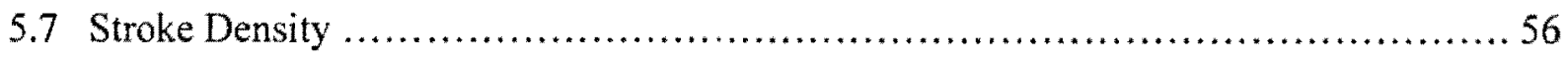

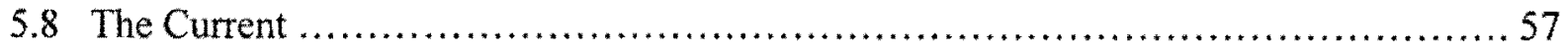

5.9 The Lightning Electromagnetic Pulse (LEMP) ..................................... 62

6 Conclusions and Future Research $\quad \mathbf{6 5}$

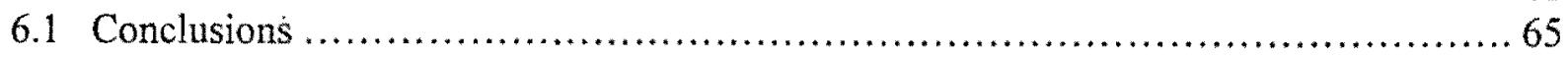

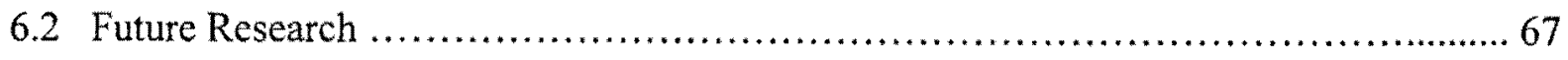

$\begin{array}{lr}\text { References } & 68\end{array}$

$\begin{array}{lr}\text { Publications Related to this Research } & \mathbf{7 0}\end{array}$ 


\section{List of Tables}

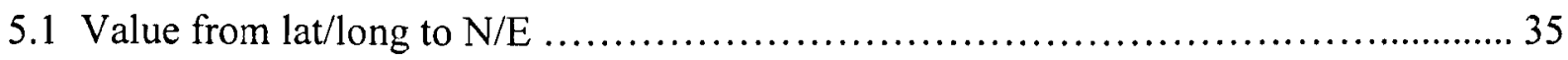




\section{List of Figures}

2.1 Franklin's original experiment (Adapted from $[3,4]$.) ........................... 4

2.2 Franklin's electrical kite experiment (Adapted from $[3,4]$.) ....................... 5

2.3 Categorization of the four types of lightning (Adapted from $[3,4].) \ldots \ldots \ldots \ldots \ldots \ldots .6$

2.4 Various processes comprising a negative cloud-to-ground lightning flash (Adapted

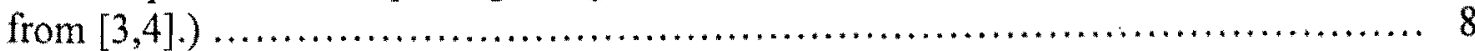

2.5 A still photograph of a typical cloud-to-ground flash (Adapted from [3,4].) .......... 9

2.6 (a) Streak photograph of the attachment process to tower on Mount San Salvatore in Lugano, Switzerland (b) Still photograph of the flash from (a) and another flash that struck the tower below its top (Adapted from [4].) ............................ 12

3.1 The CN Tower with the locations of instruments ................................ 14

3.2 A typical CN Tower flash recorded by the high-speed camera on Aug. 19, 2005 at

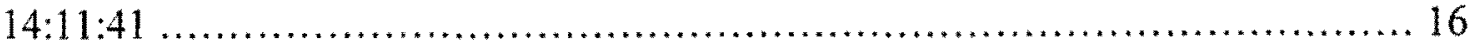

3.3 The old Rogowski coil and its location ....................................... 17

3.4 Current derivative signal captured on August 19,2005 at 14:11:41 ............... 18

3.5 Current waveform (time integral of current derivative signal shown in Figure 3.4) ... 18

3.6 The electric field generated by a CN Tower lightning stroke, August 19, 2005 at

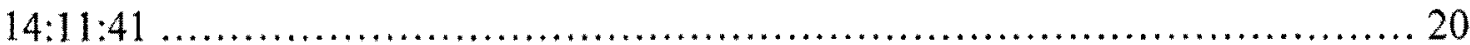

3.7 The magnetic field generated by a CN Tower lighting stroke, August 19, 2005 at

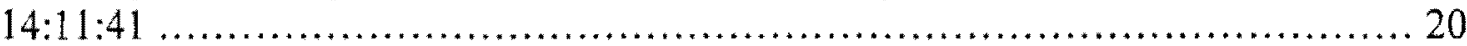

4.1 NALDN system after the 2003 upgrade (Adapted from [12].) ....................... 22

4.2 NALDN based Lightning Detection Technologies (Adapted from [16].) ............. 23

4.3 Four Panel display shows the annual ground flash density in North America for the individual years (a) 1998, (b) 1999, (c) 2000, and (d) the mean flash density for the 3 year combined (Adapted from [14].)

5.1 Percentage of the number of flashes vs months for 2005 within $100 \mathrm{~km}$ radius around the $\mathrm{CN}$ Tower ....

5.2 Percentage of the number of flashes vs local Toronto time for all Flashes within 10 $\mathrm{km}$ radius around the $\mathrm{CN}$ Tower for the 2005 (Including the 7 flashes that hit the $\mathrm{CN}$ Tower)

5.3 Percentage of the number of flashes vs local Toronto time for all flashes within 10 $\mathrm{km}$ of the CN Tower for July and August 2005 (Including the 6 flashes that hit the $\mathrm{CN}$ Tower)

5.4 Percentage of the number of flashes vs local Toronto time for all flashes within 10 $\mathrm{km}$ of the $\mathrm{CN}$ Tower on August 19,2005 (Including the 6 flashes that hit the $\mathrm{CN}$ Tower)

5.5 Location of flashes within $20 \mathrm{~km}$ radius around the CN Tower for August 19, 2005. Each grid is for $2 \mathrm{~km}(0-2,2-4, \ldots, 18-20)$ and 45 degrees $(0-360$ deg $C W$ from $N) \ldots 36$

5.6 Location of flashes within $10 \mathrm{~km}$ radius around the $\mathrm{CN}$ Tower for August 19, 2005 Each grid is for $1 \mathrm{~km}(0-1,1-2, \ldots, 9-10)$ and 45 degrees $(0-360 \mathrm{deg} \mathrm{CW}$ from $\mathrm{N}) \ldots . .37$ 
5.7 Location of flashes within $1 \mathrm{~km}$ radius around the $\mathrm{CN}$ Tower for August 19, 2005 Each grid is for $0.1 \mathrm{~km}(0-0.1,0.1-0.2, \ldots, 0.9-1.0)$ and 45 degrees $(0-360 \mathrm{deg} \mathrm{CW}$ from $\mathrm{N}$ )

5.8 Ground Flash Density (GFD) for 2005 ( 3047 flashes) within $20 \mathrm{~km}$ radius around the CN Tower $(0-2,2-4, \ldots, 18-20)$

5.9 Ground Flash Density (GFD) for August 19, 2005 (1307 flashes) within $20 \mathrm{~km}$

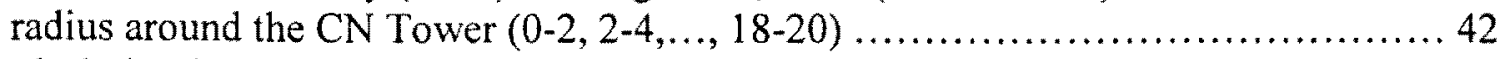

5.10 Flash density vs distance $(0-20 \mathrm{~km})$ excluding $\mathrm{CN}$ Tower flashes for $2005 \ldots \ldots \ldots \ldots 44$

5.11 Flash density vs distance $(0-20 \mathrm{~km})$ excluding $\mathrm{CN}$ Tower flashes for August 19 , 2005

5.12 Number of flashes vs distance from the CN Tower (0-10 km radius) August 19, 2005 lightning events

5.13 Number of -ve and +ve flashes vs distance from the CN Tower $(0-10 \mathrm{~km}$ radius) for August 19, 2005 lightning events ........................................ 47

5.14 Flash multiplicity vs distance from Tower (10 km radius) August 19, 2005 ............. 49

5.15 Cumulative distribution of the number of strokes per flash for August 19, 2005 ..... 52

5.16 Average flash duration for multiple stroke flashes vs distance from the Tower (10 km radius) August 19, 2005

5.17 Cumulative Distribution of the Number of Multiple Stroke Flashes for August 19,2005

5.18 Average peak current $(\mathrm{kA})$ vs distance from the $\mathrm{CN}$ Tower $(10 \mathrm{~km}$ radius) August 19,2005 lightning events (distance is defined as $\left.0^{+}-1,1^{+} 2, \ldots, 9^{+}-10\right) \ldots \ldots \ldots \ldots \ldots . \ldots . \ldots 59$

5.19 Cumulative distribution of the peak current for August 19, 2005

5.20 Cumulative distribution of the electric field peak for August 19, 2005 lightning events 62

5.21 Cumulative distribution of electric field risetime for August 19, 2005 lightning events 


\section{Chapter 1}

\section{Introduction}

The $\mathrm{CN}$ Tower has been the center of tourism in Toronto since it first opened to the public on June 26, 1976. It is the world's tallest building as well as Canada's most recognizable icon standing at a height of 553 meters or 1815 feet [1]. The $\mathrm{CN}$ Tower has generated a lot of tourism money for Toronto and it definitely attracts a lot of people to visit this great city but as with everything else, there is a down side to this incredible structure. Does it attract more lightning; potentially putting the surrounding area around the $\mathrm{CN}$ Tower in harm's way, e.g., due to the lightning-generated electromagnetic pulse (LEMP)? I'd say yes. The research at the CN Tower is important in order to understand the physics of tall-structure lightning, which enables the establishment of more sophisticated lightning protection procedures, especially at tall structures and power lines routed through mountainous terrain. This will also help in understanding the risk of electromagnetic interference resulting from LEMP to electronic and communication equipment located in the vicinity of a tall structure.

What happens with tall structures and lightning storms is quite interesting. Tall structures, especially at such a height as the CN Tower, actually initiate lightning flashes most of the time [1]. This is called ground-to-cloud lightning as it starts from the object and goes upwards to the cloud. It has long been assumed that the $\mathrm{CN}$ Tower, because of its extreme height, would provide protection to objects in its vicinity. Figures and analysis show that there is an area around the tower within a few km's that receives very little if any flashes when compared to the rest of the surrounding area. 
August 19, 2005 was a famous stormy day that significantly contributed to this research. There are a lot more flashes per square kilometer per year in the area around the tower than one would like to see. This is referred to as the flash density. When looking only at August 19, 2005, the flash density for that whole day ( 24 hour period) for $100 \mathrm{~km}$ radius around the $\mathrm{CN}$ Tower was 0.399 flashes per square $\mathrm{km}$ whereas the flash density for $1 \mathrm{~km}$ radius around the $\mathrm{CN}$ Tower on that day was 2.546 flashes per square $\mathrm{km}$. This means there was $538 \%$ more lightning flashes within $1 \mathrm{~km}$ around the $\mathrm{CN}$ Tower than there was within $100 \mathrm{~km}$ around the $\mathrm{CN}$ Tower. That is quite significant when seeing the amount of damage even 1 lightning flash can cause.

Further, a lightning flash can contain several strokes. The number of strokes in a flash is referred to as flash multiplicity. For most flashes, the subsequent strokes (strokes which occur after the first stroke of a flash) will contact the Earth or a structure at the same strike point as the first stroke but about one third of all flashes can contain strokes with different ground strike points, separated by a few hundred meters to several kilometers. This being said, when looking at the flash multiplicity for that famous stormy day of August 19,2005, within $100 \mathrm{~km}$ radius of the $\mathrm{CN}$ Tower the value was 2.46 whereas the flash multiplicity for $1 \mathrm{~km}$ radius around the tower was 4 . This means that there was $62.6 \%$ more strokes per flash within $1 \mathrm{~km}$ of the tower than there was within $100 \mathrm{~km}$ of the tower.

Lightning strikes can kill people, knock out radio communications, electrical power, and destroy homes and/or business and trees.

Investigations of $\mathrm{CN}$ Tower lightning characteristics show that the magnitude of the electromagnetic pulse generated by lightning strikes to the tower is significantly higher than that of those generated by lightning strikes to ground. This means that there will be higher electromagnetic interference in the vicinity around a tall structure than elsewhere, possibly affecting electronic and communication systems.

In Canada, lightning kills an average of seven people and seriously injures 60 to 70 people per year [2]. When a person is struck by lightning the chances are about $50 \%$ that it will be fatal. A person usually suffers cardiac arrest, apart from burns, temporary blindness and deafness. A 
strike can have profound effects on someone's life, if the person survives. In many cases neurons are permanently damaged.

When a house and/or building are hit by lightning, the electrical current will find its way down by anything conductive, preferably around the outside of the structure. This may include antennas, plumbing and gutters. Any person taking a bath, making a phone call, washing their hands, or otherwise touching metal plumbing either directly or indirectly, may be shocked or killed. Electrical appliances are likely to be damaged or destroyed and a surge protector may not always protect the appliance plugged into it.

In Chapter 2, this phenomenon called lightning, which is both fascinating and deadly at the same time is discussed. This chapter gives background for how and why lightning occurs and the importance of lightning current.

In Chapter 3, procedure and devices used to track the lighting at the $\mathrm{CN}$ Tower and surrounding area is outlined and touches on the lightning electromagnetic pulse seen.

Chapter 4 discusses the North American Lightning Detection Network (NALDN). All the data used in this paper comes from the NALDN, therefore it is very important to note how this network works and the results it gives for lightning occurring all over North America.

The most important information for this thesis and the conclusions obtained come from Chapter 5 as all recent lightning data, particularly for the famous stormy day of August 19 , 2005 , is analyzed in this chapter. At the end of this chapter the characteristics of the lightninggenerated electromagnetic pulse (LEMP) is discussed. It is very important to determine the risk of the LEMP to communication and electrical equipment around a tall structure.

In Chapter 6, the conclusions arrived at from the results of the previous chapters are presented along with suggestions for improvement and future research. 


\section{Chapter 2}

\section{Lightning Phenomenon}

Lightning has been a fascination for people for hundreds of years. In 1746, Benjamin Franklin began his experiments in electricity. Even before Franklin's interest in electricity, many different scientists had suggested that lightning might be an electrical phenomenon. It was not until November 1749 that Franklin wrote about his study of lightning and then in July 1750 he designed the first experiment to prove that lightning was electrical $[3,4]$. Franklin's original experiment is shown below in Figure 2.1. This experiment was used to show that thunderclouds are electrified. In 2.1 (a), a man on an electrical stand holds an iron rod with one hand and obtains an electrical discharge between the other hand and ground. In 2.1 (b), the man on the ground draws sparks between the iron rod and a grounded wire held by an insulating wax handle.

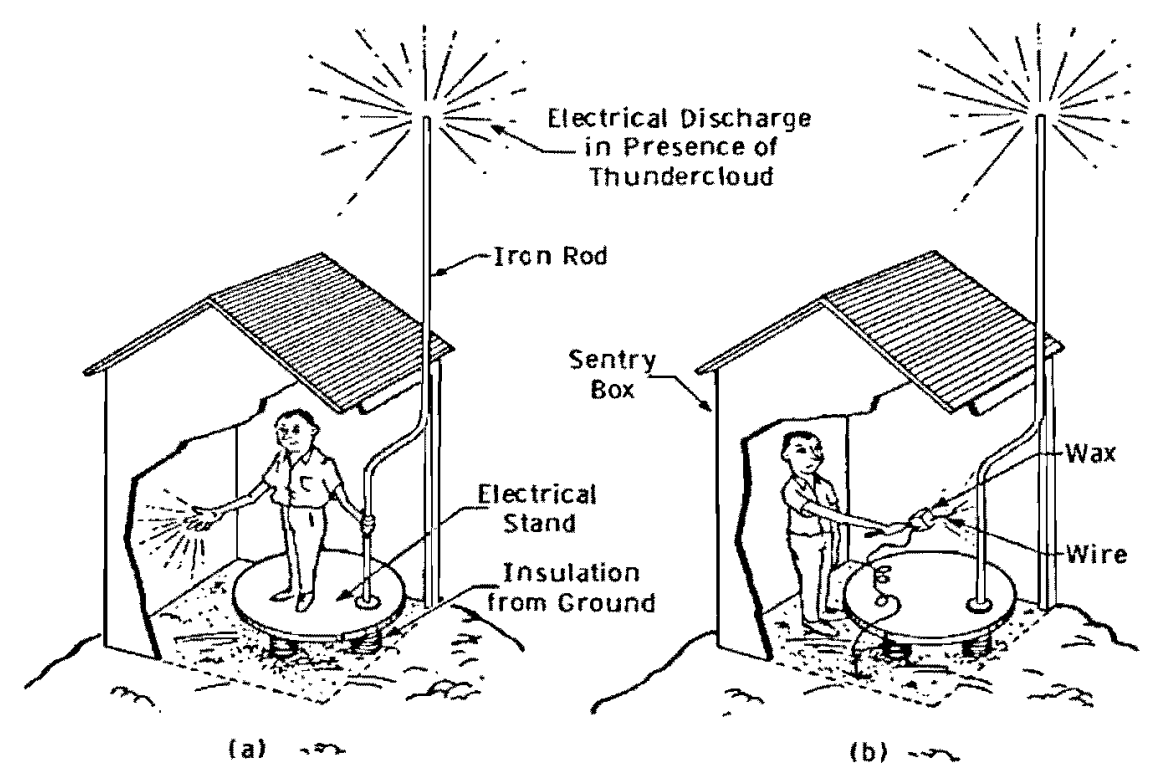

Figure 2.1: Franklin's original experiment (Adapted from $[3,4]$.) 
Franklin did not actually get around to performing the above experiment but another scientist did and was killed. Franklin found a better way to prove his theory - an electrical kite. It was to take place of the iron rod, since it could reach a greater elevation than the rod and could be flown anywhere. During a thunderstorm in 1752 Franklin flew the kite. This is shown below in figure 2.2. Sparks jumped from a key tied to the bottom of the kite string to the knuckles of his hand. He had verified this theory $[3,4]$.

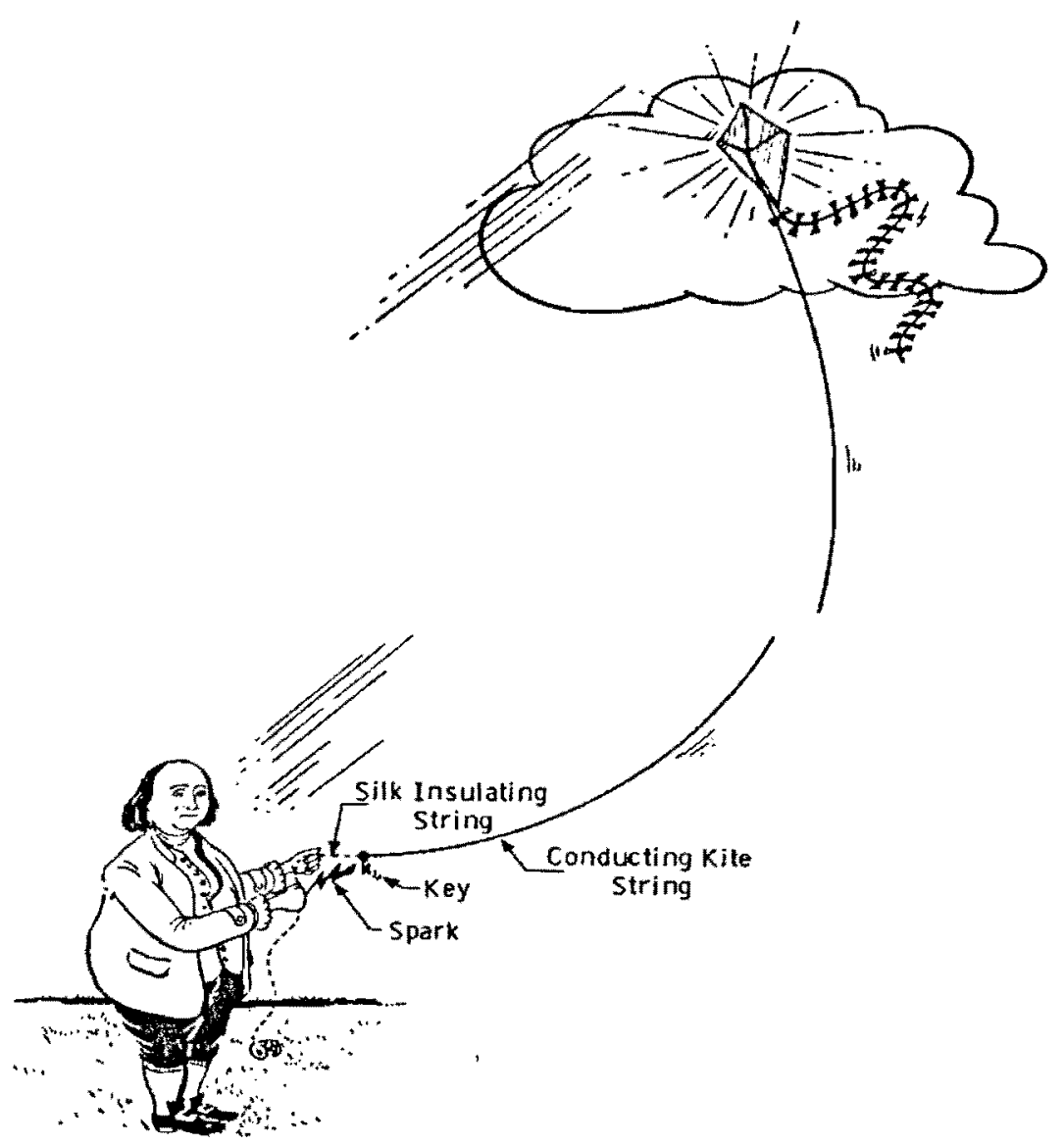

Figure 2.2: Franklin's electrical kite experiment (Adapted from [3,4].)

\subsection{What is Lightning and how does it Happen?}

Lightning is a transient, high-current electric discharge whose path length is measured in kilometers. The most common sources of lightning are the electric charge separated in ordinary thunderstorm clouds. Most of the time lightning discharges occur within the thunderstorm cloud and are called intra-cloud discharges. The usual cloud-to-ground lightning (otherwise known as 
streaked or forked lightning) has been the most studied kind. All lightning that occurs between the cloud and earth can be placed into 1 of 4 categories $[3,4]$. This is shown in figure 2.3 below.
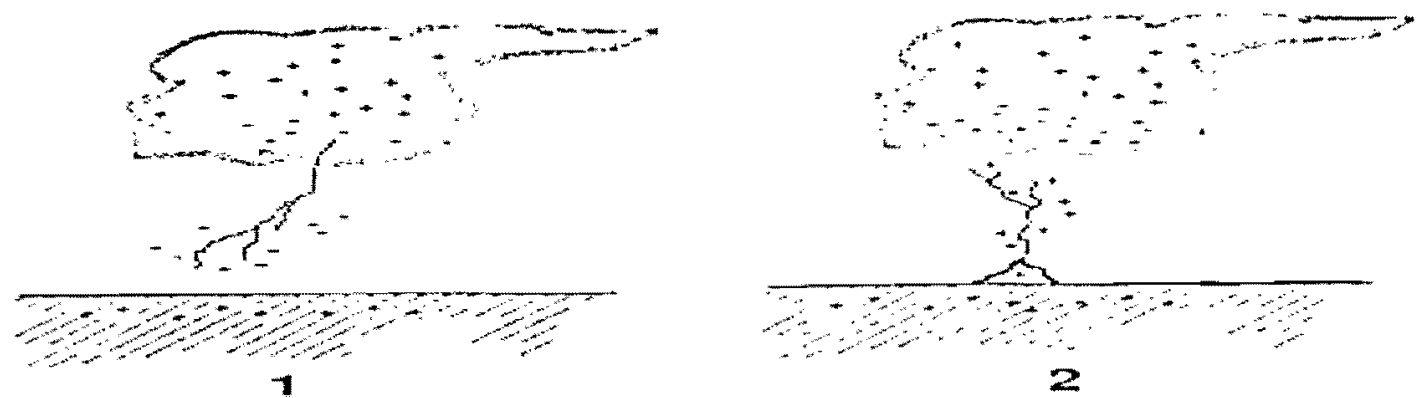

2
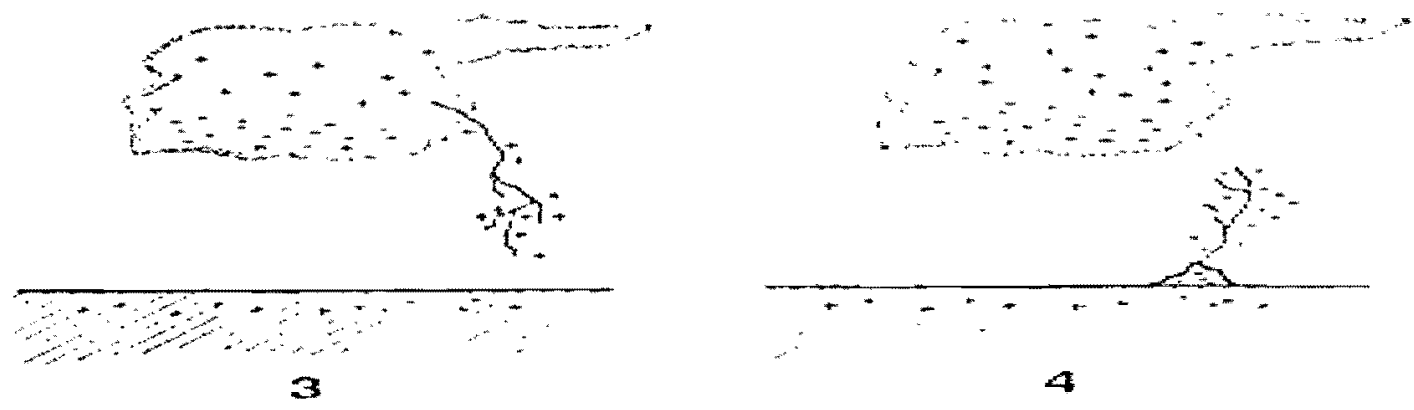

Figure 2.3: Categorization of the four types of lightning (Adapted from $[3,4]$.)

\section{Category 1 Lightning:}

This type of lightning is the most common cloud-to-ground lightning. It accounts for over $90 \%$ of the worldwide cloud-to-ground flashes. It is initiated by a downward-moving negatively charged leader, as shown in Figure 2.3 category 3, and hence lowers a negative charge to the earth.

\section{Category 2 Lightning:}

This type of lightning is initiated by leaders that move upward from the earth and are sometimes called ground-to-cloud discharges. These upward-initiated discharges are relatively rare and generally occur from mountain tops and tall man-made structures. This category has a positively charged leader and may lead to the lowering of negative cloud charge. 


\section{Category 3 Lightning:}

This type of lightning, just like category 1, is also initiated by a downward-moving leader, but the leader is positively charged therefore the discharge lowers positive charge. Less then $10 \%$ of the worldwide cloud-to-ground lightning is of this type.

\section{Category 4 Lightning:}

This type of lightning, just like category 2 , is also initiated by leaders that move upward from the earth but the leader is negatively charged therefore leading to the lowering of positive cloud charge.

\subsection{Lightning Terminology}

When considering the most popular type of discharge, a negative cloud-to-ground discharge (as in Figure 2.3 category 1), the total discharge is termed a flash and has a time duration of about half a second $[3,4]$. A flash is made up of various discharge components, among which are typically three or four high-current pulses called strokes [3,4]. Each stroke lasts about a millisecond and the separation time between strokes is usually several tens of milliseconds. Lightning usually appears to "flicker" because the human eye can just resolve the individual light pulse associated with each stroke. Figure 2.4 shows an idealized model of the cloud charges. The main charge regions, $\mathrm{P}$ and $\mathrm{N}$, are of the order of many tens of coulombs of positive and negative charge, respectively, and the lower $\mathrm{p}$ region contains a smaller positive charge. When looking at Figure 2.4, the stepped leader initiates the first return stroke in a flash by propagating from cloud to ground in a series of discrete steps. The stepped leader is itself initiated by a preliminary breakdown within the cloud, although there is a disagreement about the exact form and location of this process. Nevertheless, Figure 2.4 shows the preliminary breakdown in the lower part of the cloud between the $\mathrm{N}$ and $\mathrm{p}$ regions. The preliminary breakdown sets the stage for a negative charge to be lowered toward ground by the stepped leader. When looking at photographs that display this phenomenon, leader steps are usually $1 \mu \mathrm{sec}$ in duration and tens of meters in length, with a pause time between steps of about $50 \mu \mathrm{sec}$. A fully developed stepped leader lowers up to 10 or more coulombs of negative cloud charge towards ground in tens of milliseconds with an average downward speed of about $2 \times 10^{5} \mathrm{~m} / \mathrm{sec}[3,4]$. The average leader current is in the 100-1000 A range [3,4]. The steps have pulse currents of at least $1 \mathrm{kA}$. There are 
electric and magnetic field pulses associated with these currents that have widths of around 1 $\mu \mathrm{sec}$ or less. The stepped leader, during its trip toward ground, branches in a downward direction producing the downward-branched geometrical structure seen in Figure 2.5. The preliminary breakdown, the subsequent lowering of negative charge by the stepped leader, and the resultant depletion of negative charge in the cloud combine to produce a total electric field change that can be as short as a few milliseconds or as long as a few hundred milliseconds $[3,4]$.

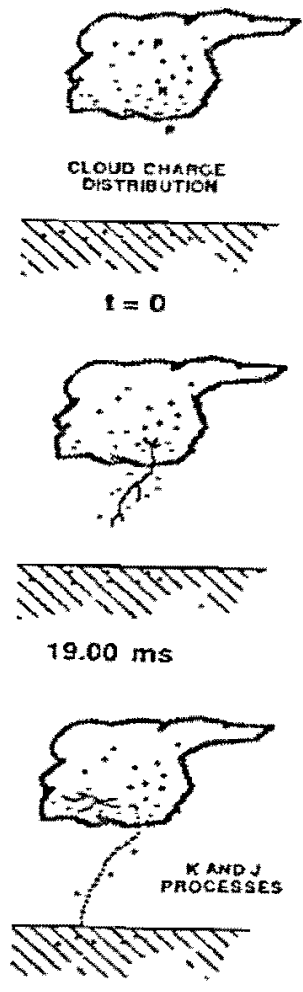

$40.00 \mathrm{~ms}$

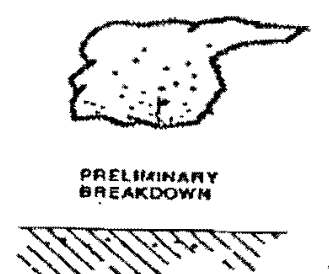

$1.00 \mathrm{~ms}$

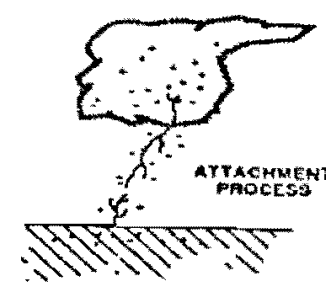

$20.00 \mathrm{~ms}$

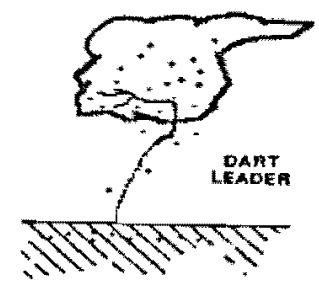

$60.00 \mathrm{~ms}$

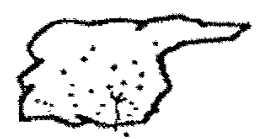

SFEFPED
LEADEA

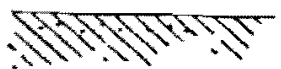

$1.10 \mathrm{~ms}$

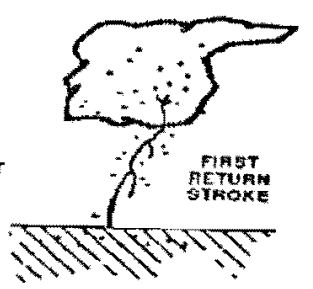

$20.10 \mathrm{~ms}$

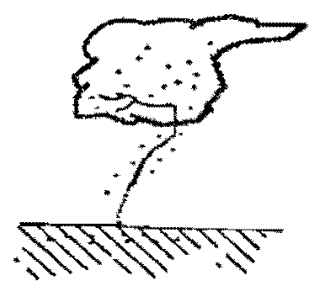

$61.00 \mathrm{hs}$
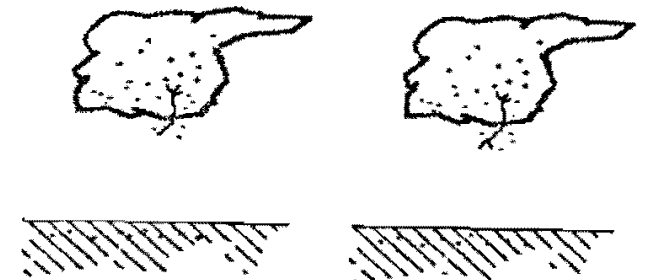

$1.15 \mathrm{~ms}$

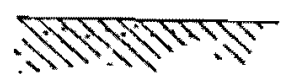

$1.20 \mathrm{~ms}$

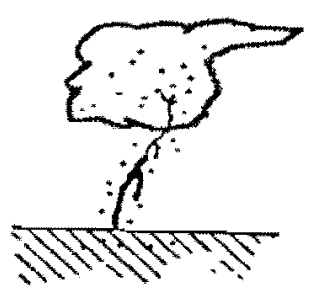

$20.15 \mathrm{~ms}$

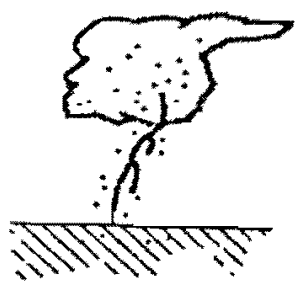

$20.20 \mathrm{~ms}$

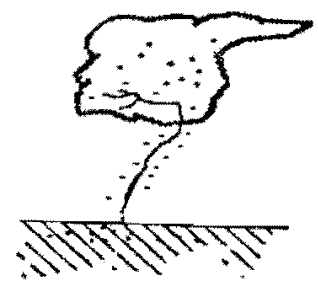

$62.00 \mathrm{~ms}$

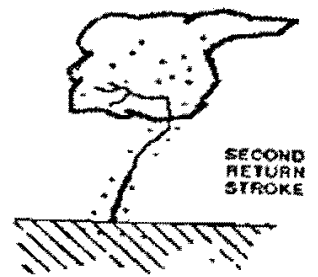

$62.05 \mathrm{~ms}$

Figure 2.4: Various processes comprising a negative cloud-to-ground lightning flash (Adapted from [3,4].) 


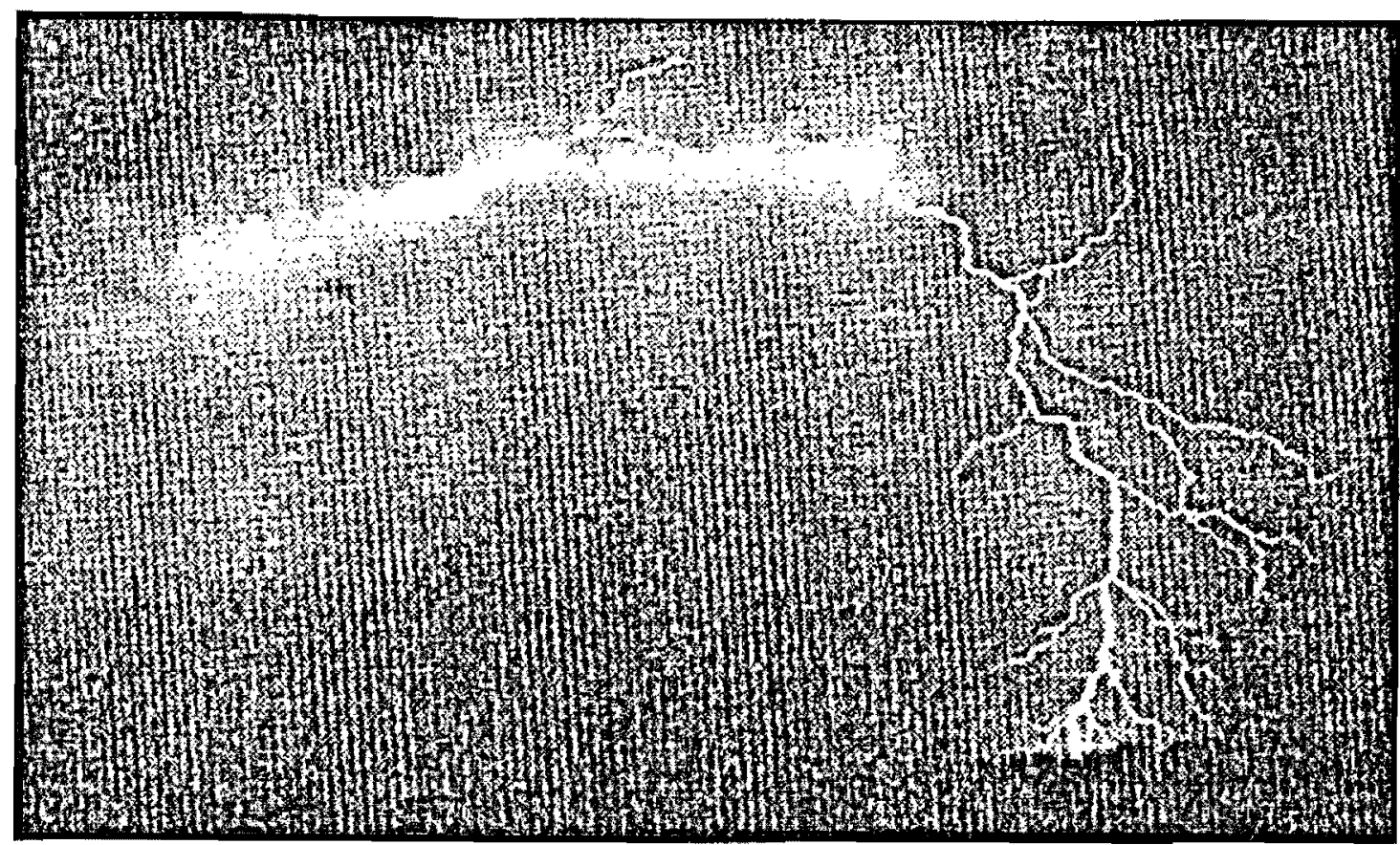

Figure 2.5: A still photograph of a typical cloud-to-ground flash (Adapted from $[3,4]$.)

The electric potential of the bottom of the negatively charged leader channel with respect to ground has a magnitude in excess of $10^{7} \mathrm{~V}$. As the leader tip nears ground, the electric field at sharp objects on the ground or at irregularities of the ground itself exceeds the breakdown value of air and one or more upward-moving discharges are initiated from these points, thus beginning the attachment process $[3,4]$. When one of the upward-moving discharges (or streamers) from the ground contacts the downward-moving stepped leader some tens of meters above the ground, the leader tip is connected to ground potential. The leader channel is then discharged when a ground potential wave, the first return stroke, propagates continuously up the previously ionized and charged leader path. The upward speed of a return stroke near the ground is typically onethird or more times the speed of light, and the speed decreases with height. The total transit time from ground to the top of the channel is typically about $100 \mu \mathrm{sec}$. The first return stroke produces a peak current near ground of around $30 \mathrm{kA}$, with a time from zero to a peak of a few milliseconds. The current measured at the ground falls to half of the peak value in about $50 \mu \mathrm{sec}$. The rapid release of return-stroke energy heats the leader channel to a temperature near $30,000 \mathrm{~K}$ and generates a high-pressure channel that expands the creates the shock waves that eventually become thunder. The return stroke effectively lowers to ground the charge originally deposited on the stepped leader channel as well as other charges that may be available to the top of its 
channel, and in the process produces an electric field change with time variations that range from a sub microsecond scale to many milliseconds $[3,4]$. After the return-stroke current stops flowing, the flash, including any charge motion in the cloud, may end. The lightning is then called a single stroke flash. Moreover, if any additional charge is made available to the top of the channel, a continuous dart leader may propagate down the residual first-stroke channel at a speed of about $3 \times 10^{6} \mathrm{~m} / \mathrm{sec}$. During the time between the end of the first stroke and the initiation

of a dart leader, J- and K-processes occur in the cloud. The J- or "junction" -process takes place in the cloud during the time interval between return strokes $[3,4]$. It is identified with an electric field having a relatively steady change on a time scale of tens of milliseconds. The J-change can be either positive or negative, is generally smaller than the field change due to continuing current. Small, relatively rapid electric field variations termed K-changes also occur between strokes generally at intervals of $2-20 \mathrm{msec}$, and hence appear to be superimposed on the overall electric field change associated with the J-process. The dart leader lowers a charge of the order of $1 \mathrm{C}$ by virtue of a current of about $1 \mathrm{kA}[3,4]$. The dart leader then initiates the second (or any subsequent) return stroke. Some leaders begin as dart leaders but toward the end of their trip toward ground become stepped leaders. These leaders are known as dart-stepped leaders. Dart leaders and return strokes subsequent to the first are usually not branched $[3,4]$.

\subsection{Importance of Measuring the Lightning Current}

When lightning strikes occur to the ground or to objects attached to the ground, a reasonable charge distribution is assumed for the leader channel, and the resulting fields on the ground or nearby objects are calculated. The leader is assumed to be at the striking distance when the field at some point exceeds a critical breakdown value that can be determined from laboratory tests [2]. In the design of power line protection, which is very important to avoid power disruptions during lightning storms, the striking distance to the peak current of the following return stroke is of interest since the probability of a stroke having a given current magnitude is somewhat known. In order to find the current-striking distance relationship, the peak current must be related to the stepped-leader charge. Since the stepped-leader charge can be spread over a rather large volume in various leader branches, it is not clear from a physical point of view that these two quantities are related. On the other hand, the peak stroke current is attained in a few $\mu$ sec in 
a short channel section that is attached to ground. Berger (1972) has been able to show that there is a relationship between the measured return-stroke peak current at ground and the total charge transfer to ground in the first $1 \mathrm{msec}$ [4]. Berger (1972) developed an expression relating peak current, I, to charge transfer, Q, which best fits the available data for 89 negative first strokes. This expression is:

$\mathrm{I}=10.6 \mathrm{Q}^{0.7}$ (Eq. 1),

where $\mathrm{I}$ is measured in $\mathrm{kA}$ and $\mathrm{Q}$ in coulombs [4]. A typical peak current of $25 \mathrm{kA}$ is obtained from the above expression, which corresponds to a total charge, assumed to originally reside on the leader, of 3.3 C. Combining Eq. 1 with the relation between charge and breakdown field, the relation for striking distance, $d_{s}$, can be found in terms of the peak current. According to Golde (1977):

$\mathrm{d}_{\mathrm{s}}=10 \mathrm{I}^{0.65}$ (Eq. 2),

where $d_{s}$ is in meters and I is in kA [4]. To measure the current from lightning strikes hitting at tall structure, Berger (1977) and Berger and Vogelsanger (1966) gives a streak photograph, shown in Figure 2.6, in which the stepped leader ends about $40 \mathrm{~m}$ above and $40 \mathrm{~m}$ horizontally away from a tower (point $\mathrm{A}$ in the figure) located on Mount San Salvatore in Lugano, Switzerland [4]. The connection between the leader and the tower top is made by an upwardmoving positive discharge from the tower that branches at point $B$ (in the figure). These measured tower currents rise to a few kiloamperes in a few microseconds and then to tens of kiloamperes in the next few microseconds. The problem is that it is not possible to identify the part of the current that is due to the upward connecting discharge [4]. 

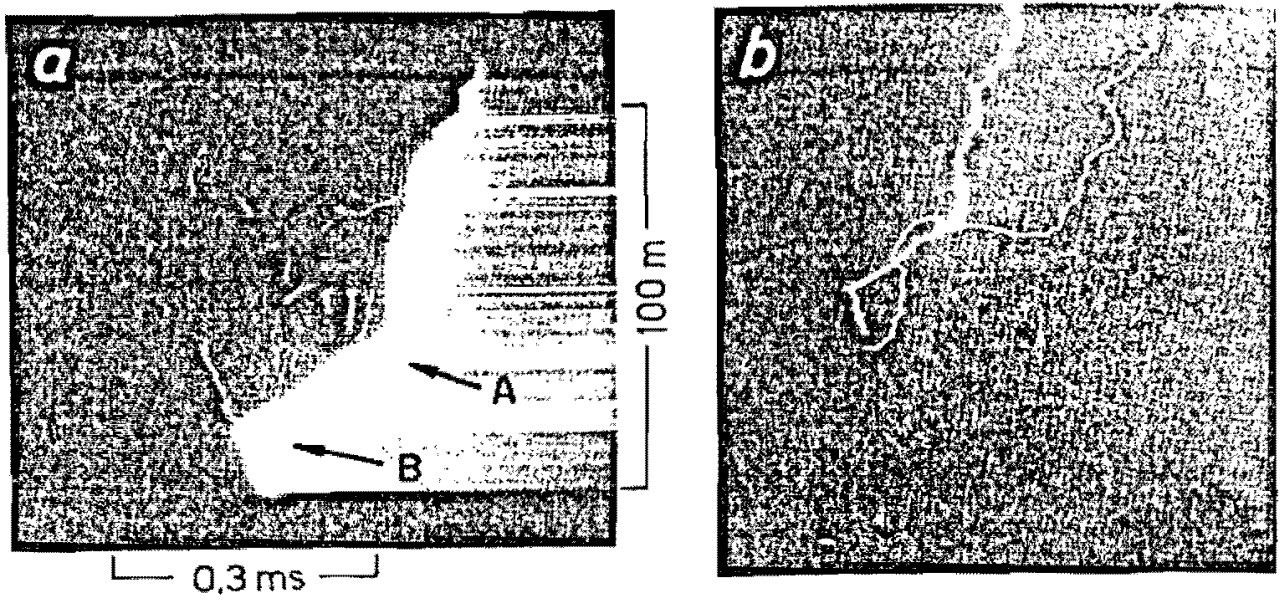

Figure 2.6: (a) Streak photograph of the attachment process to tower on Mount San Salvatore in Lugano, Switzerland (b) Still photograph of the flash from (a) and another flash that struck the tower below its top (Adapted from [4].)

Most commonly, the lightning current ceases in about a millisecond for a given stroke, but sometimes there is a continuing current on the order of $100 \mathrm{amps}$ following one or more of the strokes. This is called "hot lightning" and it is the cause of lightning fires, particularly in the woods, according to Martin Uman [4]. The temperatures of lightning are $15,000-60,000^{\circ} \mathrm{F}$ for both "cold" and "hot" lightning but it is the continuing current that starts some 10,000 fires per year in the U.S. in the estimation of Uman [4]. 


\section{Chapter 3}

\section{Tracking Lightning at the $\mathrm{CN}$ Tower}

Lightning studies at tall structures is very important as one learns how to protect structures from lightning damage. Since 1978 lightning strikes to the CN Tower have been observed [5].

This section is a review of various aspects of $\mathrm{CN}$ Tower lightning investigations during the past many years, which provides the rationale behind taking up the research work that has led to the formulation of this thesis. A brief description of the $\mathrm{CN}$ Tower measurement systems and a sample of typical observations are also included.

Although the lighting flash density (number of flashes per square kilometre per year) in the Toronto area is about two, the Canadian National (CN) Tower, the tallest manmade freestanding structure in the world, standing at $553 \mathrm{~m}$, usually receives many tens of lighting strikes yearly [6]. For example, VHS video records show that in 1991, the CN Tower was hit with 78 flashes, 24 of which occurred within 100 minutes. Therefore, the $\mathrm{CN}$ Tower presents one of the best sites in the world to observe lighting for the purpose of studying the phenomenon of tall-structure lighting, and deriving extensive statistics concerning the visual characteristics of lightning flashes [6,7] and the waveform characteristics of the lightning current [8] and its generated electromagnetic pulse [9]. Furthermore, lightning return-stroke current models for elevated objects [10] and the performance characteristics of the North American Lightning Detection Network are evaluated based on the CN Tower lightning return-stroke data [5].

Lightning strikes to the CN Tower have been observed for over 28 years [6]. In 1991, five recording stations were in operation to simultaneously capture the $\mathrm{CN}$ Tower lighting parameters; namely, the return-stroke current derivative at the tower (using a Rogowski coil and 
RTD 710A Tektronix digitizers), the vertical component of the electric field and the azimuthal component of the magnetic field $2 \mathrm{~km}$ north of the tower (using broadband active sensors and RTD 710A Tektronix digitizers), the return-stroke velocity, RSV (using a photodiode system), and two dimensional images of the flash trajectory (taken using video cameras from directions that are approximately perpendicular to each other for the purpose of constructing the threedimensional lightening trajectory image). Figure 3.1 shows the $\mathrm{CN}$ Tower and the locations of instruments.

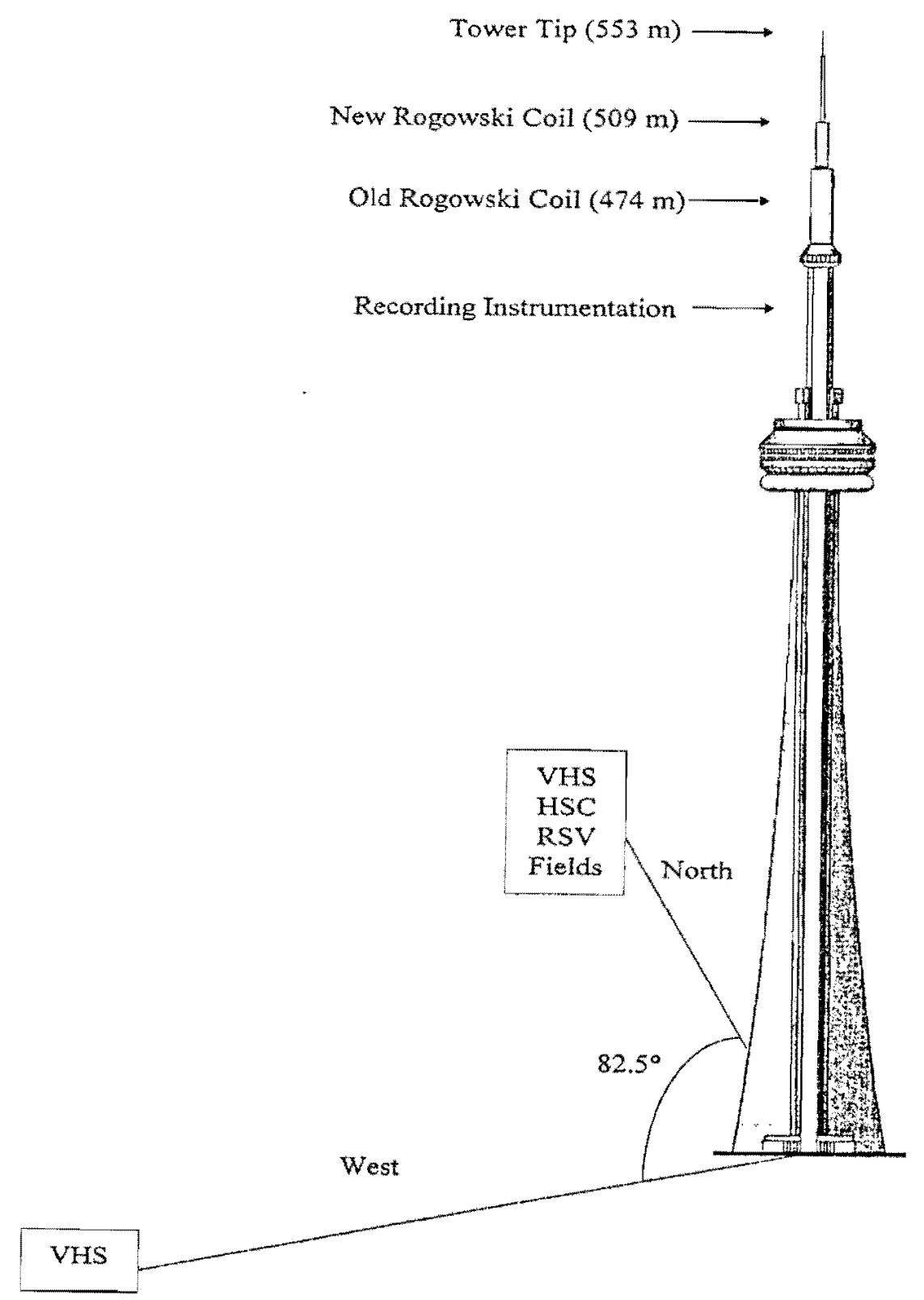

Figure 3.1: The $\mathrm{CN}$ Tower with the locations of instruments 
Since 1996, an expansion of the measurement facilities has been taking place. A 1000frame/sec high-speed camera (HSC) was acquired in 1996 (Figure 3.1). In 1997, a noiseprotected current sensing system consisting of a new Rogowski coil and an optical fiber link was installed at the tower (Figure 3.1). In 2001, two LeCroy LT362 double-channel digitizers with 2ns time resolution and large segmented memory were acquired to record the lighting returnstroke current derivative at the tower and its corresponding electromagnetic field. For time synchronization of the $\mathrm{CN}$ Tower lightning recording instruments, four Global Positioning System (GPS) units were also acquired.

\subsection{Flash Trajectory}

Two Hitachi VM-3100A video cameras (one placed $2 \mathrm{~km}$ north of the tower and the other $11.8 \mathrm{~km}$ west of it) record images at the rate of 30 frames per second. Each frame is composed of two interlaced adjacent fields.

In 1996, a Phantom v2.0 high-speed digital imaging system (camera) was installed $2 \mathrm{~km}$ north of the CN Tower. Running using Windows Operating System, the high-speed imaging system continuously records $\mathrm{CN}$ Tower images. These images are temporarily stored and new images replace the old ones. The system is automatically triggered by sudden changes in brightness. When triggered, it saves 255 frames on file in binary format. The system is set to record 100 pretriggered frames and 155 frames after triggering. Each frame has 512 rows and 512 columns of pixels. Each pixel uses greyscale intensity values (from 0 for black to 255 for white). The files are viewed using Phantom Software. A typical image of a CN Tower lightning strike captured by the high-speed camera on the famous stormy day of August 19, 2005 is shown in Figure 3.2. 


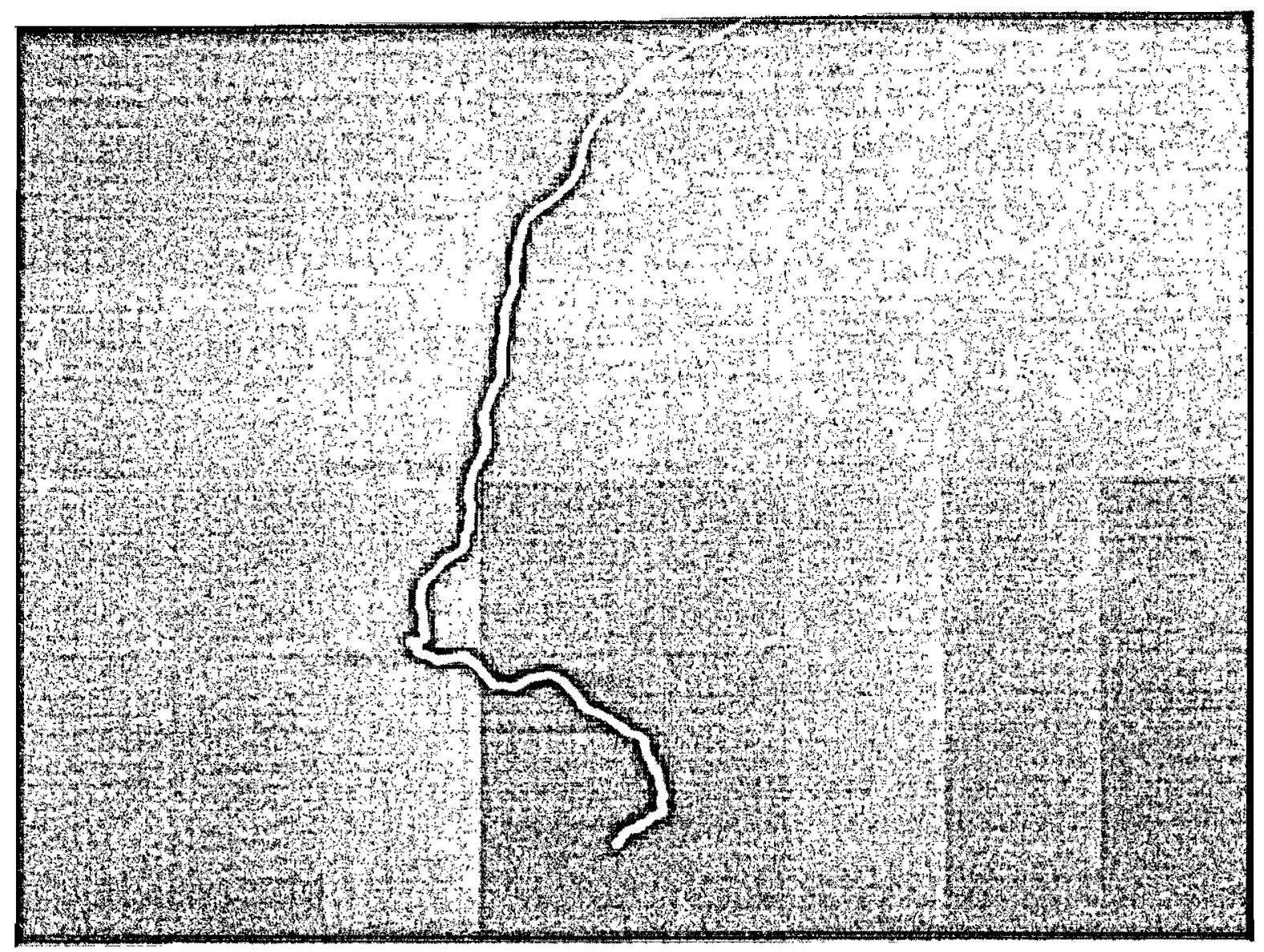

Figure 3.2: A typical CN Tower flash recorded by the high-speed camera on Aug. 19, 2005 at 14:11:41

\subsection{Lightning Current Derivative}

The system installed at the $\mathrm{CN}$ Tower in 1990 for the purpose of measuring the lightning current derivative utilizes a $3 \mathrm{~m}, 40 \mathrm{MHz}$ Rogowski current sensing coil [1]. The tower's steel structure has five identical plates joined together to form a conical shape with a pentagon crosssection [8]. At the $474 \mathrm{~m}$ above ground level ( $\Lambda \mathrm{GL}$ ), each steel plate has an elliptical-shaped hole at its centre [8]. The Rogowski coil, shown in Figure 3.3, encircles one corner of the fivesided structure by passing through two adjacent holes. Due to structural symmetry, the captured signal is assumed to correspond to $20 \%$ of the total lightning current. The coil is connected via a triaxial cable to a recording station placed at the $403 \mathrm{~m}$ AGL (Figure 3.1), which has a 10-ns, $10-$ bit computer-controlled double-channel digitizer with segmented memories (Tektronix RTD710A) [1]. During the summer of 1997, a noise-protected current derivative measurement system was installed at the tower. This system features a $6 \mathrm{~m}, 20 \mathrm{MHz}$ Rogowski coil 
surrounding the entire steel structure of the tower at the $509 \mathrm{~m} \mathrm{AGL}$ and is connected to the recording station via an optical fiber link [8]. In 2001, a LeCroy LT362 double-channel digitizer with 2 ns time resolution and large segmented memory was added to the current measurement system.
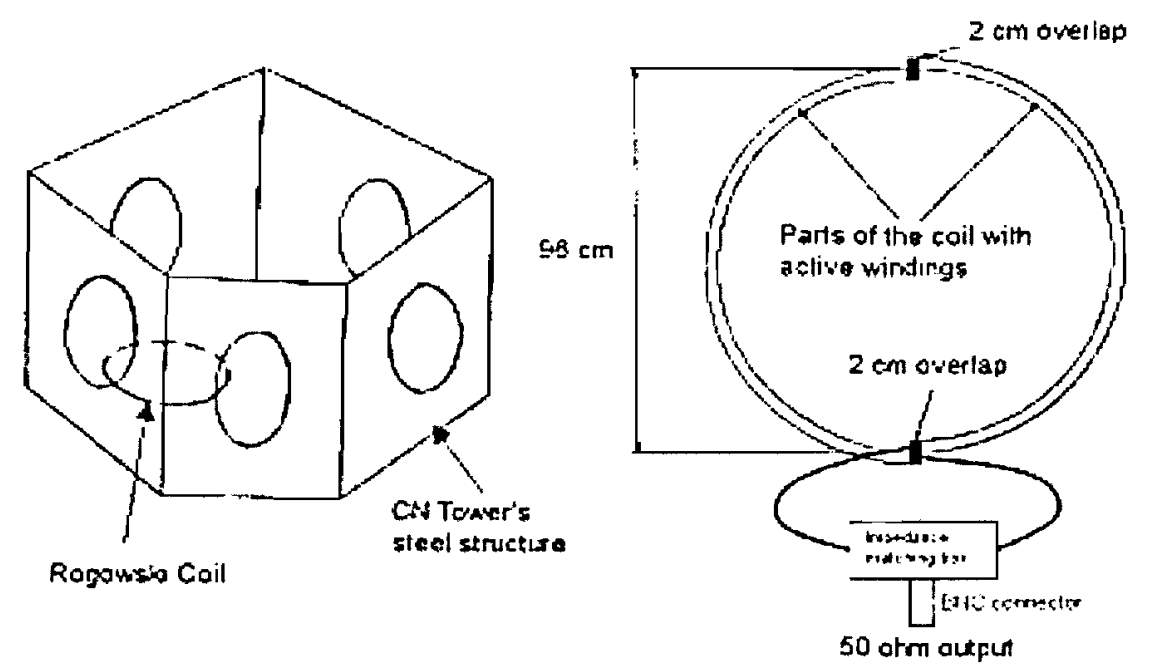

Figure 3.3: The old Rogowski coil and its location

The $\mathrm{CN}$ Tower lightning return-stroke current derivative and current waveforms that correspond to the sixth return stroke of the above-mentioned flash (Figure 3.2) are presented in Figures 3.4-3.5. The current derivative signal shown in Figure 3.4 was captured by the old Rogowski coil (the new Rogowski coil was not operational during 2005). The lightning current waveform, shown in Figure 3.5 is obtained by numerical integration of the corresponding current derivative signal (Figure 3.4). 


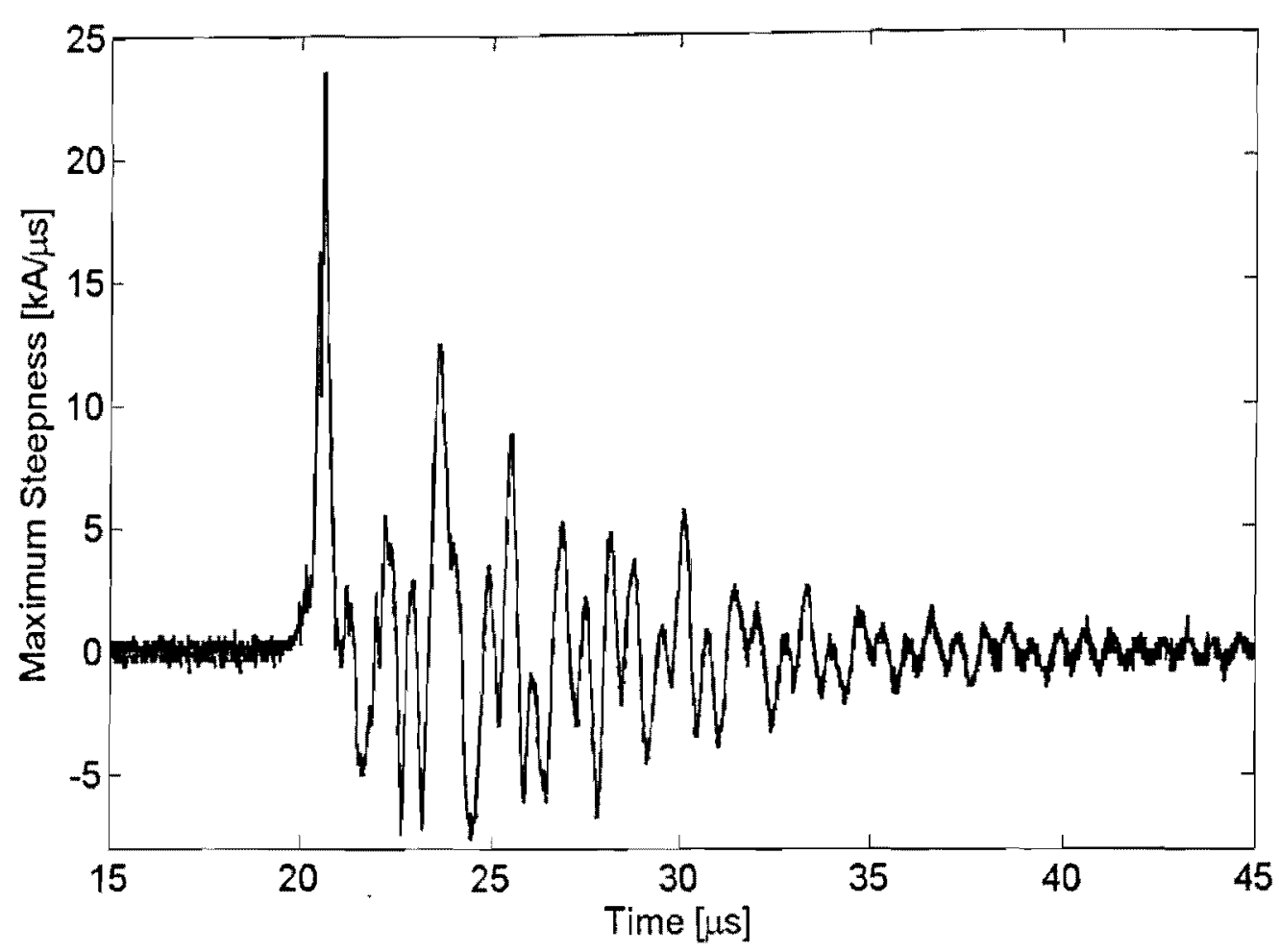

Figure 3.4: Current derivative signal captured on August 19,2005 at 14:11:41

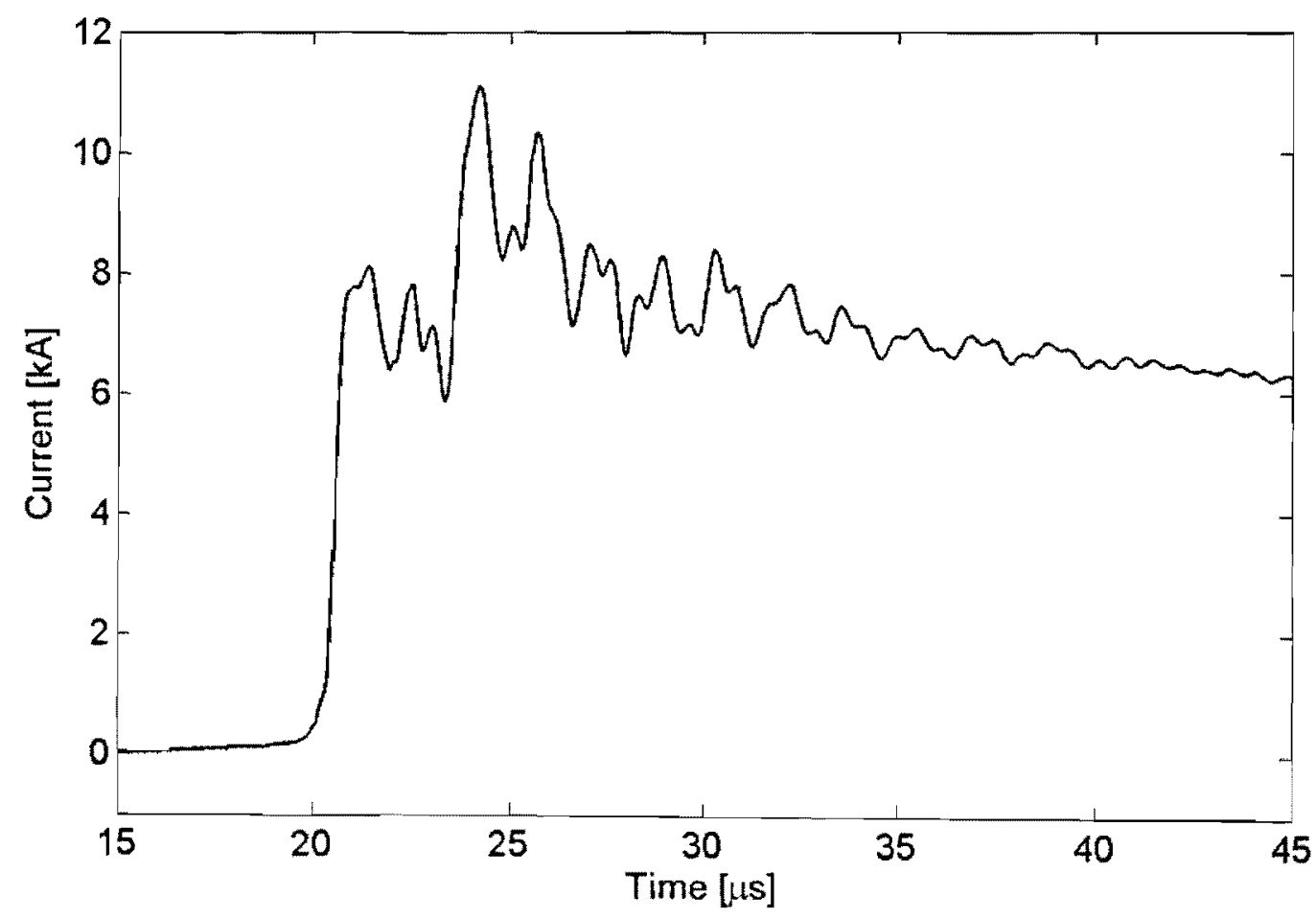

Figure 3.5: Current waveform (time integral of current derivative signal shown in Figure 3.4) 


\subsection{Lightning Electromagnetic Pulse}

The vertical component of the electric field $\left(E_{z}\right)$ and the azimuthal component of the magnetic field $\left(\mathrm{H}_{\varphi}\right)$, generated by lightning return-strokes to the $\mathrm{CN}$ Tower as well as those occurring in its vicinity, have been captured by broadband active field sensors since 1991. The electric field sensor is a hollow, hemi-spherically shaped monopole with a sensitivity of $2.38 \mathrm{mV} /(\mathrm{V} / \mathrm{m})$. The sensor has low and high 3-dB roll-off frequencies of $47 \mathrm{~Hz}$ and $100 \mathrm{MHz}$, respectively. The magnetic field sensor is of the small-loop antenna type with a sensitivity of $0.421 \mathrm{~V} /(\mathrm{A} / \mathrm{m})$. It has low and high 3-dB roll-off frequencies of $635 \mathrm{~Hz}$ and $150 \mathrm{MHz}$, respectively [9].

The circular loop of the magnetic field sensor is oriented in such a way as to capture the azimuthal component of the magnetic field generated by CN Tower lightning strokes. In 1990, the field sensors were connected via $50-\Omega$ coaxial cables to two double-channel Tektronix $710 \mathrm{~A}$ digitizers. In 2001, a LeCroy LT362 digitizer was added to the field measurement system.

The electric and magnetic field waveforms generated by the $\mathrm{CN}$ Tower lightning returnstroke, whose current is shown in Figure 3.5, are presented in Figures 3.6 and 3.7, respectively. 


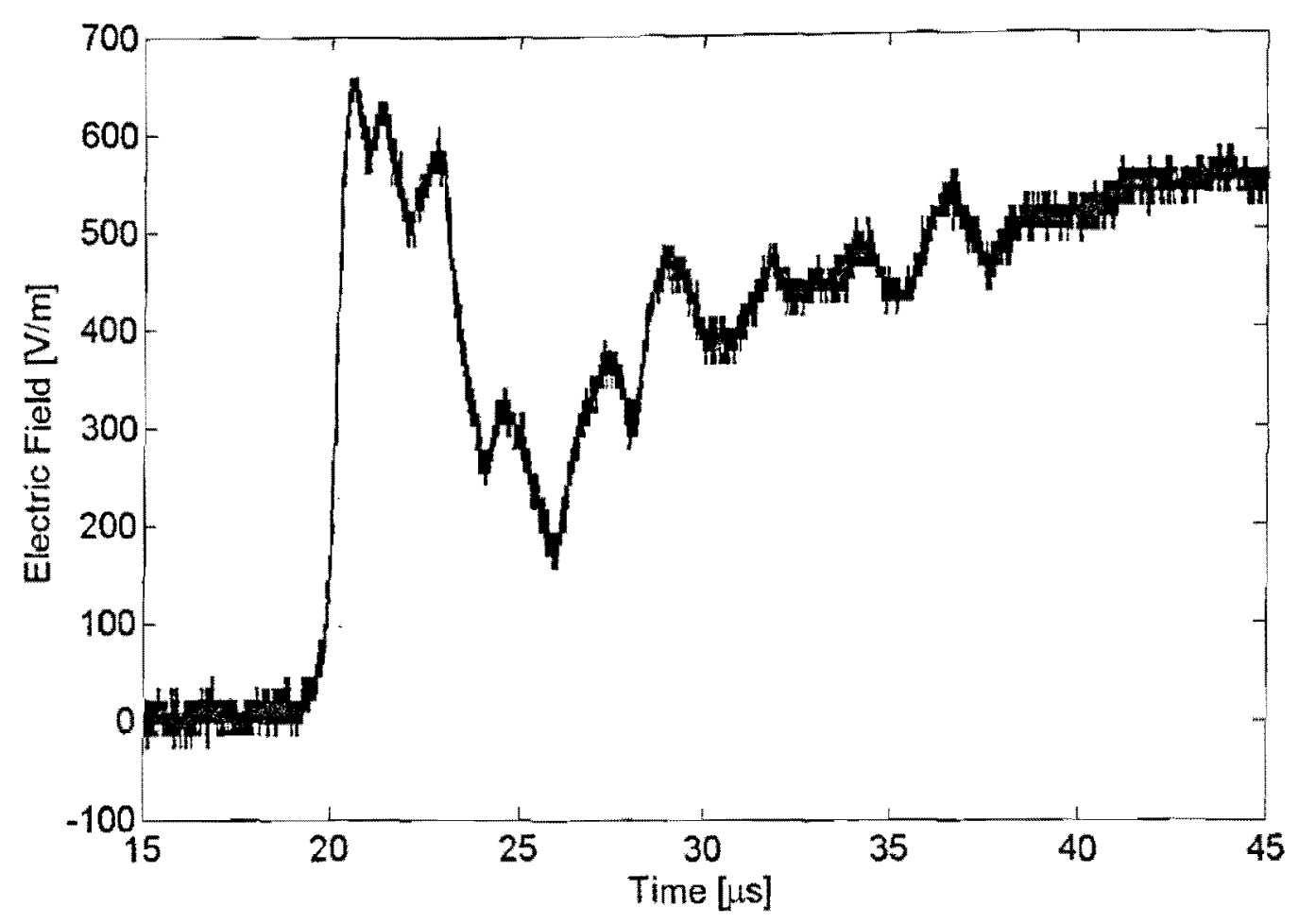

Figure 3.6: The electric field generated by a CN Tower lightning stroke, August 19, 2005 at 14:11:41

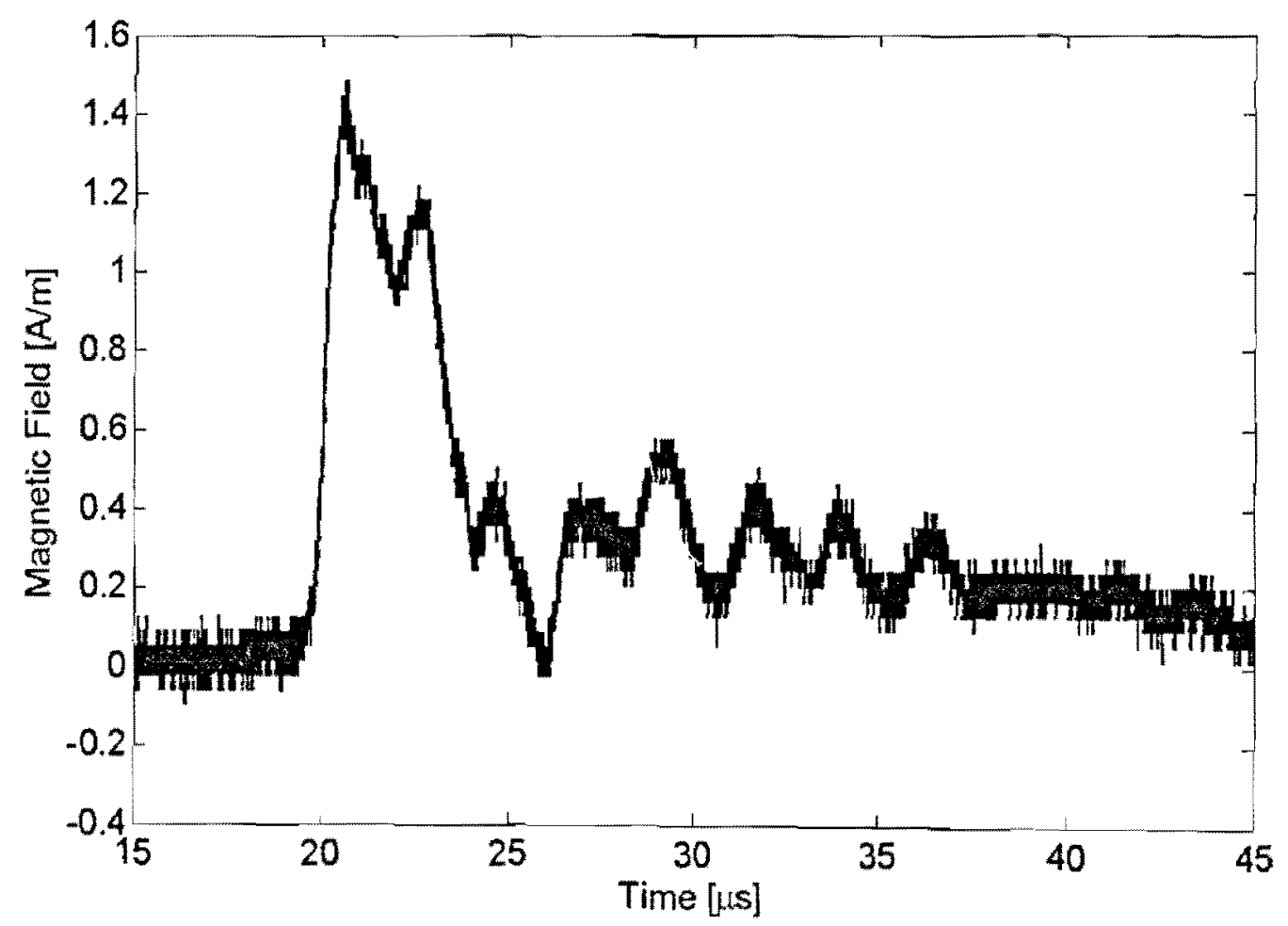

Figure 3.7: The magnetic field generated by a CN Tower lighting stroke, August 19, 2005 at 14:11:41 


\section{Chapter 4}

\section{North American Lightning Detection Network}

Since most of the data analyzed in this thesis was obtained from Vaisala Inc, which runs the North American Lightning Detection Network (NALDN), it is important to give a summary of this network and its operation.

Since 1995, Vaisala has provided lightning data for Southern Canada due to its southern positioning, enabling most of the province of Ontario to be covered by NALDN sensors [11]. The NALDN measures and provides the following lightning information: location, time, polarity, peak current, and confidence ellipse of each lightning return stroke [12, 13]. Figure 4.1 shows the NALDN system after being updated in 2003: 


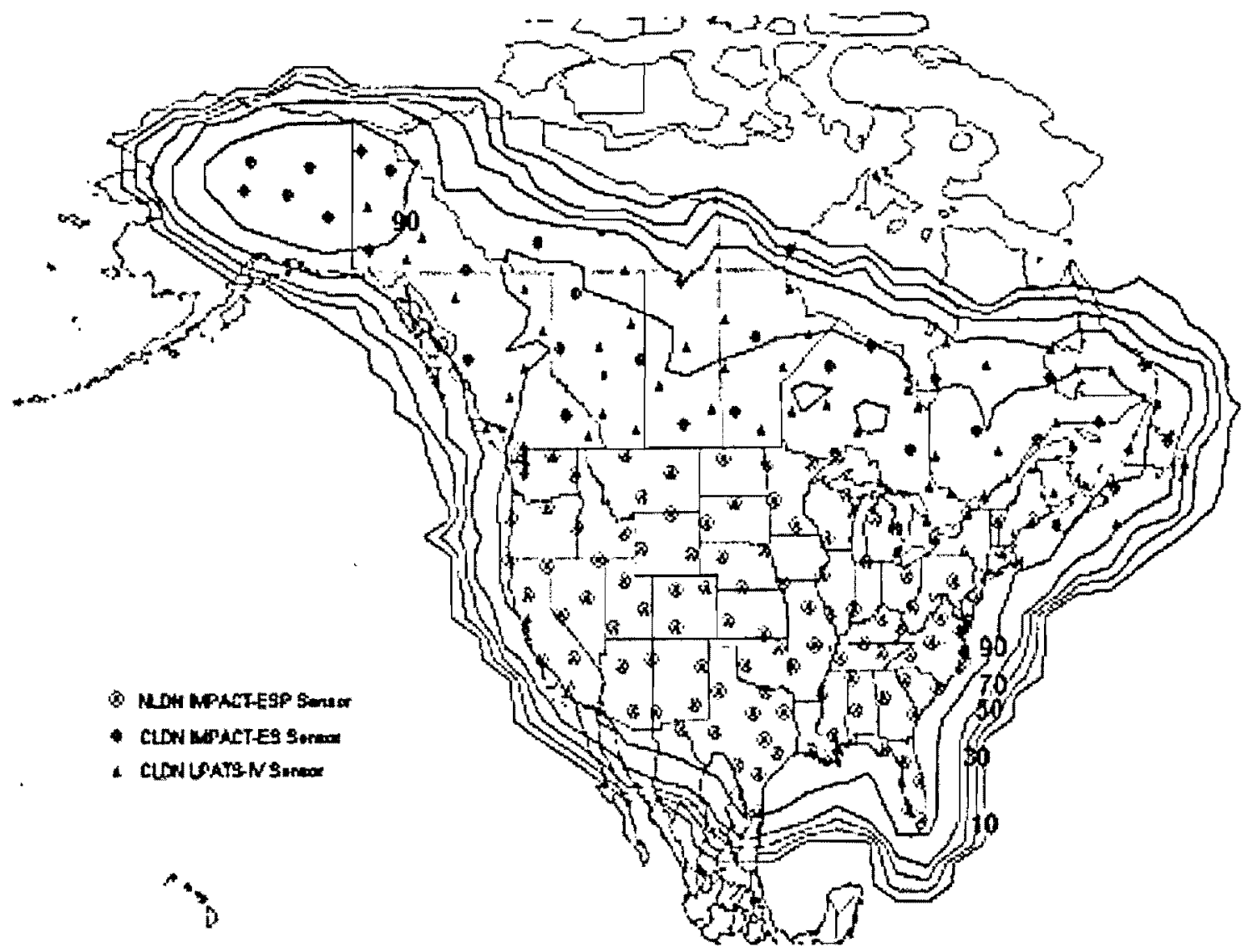

Figure 4.1: NALDN system after the 2003 upgrade (Adapted from [12].)

The NALDN has made it possible to analyze a number of unique lightning-related observations by creating this single homogeneous network covering nearly 20 million $\mathrm{km}^{2}$ over latitudes ranging from 25 degrees to 67 degrees west, and 25 degrees to 55 degrees east [14].

The NALDN allows lightning activity to be monitored in real-time for the protection of North American forests, electric power lines, and for public safety. According to Vaisala, the data acquired by the network is regularly used by [15]:

- The National Weather Service

- The Federal Aviation Administration

-The Weather Channel

-The Professional Golfers' Association (PGA) Tour

-Major power companies 
-International and regional airports

-Thousands of businesses

This shows that NALDN data is deemed accurate and if it is acceptable to the above groups, then its data is definitely acceptable for the lightning studies at the CN Tower and hence, used for this thesis.

NALDN accurately locates the ground strike point of cloud-to-ground lightning. Cloud-toground discharges are usually detected using the strong VLF and LF signals generated by return strokes. Because the locating system based on VHF signals have a limited detection range due to the line of sight propagation of the signals, the VLF/LF systems are better for the detection of cloud-to-ground lightning strikes. This is because they will propagate for long distances along the earth's surface or in the earth-ionosphere waveguide as shown below in Figure 4.2. The NALDN network uses a combination of magnetic direction finders (DFs) and time-of-arrival (TOA) sensors to locate lightning. Both of these operate in the VLF and LF range.

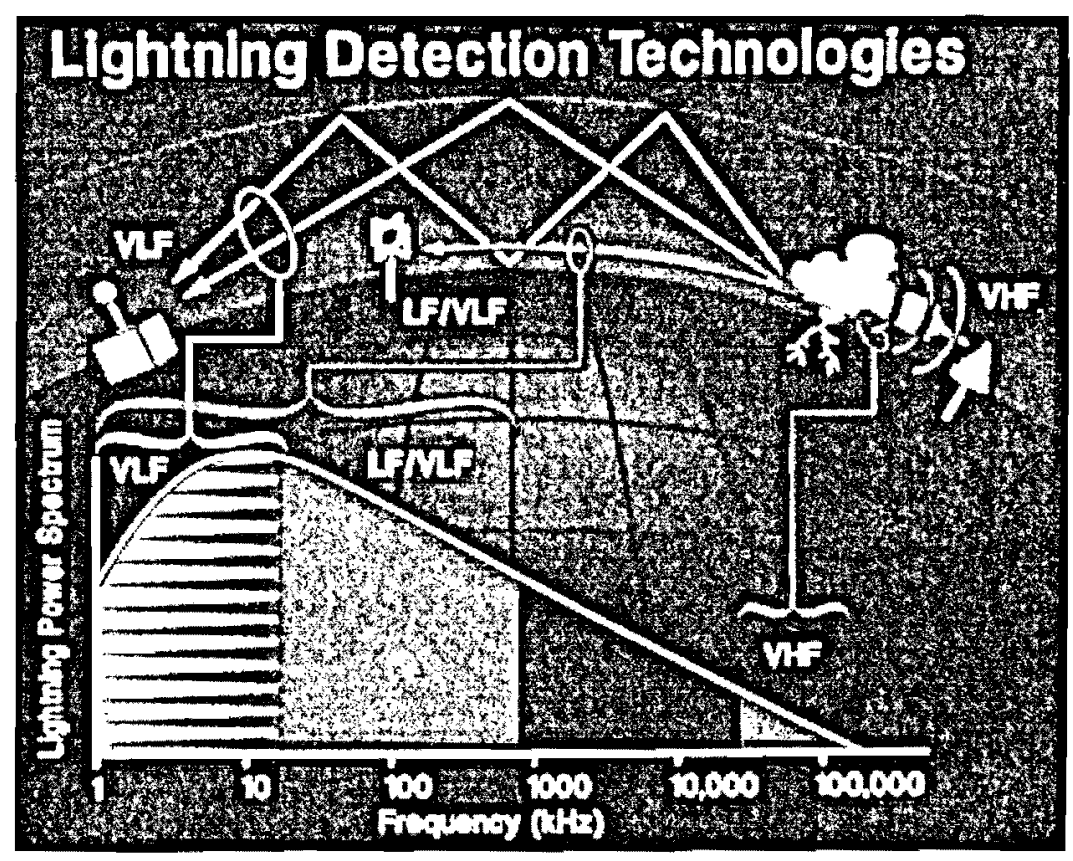

Figure 4.2: NALDN based Lightning Detection Technologies (Adapted from [16].) 


\subsection{Magnetic Field Direction Finding}

Magnetic field direction finding is used to measure the magnetic field of the lightning strike using a crossed-loop antenna with two vertical loops mounted perpendicular to each other. One of the loops is oriented north-south while the other is east-west [17]. The design is used because it is assumed that the lightning strike that is being located is completely vertical, producing a magnetic field which only has an azimuthal component. By Faraday's law, the output voltage induced in each vertical loop is proportional to the derivative of the magnetic field and to the cosine of the angle between the magnetic field vector and the normal vector to the plane of the loop [18]. It is important to note that positive strikes and negative strikes induce the same signal polarity, making them indistinguishable.

Site errors are the largest source of error in the magnetic DF system. Site errors are caused by the presence of unwanted magnetic fields due to non-flat terrain and nearby conducting objects such as underground and overhead power lines which are excited to radiate by the incoming lightning field [18]. In order to correct site errors, the data from a network of at least three DFs is recorded and analyzed for one to three months to determine a site correction curve as a function of angle for each DF [18]. In 2003 an upgrade of the U.S. National Lightning Detection Network (NLDN) was done, which has enabled the site errors to be corrected much faster.

\subsection{Time-of-Arrival Technique}

A time-of-arrival (TOA) sensor provides the time at which some portion of the lightning electromagnetic field arrives at the sensing antenna [18]. There are three types of TOA systems for locating lightning [18]:

- Very short baseline (tens to hundreds of meters)

- Short baseline (tens of kilometers)

- Long baseline (hundreds to thousands of kilometers) 
The long baseline system operates at VLF and LF. VLF and LF signals are associated with the high currents from lightning return strokes. This system is used to identify the strike point of cloud-to-ground lightning and is the system used by NALDN.

To summarize and clarify, in the NALDN, the TOA is simply used to create a range circle around a sensor, which depicts the possible radial range at which a lightning stroke has occurred. The magnetic DF still provides azimuth information.

\subsection{NALDN: Observations and Findings for North America}

Cloud to ground lightning data have been analyzed for the years 1998-2000 for North America for all ground flashes, positive flashes, the percentage of positive lightning, peak currents for negative and positive lightning, and for negative and positive multiplicity [14].

The highest flash densities in Canada are along the U.S. Canadian border (1-3 flashes $\left.\mathrm{km}^{2}\right)$ and in the United States along the Gulf of Mexico coast and Florida (more than 9 flashes $\mathrm{km}^{2}$ ). Areas of greater than $20 \%$ positive lightning occur throughout British Columbia and the Midwest U.S extending into Manitoba and Ontario [14]. The area of maximum mean negative multiplicity, exceeding 2.6 strokes per flash occurs in western Canada [14]. The time of maximum flash rate in North America is over land in the daytime hours with the exception of a region of maximum nighttime lightning in the mid-continent that extends from the Midwestem United States into Canada. For Toronto, this is the opposite, where most flashes occur during the night (just like the Southeastern United States).

The area over which the flash density is calculated varies from $+24 \mathrm{~km}^{2}$ at 30 degrees North. to $346 \mathrm{~km}^{2}$ at 45 degrees North, to $245 \mathrm{~km}^{2}$ at 60 degrees North [14]. This means that the flash density decreases as the latitude of the area increases. 


\subsubsection{Flash Density for North America}

Figure 4.3 shows the annual ground flash density in North America for the individual years (a) 1998 , (b) 1999 , (c) 2000 , and (d) the mean flash density for the 3 years combined [14].

The flash density varies from less than 0.1 flashes $/ \mathrm{km}^{2} / y$ ear over the northern and western extremes of Canada (e.g. British Columbia) and western United States, to over 9 flashes $/ \mathrm{km}^{2} /$ year [14], It is interesting to note that at the boundary between the British Columbia - Alberta borders, the flash density on the western side is $0.1-0.25$ flashes $/ \mathrm{km}^{2} /$ year and just on the eastern side is $1-3$ flashes $/ \mathrm{km}^{2} /$ year [14]. The flash density in Canada does not exceed 3 flashes $/ \mathrm{km}^{2} /$ year [14]. High values close to 2.4 flashes $/ \mathrm{km}^{2} /$ year occur in Toronto. Lower values of flash densities are associated with areas that have air masses that are cool and stable or have relatively low moisture content [14].

Lightning flash density is sometimes greater over the slopes leading to higher terrain and is less over large areas of rough terrain [14]. In contrast, there is sometimes a strong relationship between flash density and very elevated terrain features, where the flash density increases with the elevation along the sides of terrain features and then decreases at the top as was found in the CLDN data by Burrows et al. (2002) [14]. This explains the high flash density at the $553 \mathrm{~m}$ high CN Tower in Toronto when compared to the surrounding area. This relationship is also seen over the Adirondack Mountains of New York and over the Appalachian Mountains [14].

Very high flash densities occur in Florida, along the Gulf Coast, in the Upper Midwest and over the Gulf Stream [14]. The weather in this area is very hot and has little or no winter whereas Ontario is much colder which shows why the flash densities are lower in comparison. 


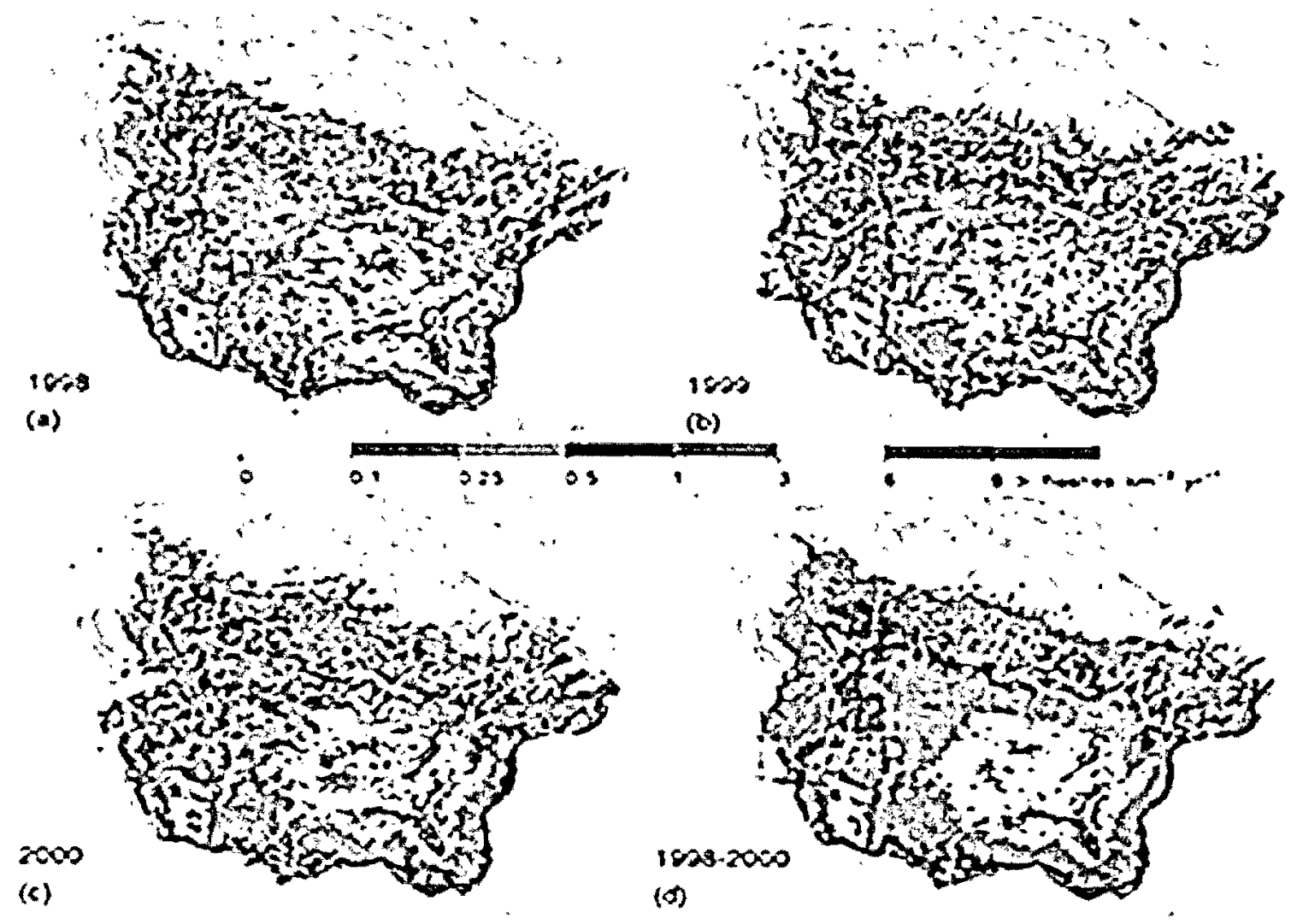

Figure 4.3: Four Panel display shows the annual ground flash density in North America for the individual years (a) 1998 , (b) 1999 , (c) 2000 , and (d) the mean flash density for the 3 year combined (Adapted from [14].)

\subsubsection{Time of Flash Rate for North America}

Daytime hours are considered between $8 \mathrm{am}-8 \mathrm{pm}$ and nighttime hours are considered between 8pm-8am. When looking at the data for North America from 1998-2000, the time of the maximum flash rate over land is in the daytime hours with the exception of a region of maximum nighttime lightning in the mid-continent, which extends from the Midwestern U.S into Canada. Over the waters surrounding the North American continent, the time of maximum lightning is mostly at night, including coastal Pacific, the Gulf of California, the Gulf of Mexico, and the coastal waters on the North Atlantic [14]. For the Toronto region, most of the lightning occurs at night, where just south of Toronto is a body of water, Lake Ontario. 


\subsubsection{Peak Current for North America}

In general, over the North American landmass the peak negative current in the first strokes decreases from lower to higher latitudes [14].

Negative peak currents are higher near bodies of water. Lower altitudes means higher negative peak current. These differences in peak currents can be explained by the change in the electric field with time being different of signals received from lightning over land (lower) to those received from lightning occurring over ocean (higher) [14]. This means that the electric field is higher over water, which is at lower altitudes, so there should be higher negative peak currents.

Now, when looking at positive peak current, the highest median positive peak current over land occur in the upper Midwest and Great Plains of the U.S and continue into southern Manitoba in Canada [14]. Median positive peak currents less than $15 \mathrm{kA}$ occur in western Canada. The high positive currents are uniquely associated with the mesoscale convective systems that occur often in this area [14]. In the Midwest, positive lightning was produced mainly during the summer.

\subsubsection{Flash Multiplicity for North America}

The highest values of mean negative multiplicity exceeds 2.6 strokes/flash in the U.S. over the Midwest, southeastern states, and northern sections of Montana and North Dakota, and in Canada over the three Prairie Provinces, northern Ontario, and the Gulf of St. Lawrence [14]. Highest values of mean positive multiplicity in Canada are in the same regions in which high mean negative multiplicity occurs [14]. The areas of higher multiplicity are the effect of more strokes per flash occurring there. These high values in Southern Ontario, specifically Toronto, may be partly attributed to the tallest structure in the world being located there, the $\mathrm{CN}$ Tower. 
Further, in general, the multiplicity increases with higher negative peak currents whereas multiplicity decreases with positive peak currents [14]. Again, mostly negative currents hit tall structures, such as the $\mathrm{CN}$ Tower. 


\section{Chapter 5}

\section{Flash Characteristics}

This section concentrates not only on analyzing lightning data of the entire year of 2005 , but also on the famous stormy day of August $19^{\text {th }}, 2005$ for flash characteristics to and within 100 $\mathrm{km}$ radius of the $\mathrm{CN}$ Tower.

The storm of August 19,2005 was a typical storm like many that have hit the $\mathrm{CN}$ Tower through the years [6]. The lightning data of August 19, 2005 has been analyzed in order to answer a number of important questions.

\subsection{Monthly Lightning Rate}

Figure 5.1 presents the percentage of the number of flashes for each of the 2005 months. The total number of flashes that occurred within a $100 \mathrm{~km}$ radius around the CN Tower (including 7 flashes that hit the tower) is 74,829 . The figure shows that the peak of the lightning activity takes place during July and August. During 2005, one of the 7 flashes that hit the tower occurred on June $15^{\text {th }}$ and the remaining 6 occurred on August $19^{\text {th }}$. The figure also shows a sharp increase of flashes during June-August and $66.92 \%$ of the observed lightning events in 2005 occurred in the months of July and August. 


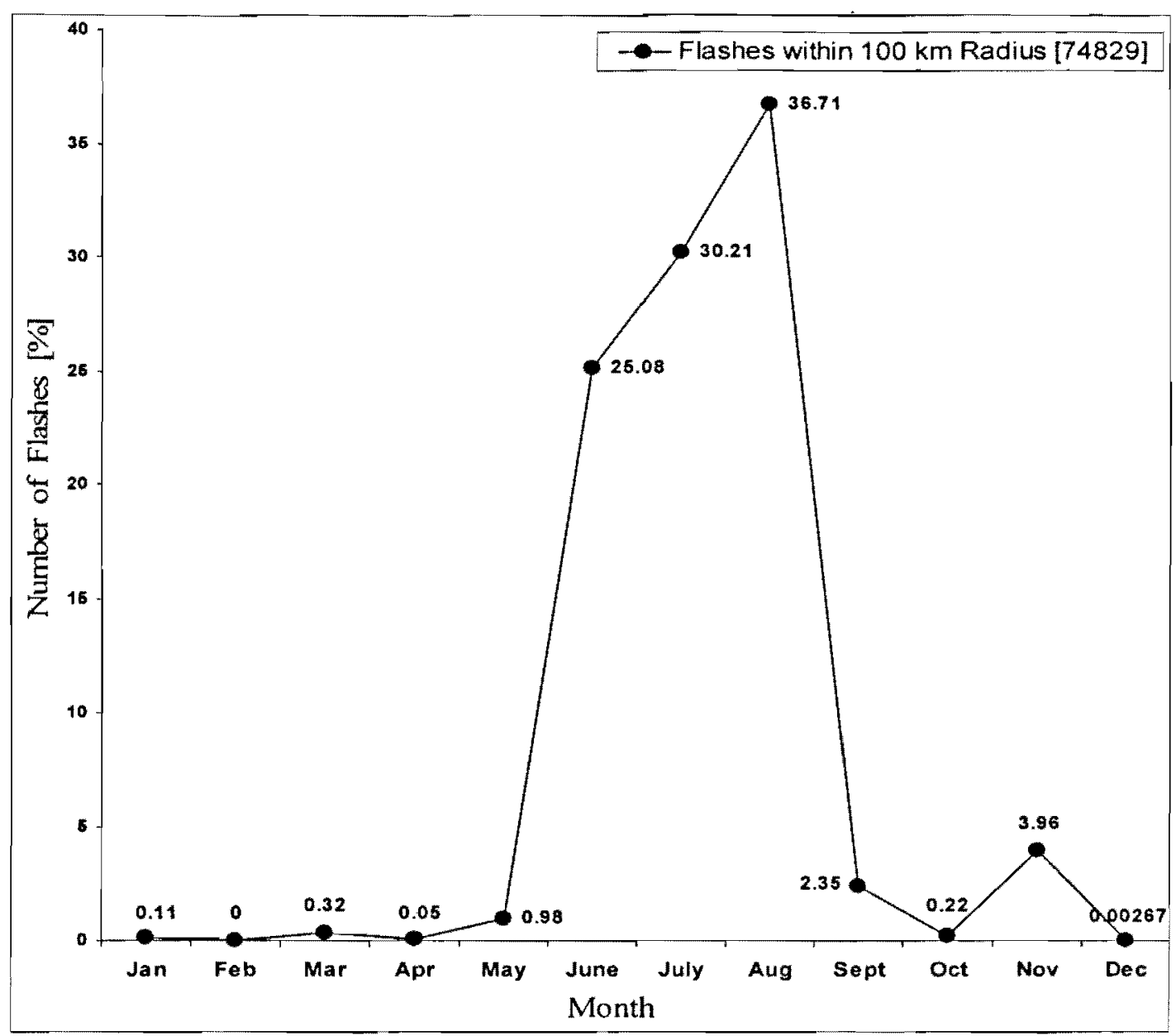

Figure 5.1: Percentage of the number of flashes vs months for 2005 within $100 \mathrm{~km}$ radius around the CN Tower

\subsection{Diurnal Distribution of Flashes}

Figure 5.2 presents the percentage of the number of flashes versus local Toronto time for all the flashes that occurred during 2005. As shown in the figure, the majority of flashes, $39.87 \%$, occurred between $2^{+}-3 \mathrm{pm}$ followed by $20.49 \%$ occurring between $4^{+}-5 \mathrm{pm}$ (between $2-3 \mathrm{pm}$ means just slightly after 2 to 3 or $2^{+}-3$ ). 


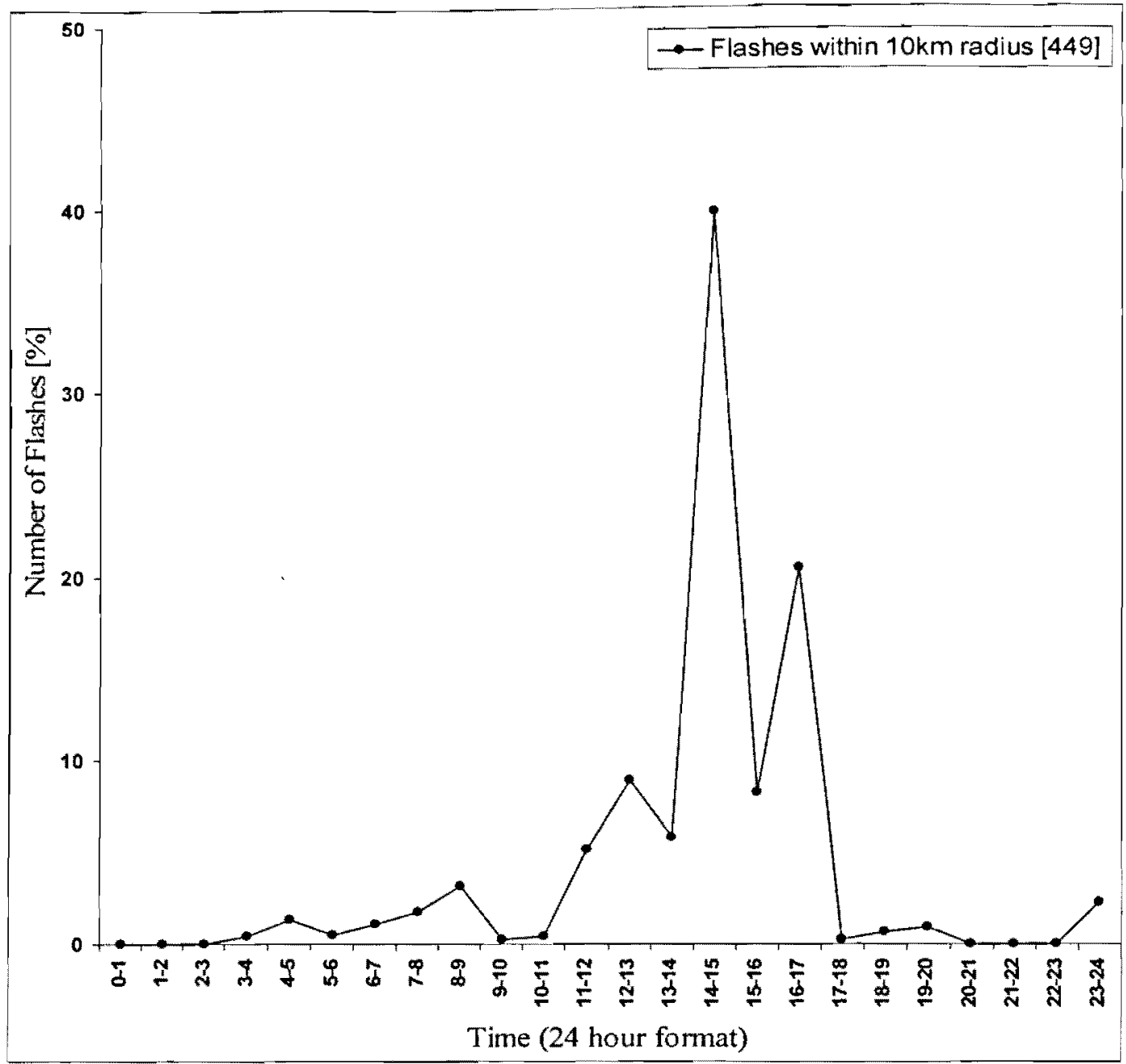

Figure 5.2: Percentage of the number of flashes vs local Toronto time for all Flashes within $10 \mathrm{~km}$ radius around the $\mathrm{CN}$ Tower for the 2005 (Including the 7 flashes that hit the $\mathrm{CN}$ Tower)

The diurnal distribution, shown in Figure 5.3, for the region within $10 \mathrm{~km}$ radius of the tower during the months of July and August 2005, shows that the majority (62.5\%) of the flashes occurred between $2^{+}-3 \mathrm{pm}$. 


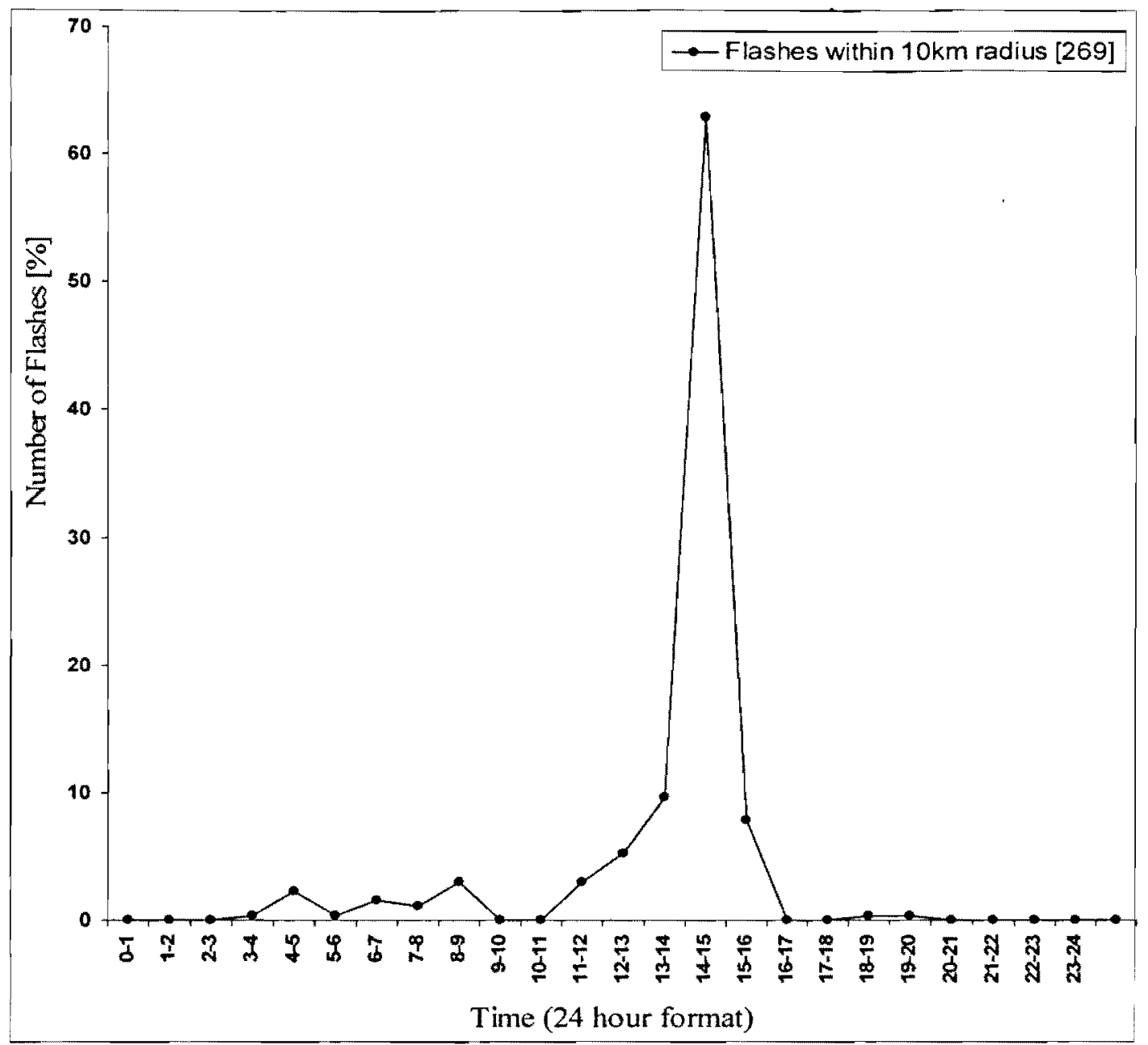

Figure 5.3: Percentage of the number of flashes vs local Toronto time for all flashes within $10 \mathrm{~km}$ of the CN Tower for July and August 2005 (Including the 6 flashes that hit the $\mathrm{CN}$ Tower)

For the purpose of comparison, the diurnal distribution of August $19^{\text {th }} 2005$ within a $10 \mathrm{~km}$ radius of the $\mathrm{CN}$ Tower of flashes occurring is shown in Figure 5.4. Out of the 235 flashes that occurred during the month of August, 180 occurred on this day. That accounts for $76.59 \%$ of the flashes for August. For Figure 5.4, the 6 flashes that hit the tower on this day occurred during the following local Toronto time:

-1 flash between 12-13 hours (12-1PM)

-4 flashes between 13-14 hours (1-2PM)

-1 flash between $14-15$ hours (2-3PM) 
When looking at a $10 \mathrm{~km}$ radius of the $\mathrm{CN}$ Tower on August 19,2005, the majority of the flashes, $84.44 \%$, occurred between $2^{+}-3 \mathrm{pm}$ local Toronto time.

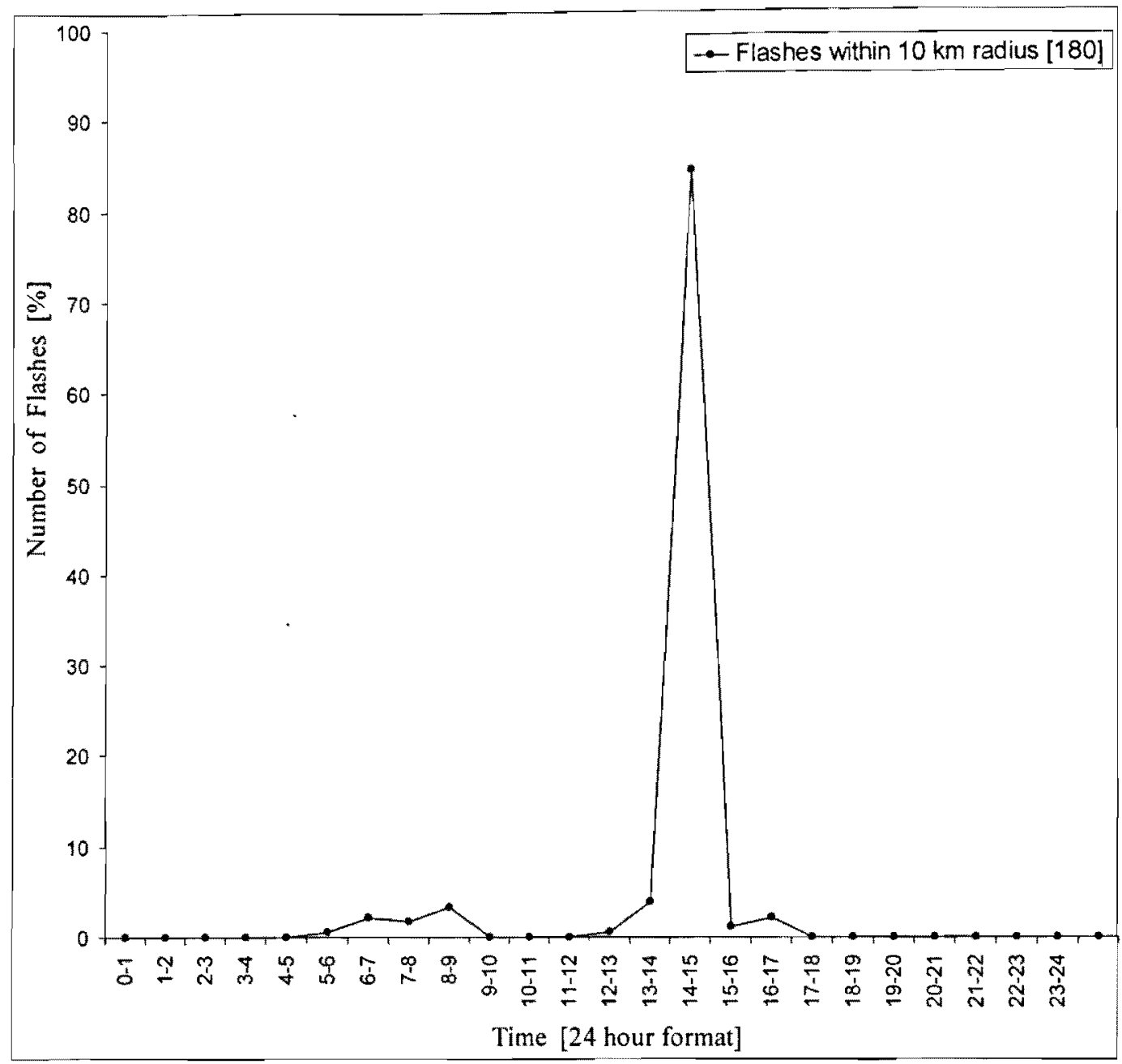

Figure 5.4: Percentage of the number of flashes vs local Toronto time for all flashes within $10 \mathrm{~km}$ of the CN Tower on August 19, 2005 (Including the 6 flashes that hit the $\mathrm{CN}$ Tower)

The diurnal distribution of flashes (Figures 5.2-5.4) show that the majority of flashes occurred in the mid afternoon for the summer months. Although more years of data could show further details concerning diurnal distribution, the analysis points out to the best time to do any repair or maintenance work in power utilities at or within a close proximity of the $\mathrm{CN}$ Tower would be during the morning hours and even better during the late evening hours, at least for the summer months. 


\subsection{Flash Location}

Figures 5.5-5.7 show all flashes for north versus east for $20 \mathrm{~km}$ radius, $10 \mathrm{~km}$ radius and $1 \mathrm{~km}$ around the $\mathrm{CN}$ Tower, respectively. Once again, for the flash data, the data corresponding to the first stroke of each flash represents the data for that flash. The NALDN strike location data has been converted from latitude and longitude in degrees to north-south and east-west in $\mathrm{km}$ [19]. The $\mathrm{CN}$ Tower is then placed at $\mathrm{E}, \mathrm{N}=0,0$ (the origin) and all north and east values were subtracted from the north and east values for the $\mathrm{CN}$ Tower in order to normalize to 0,0. For example, the following Table 5.1 shows the values for one of the flashes with respect to the $\mathrm{CN}$ Tower.

\begin{tabular}{|c|c|c|c|c|c|c|c|}
\hline Time & Latitude & Longitude & kA & N-S $(\mathrm{km})$ & E-W $(\mathrm{km})$ & $\mathrm{N}(\mathrm{km})$ & $\mathrm{E}(\mathrm{km})$ \\
\hline CN TOWER & 43.6426 & 79.3871 & N/A & 4833.634883 & 313.908548 & 0 & 0 \\
\hline 19:26:00.095 & 43.645 & -79.387 & -31.9 & 4833.90152 & 313.916253 & 0.266637 & 0.007705 \\
\hline
\end{tabular}

Table 5.1: Value from lat/long to $\mathrm{N} / \mathrm{E}$

These figures help in determining the location of each flash with respect to the $\mathrm{CN}$ Tower, which is located at the origin for all figures. South of the $\mathrm{CN}$ Tower there are very little flashes if any for the $0-5 \mathrm{~km}$ south-east from the tower as Lake Ontario is located there. Most flashes are located in the region north-west of the tower. There are less flashes occurring north-east of the Tower. The CN Tower seems to provide a degree of protection the area east of it. This may be due to the fact the storms start in the west and move east. It is also interesting to see that there is an area about $0-3 \mathrm{~km}$ radius of the tower that had very few flashes. This area seems to be protected by the tower. These graphs clearly show that a protection system for the surrounding area around the tower is important.

Two of the flashes that hit the tower were located at the exact same location but different time, with a difference of enough time to ensure that they are separate flashes. Therefore, both these flashes are labeled as one point on the graphs. These points correspond to the location $E, N=0.007554,0.377732$ and are only identified as one point on Figures 5.5-5.7, most clearly seen in Figure 5.7. 
When looking at Figure 5.7 which shows the $0-1 \mathrm{~km}$ radius around $\mathrm{CN}$ Tower, 7 of the 8 flashes that occurred in this region were located north of the tower, where 5 of those 7 actually hit the tower. The $6^{\text {th }}$ flash point that hit the tower is recorded as occurring south-west of the tower.

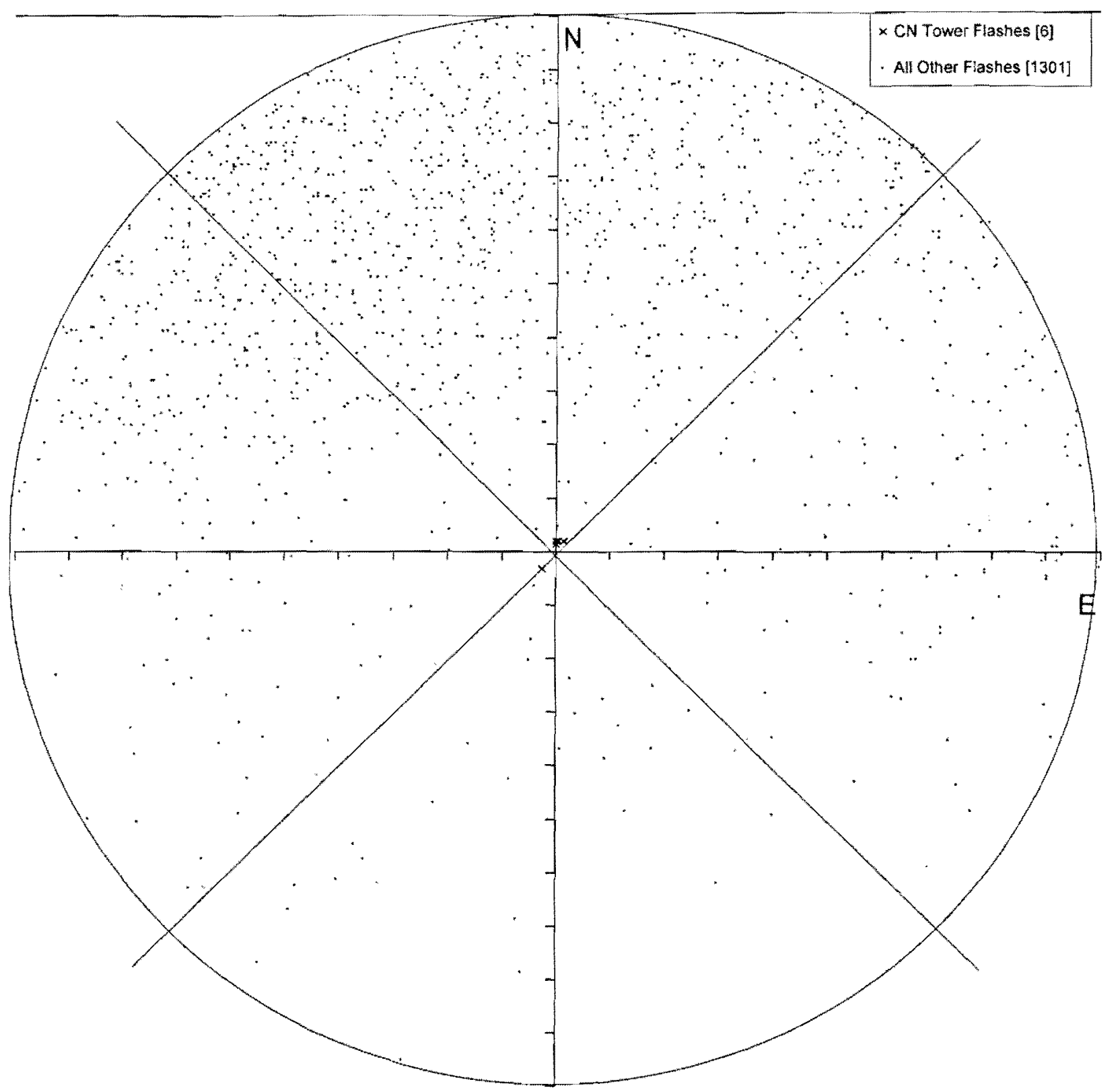

Figure 5.5: Location of flashes within $20 \mathrm{~km}$ radius around the CN Tower for August 19, 2005.

Each grid is for $2 \mathrm{~km}(0-2,2-4, \ldots, 18-20)$ and 45 degrees $(0-360 \mathrm{deg} \mathrm{CW}$ from $\mathrm{N})$ 


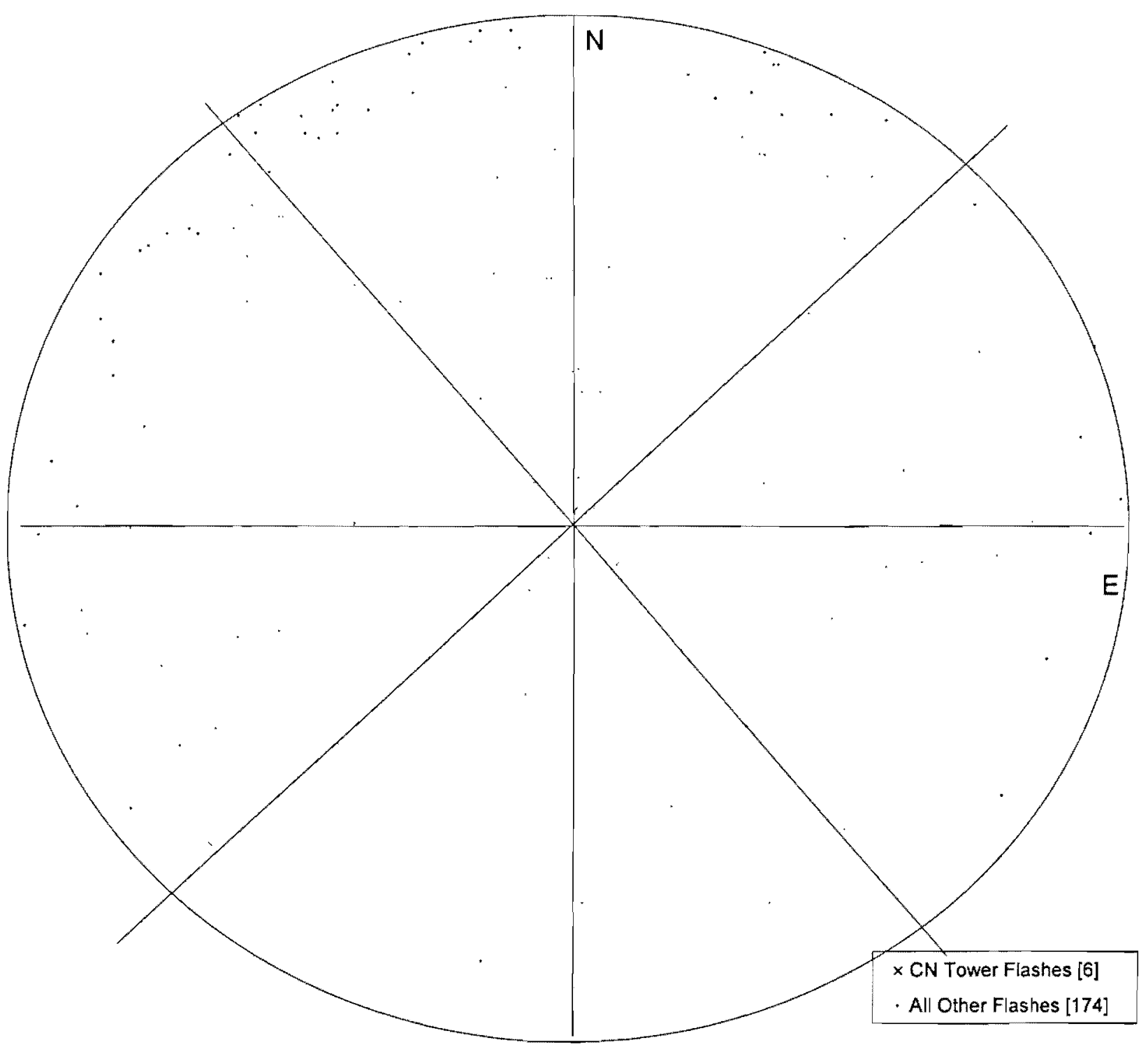

Figure 5.6: Location of flashes within $10 \mathrm{~km}$ radius around the $\mathrm{CN}$ Tower for August 19, 2005 Each grid is for $1 \mathrm{~km}(0-1,1-2, \ldots, 9-10)$ and 45 degrees $(0-360 \mathrm{deg} C W$ from $N)$ 


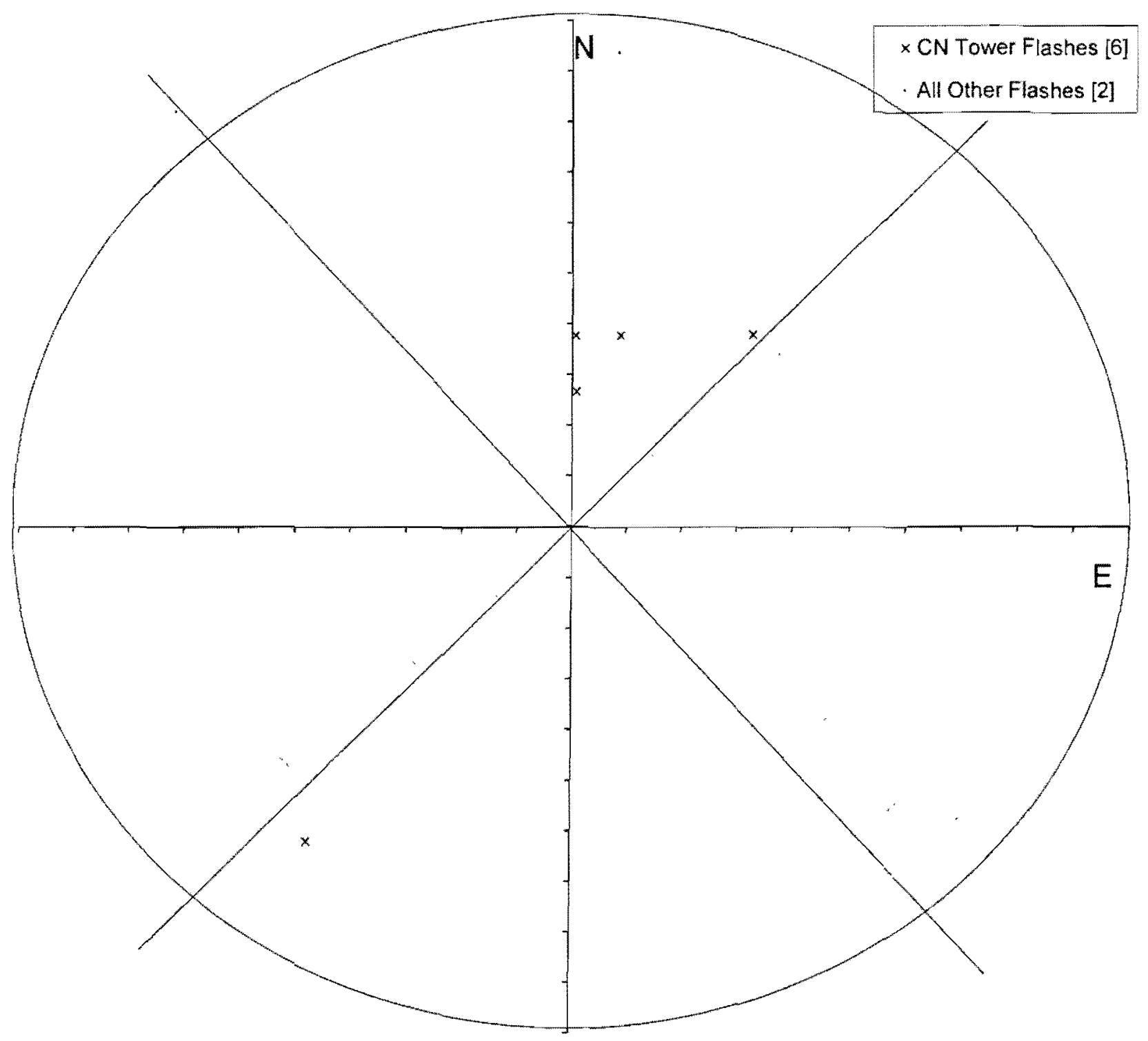

Figure 5.7: Location of flashes within $1 \mathrm{~km}$ radius around the $\mathrm{CN}$ Tower for August 19, 2005.

Each grid is for $0.1 \mathrm{~km}(0-0.1,0.1+0.2, \ldots, 0.9-1.0)$ and 45 degrees $(0-360$ deg $\mathrm{CW}$ from $\mathrm{N})$ 


\subsection{Flash Density}

Since most of this research is based on 2005 lightning data and in particular the August 19, 2005 data, flash and stroke densities for the whole year of 2005 is compared with those that occurred on August 19, 2005 which show just how severe the storms on this day were. Flash data will be looked at first.

Flash density is defined as the total number of flashes per square $\mathrm{km}$ per year. When taking into consideration a $100 \mathrm{~km}$ radius around the $\mathrm{CN}$ Tower for both positive and negative flashes combined, the total flash density for 2005 is $74829 / \pi(100)^{2}=2.382$ flashes $/ \mathrm{km}^{2} /$ year. Now, when considering only August 19, 2005 for a 24 hour period, the flash density for both positive and negative flashes combined is $12559 / \Pi(100)^{2}=0.399$ flashes $/ \mathrm{km}^{2} /$ year. This means that $16.6 \%$ of the total flashes for the 2005 occurred on this day alone. Also, when looking at a $1 \mathrm{~km}$ radius around the $\mathrm{CN}$ Tower, the flash density for August 19, 2005 is 2.546 flashes $/ \mathrm{km}^{2}$. This is very important to show the extent of the severity of the storms on this day and the effect of the $\mathrm{CN}$ Tower. This value shows that there was $538 \%$ higher flash densities within $1 \mathrm{~km}$ around the $\mathrm{CN}$ Tower than there was within $100 \mathrm{~km}^{2}$ around the tower on August 19, 2005. That is quite significant when seeing the amount of damage even 1 lightning flash can cause.

For completeness, it is a good idea to separate positive negative flashes and to determine the flash density for each category. As negative flashes are more common (only negative flashes hit the CN Tower during 2005), the flash density for this category is expected to be higher. This is confirmed as the negative and positive flash densities within $100 \mathrm{~km}$ around the tower for the whole year of 2005 are 2.244 and 0.324 , respectively.

The flash densities can be broken up in terms of each $\mathrm{km}$ radius around the tower to see the values closer to the tower compared to further way. This shows the CN Tower's effect on flash density and investigates the possibility of having a protection cone around the $\mathrm{CN}$ Tower.

Figure 5.8 presents the ground flash density (positive and negative flashes combined) for a 20 $\mathrm{km}$ radius around the $\mathrm{CN}$ Tower for the whole year of 2005 (3047 flashes). The $\mathrm{CN}$ Tower 
flashes are also included since NALDN information does not list these at $0.0 \mathrm{~km}$ but actually as $0.3 \mathrm{~km}$ and so on due to a slight margin of error for $\mathrm{CN}$ Tower flashes (except for June $15^{\text {th }}$ flash which is given as $0.0 \mathrm{~km}$ from the Tower). Figure 5.8 shows the flash densities for every $2 \mathrm{~km}$ radius from the tower (which is situated at the origin). Each grid is for every $2 \mathrm{~km}$ and 45 degrees from $0-20 \mathrm{~km}$ in total. The angles start from 0 degrees at north $(\mathrm{N})$ and move clockwise (CW). Therefore, there are 10 grids for every 45 degree section. The formula used is as follows:

$$
\begin{gathered}
\mathrm{GFD}=\text { Total Flashes/Area } \\
\text { Where } \\
\text { Area }=\text { angle }\left(\text { radius }_{2}{ }^{2}-\text { radius }_{1}{ }^{2}\right)
\end{gathered}
$$

and where angle is in radians and is 45 degrees $=0.7853981 \mathrm{rad}$ for all cases since difference between all sections is always 45 degrees, therefore each section represent 45 degrees for those grids in that section as follows:

Two examples for 0-45 deg CW from North are:

$$
\begin{aligned}
0-2.0 \mathrm{~km}: & \mathrm{FD}=10 / 0.7853981\left(2.0^{2}-0^{2}\right)=10 / 0.7853981(4)=3.18 \\
2.1-4.0 \mathrm{~km}: & \mathrm{FD}=7 / 0.7853981\left(4.0^{2}-2.1^{2}\right)=7 / 0.7853981(11.59)=0.7
\end{aligned}
$$

As Figure 5.8 shows, the $0-2 \mathrm{~km}$ radius from the tower have very high flash density numbers, especially the value for $0-45$ degrees $\mathrm{CW}$ from $\mathrm{N}$ and $0-2 \mathrm{~km}$ radius which is $3.18 .50 \%$ of the flashes that occurred in the grid actually hit the $\mathrm{CN}$ Tower. This is just north-east of the tower. There is no surprise that south-east of the tower there are very few flashes from $0-4 \mathrm{~km}$ due to Lake Ontario being located there. Density of flashes in water is usually low. The graph shows that for $2-4 \mathrm{~km}$ radius around the tower, the flash density is very low. This means that the area of 0-2 $\mathrm{km}$ gets a great deal of flashes due to the tower's presence as most of these flashes do actually hit the tower, but just slightly further away the flash densities decrease dramatically. Even the values from 4-6 km are quite low in comparison. This shows that perhaps indeed, the tower is providing a protection cone for this area. Once we get further away, specifically 10-20 $\mathrm{km}$ radius north-east and more so north-west from the tower, the flash densities are quite high. This could be because storms usually start from the west and move east [8], therefore causing much more flashes in the north-west area and lowers numbers as you move east. This shows that the $\mathrm{CN}$ Tower may actually provide some protection to the area east of it, hence acting as a lightning protection rod for that area. Therefore, it is very important to insure that the $\mathrm{CN}$ Tower 
is very well protected as not to sustain any severe damage from the lightning strikes that it receives.

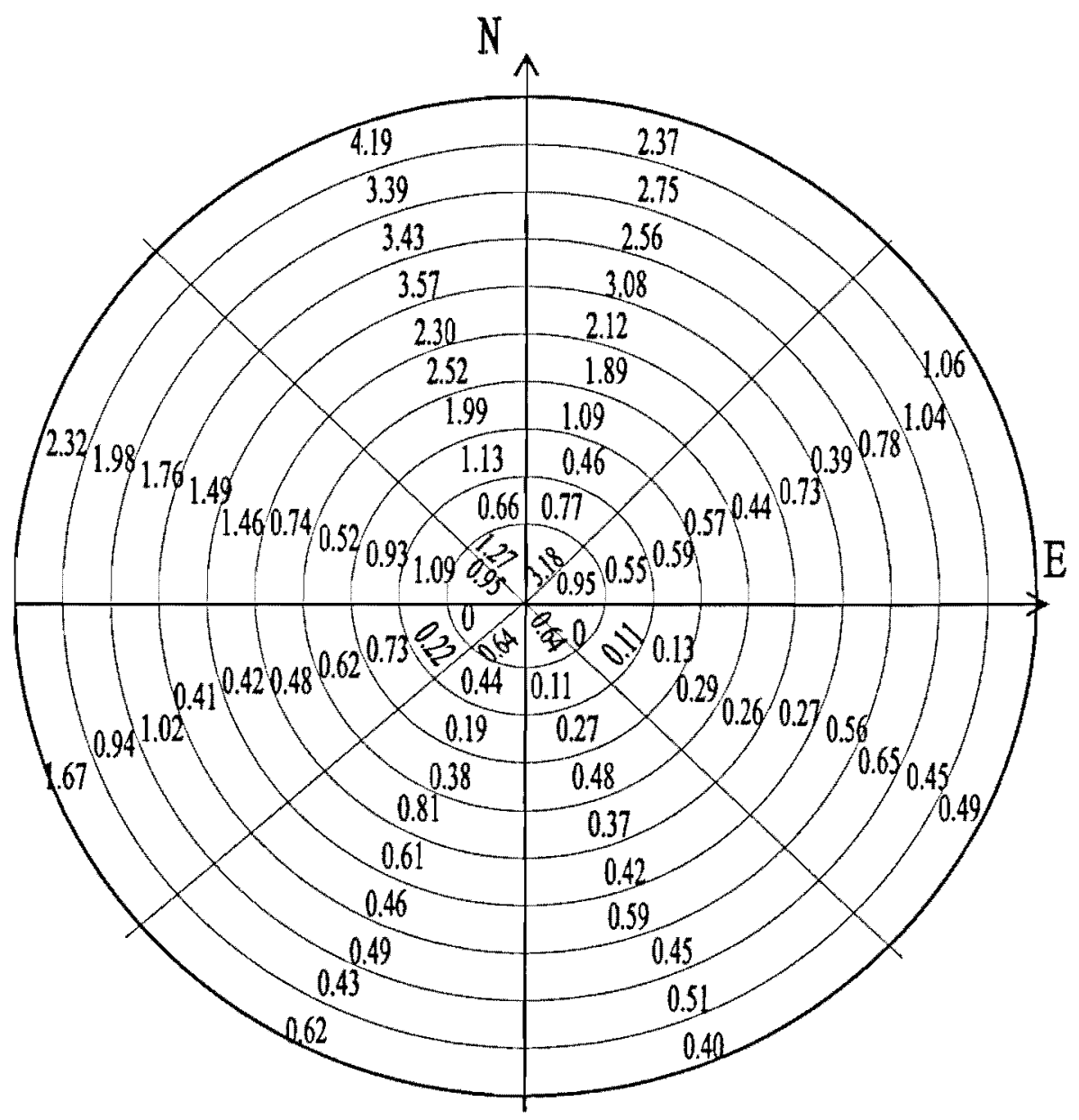

Figure 5.8: Ground Flash Density (GFD) for 2005 (3047 flashes) within $20 \mathrm{~km}$ radius around the CN Tower $(0-2,2-4, \ldots, 18-20)$

Figure 5.9 presents the ground flash density (positive and negative flashes combined) for a 20 $\mathrm{km}$ radius around the $\mathrm{CN}$ Tower for August $19^{\text {th }} 2005$ (1307 flashes). The CN Tower flashes are also included. Figure 5.9 shows the flash densities for every $2 \mathrm{~km}$ radius from the tower (which is situated at the origin). Each grid is for every $2 \mathrm{~km}$ and 45 degrees from $0-20 \mathrm{~km}$ in total. The angles start from 0 degrees at north $(\mathrm{N})$ and move clockwise $(\mathrm{CW})$. Therefore, there are 10 grids for every 45 degree section. As the values show, the $0-2 \mathrm{~km}$ radius around the tower have very high flash density numbers, especially the value for 0-45 degrees $\mathrm{CW}$ from $\mathrm{N}$ and $0-2 \mathrm{~km}$ radius which is $1.59 .80 \%$ of these flashes actually did hit the tower. This is just north east of the tower. The pattern of lightning flashes on this day matches to some extent the pattern shown for the 
whole year of 2005 in Figure 5.8. The graph shows that for $2-4 \mathrm{~km}$ radius around the tower, the flash density is very low. This means that the area of $0-2 \mathrm{~km}$ gets a great deal of flashes due to the tower's presence as most of these values do actually hit the tower (6 out of the 9 flashes that make up the data for this area actually hit the $\mathrm{CN}$ Tower), but just slightly further away the flash densities decrease dramatically. The conclusion is the same for August $19^{\text {th }}, 2005$ as it is for the whole year of 2005, which is that it is very important that the $\mathrm{CN}$ Tower is very well protected as not to sustain any severe damage from the lightning strikes that it receives.

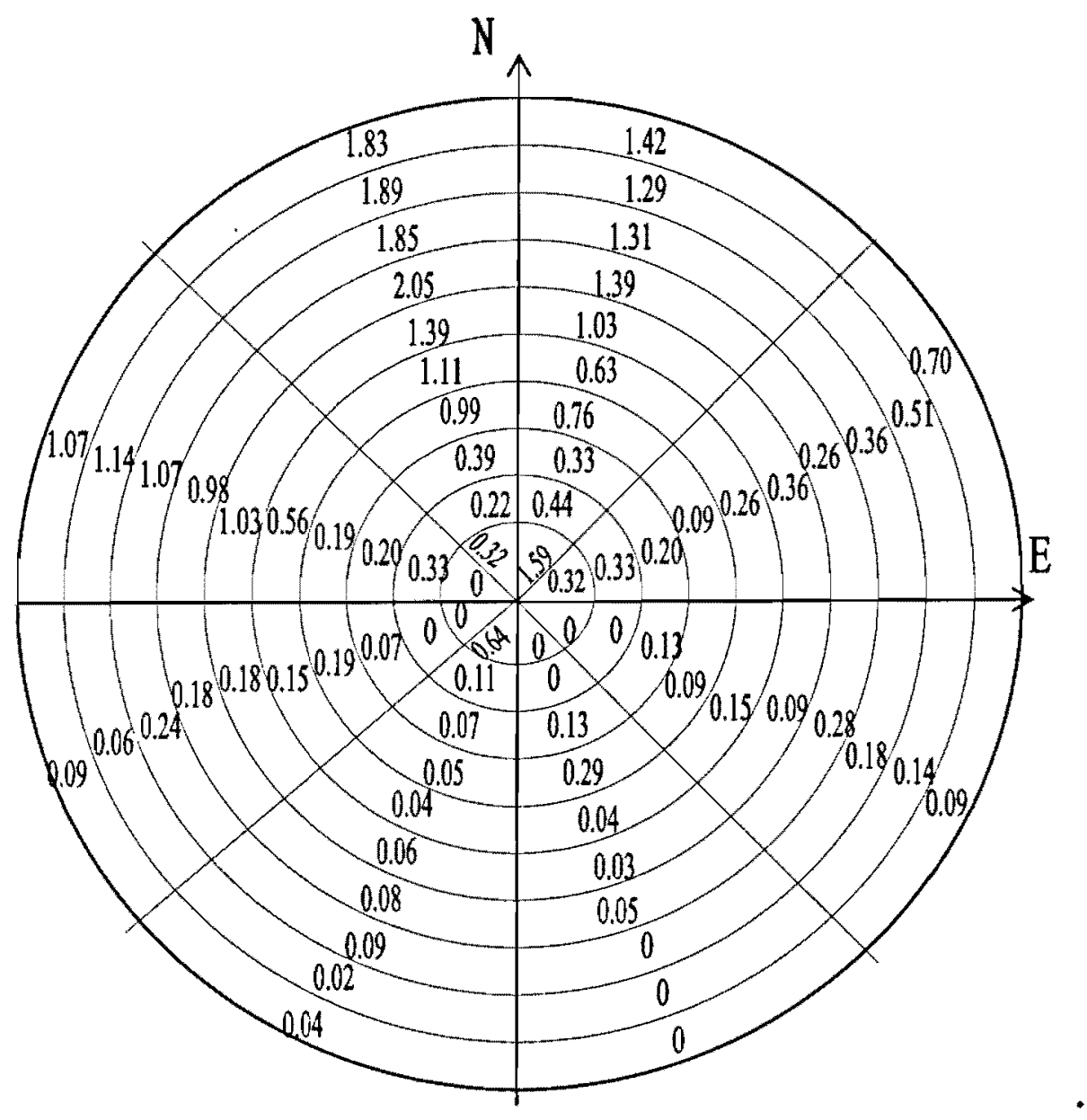

Figure 5.9: Ground Flash Density (GFD) for August 19,2005 (1307 flashes) within $20 \mathrm{~km}$ radius around the CN Tower $(0-2,2-4, \ldots, 18-20)$

Now, the data obtained from Figures 5.8 and 5.9 after removing CN Tower flashes leads to the study of the variation of flash density with distance and angle. To do this, the angles were divided into north (representing the area from $315 \mathrm{deg}-45 \mathrm{deg} \mathrm{CW}$ from $\mathrm{N}$ ), east (representing the area from $45 \mathrm{deg}-135 \mathrm{deg} \mathrm{CW}$ from N), south (representing the area from $135 \mathrm{deg}-225 \mathrm{deg}$ $\mathrm{CW}$ from $\mathrm{N}$ ), and west (representing the area from $225 \mathrm{deg}-315 \mathrm{deg} \mathrm{CW}$ from $\mathrm{N}$ ). 
First, we look at the ground flash density versus distance for $0-20 \mathrm{~km}$ radius around the $\mathrm{CN}$ Tower for the whole year of 2005 (Figure 5.10). In order to study the influence of the CN Tower on flash density within the tower's immediate vicinity, $\mathrm{CN}$ Tower flashes are excluded from the data. Also, since the NALDN estimated the location of all CN Tower flashes for 2005 to be within a radius of $0.8 \mathrm{~km}$ from the tower, we define an effective flash density for $\mathrm{CN}$ Tower strikes. This is obtained by dividing the number of $\mathrm{CN}$ Tower flashes by the area of the circle with radius of $0.8 \mathrm{~km}$ which gives $7 / \Pi(0.8)^{2}=3.48$. This shows that the effective $\mathrm{CN}$ Tower flash density is quite large in comparison with any other location. The solid line of Figure 5.10, representing the total flash density as a function of distance (for all angles), points out to a substantial reduction in the flash density in the area up to $4 \mathrm{~km}$ from the tower in comparison with other areas. The tower seems to provide a protection cone to the area in its immediate vicinity. 


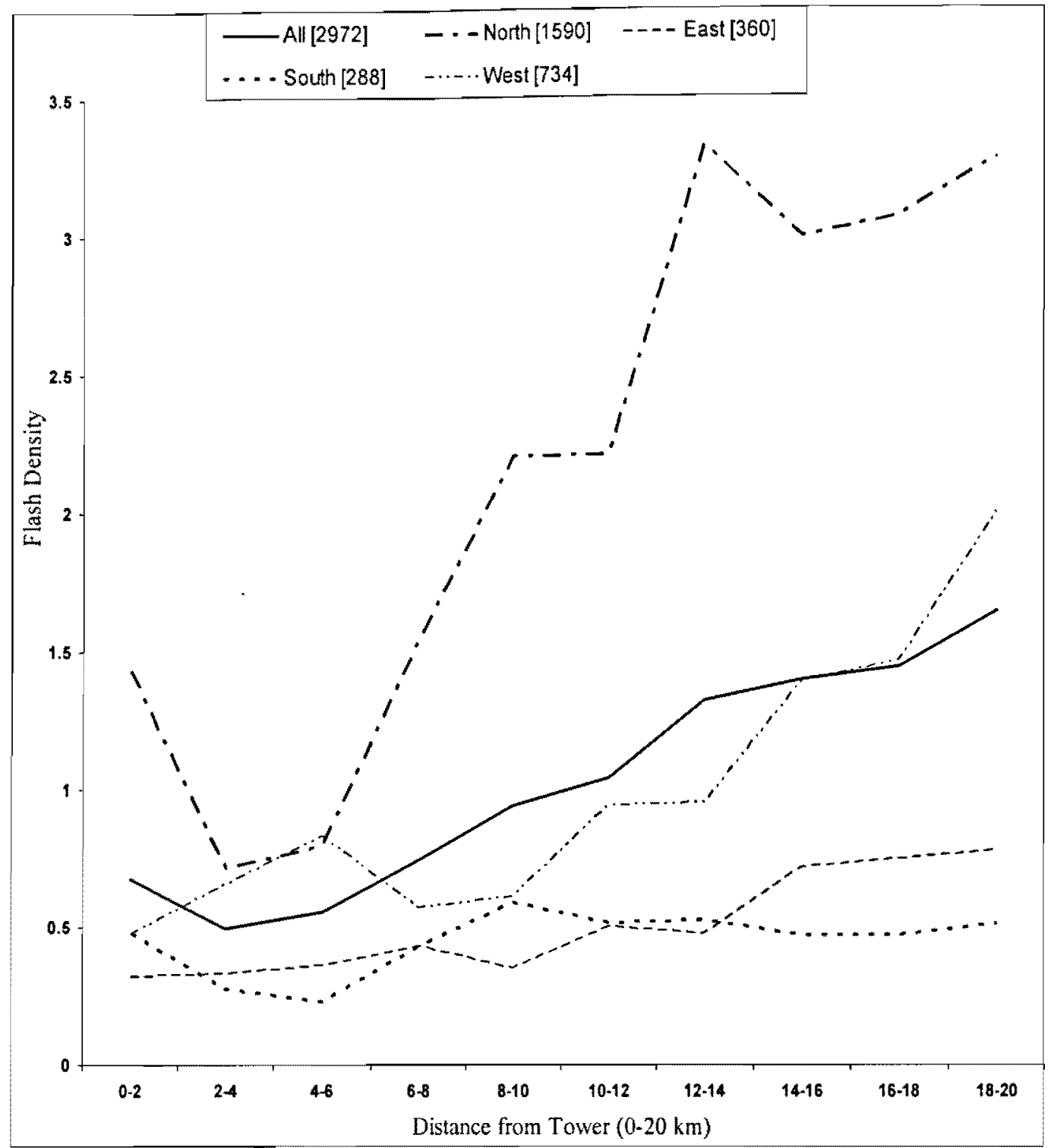

Figure 5.10: Flash density vs distance $(0-20 \mathrm{~km})$ excluding CN Tower flashes for 2005

Figure 5.11 presents the ground flash density versus distance for $0-20 \mathrm{~km}$ radius around the CN Tower for August 19, 2005 (excluding CN Tower flashes). Since the network estimated all $\mathrm{CN}$ Tower flashes for August 19 th to be within $0.8 \mathrm{~km}$ from the tower, the effective CN Tower flash density in this case is 2.98 . This confirms the results seen for 2005 and shows that the tower does provide a protection cone of about $4 \mathrm{~km}$ to the area in its immediate vicinity. 


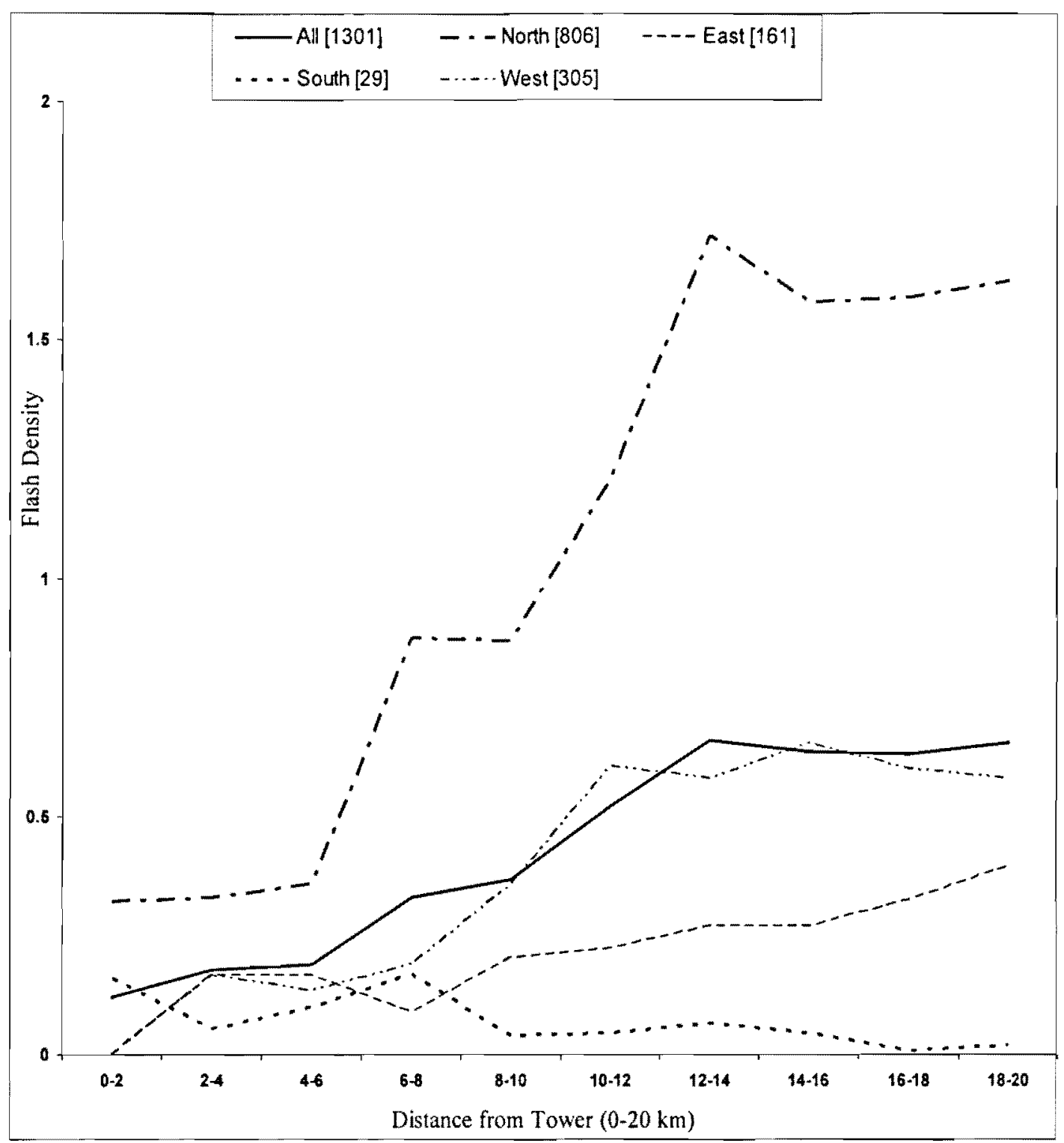

Figure 5.11: Flash density vs distance $(0-20 \mathrm{~km})$ excluding $\mathrm{CN}$ Tower flashes for August 19, 2005

Next, when looking at Figure 5.12, the number of flashes versus distance from the tower for 0-10 km radius on August 19,2005, one can see that immediately around the tower $(0-1 \mathrm{~km}$ radius) there are 8 flashes whereas right after that (1-2 km radius) there is only $1 \mathrm{flash}$. It is interesting to see this as the $1-2 \mathrm{~km}$ radius area seems to be protected by the tower. After the 2 $\mathrm{km}$, the number of flashes gradually increases. 


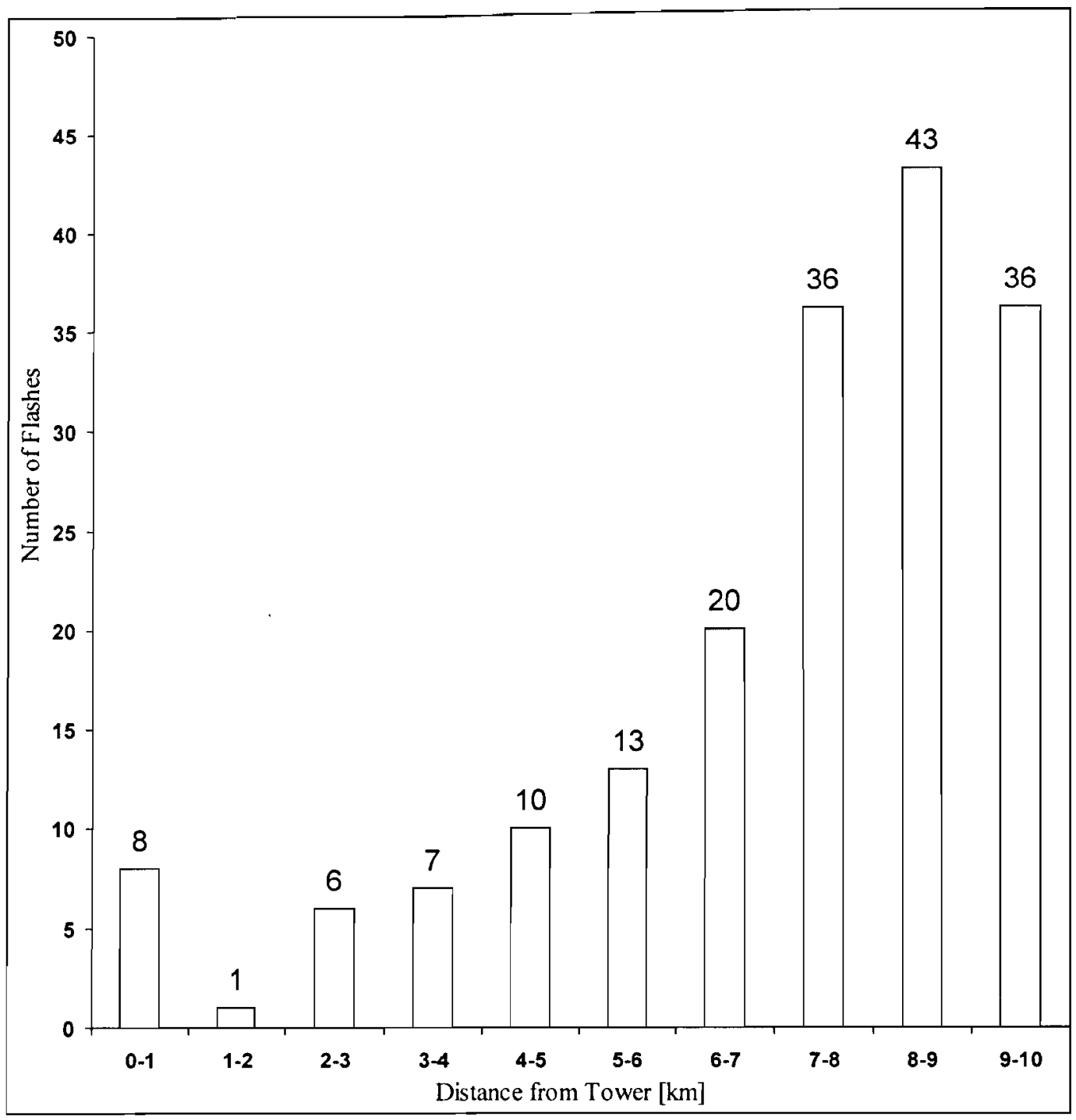

Figure 5.12: Number of flashes vs distance from the CN Tower (0-10 km radius) August 19, 2005 lightning events

Further, Figure 5.13, which is the number of --ve and +ve flashes versus distance from tower $(0-10 \mathrm{~km})$ shows the lightning strokes to the tower on this day of August 19, 2005 were all negative currents. The positive flashes do not occur until after $2 \mathrm{~km}$ from the tower. It is interesting to note the amount of positive flashes within 2-10 km occurs more often then one would think. 62 out of 180 or $34.44 \%$ of the flashes within $10 \mathrm{~km}$ are positive. Whether the first stroke in the flash is negative or positive determines the sign of that particular flash. 


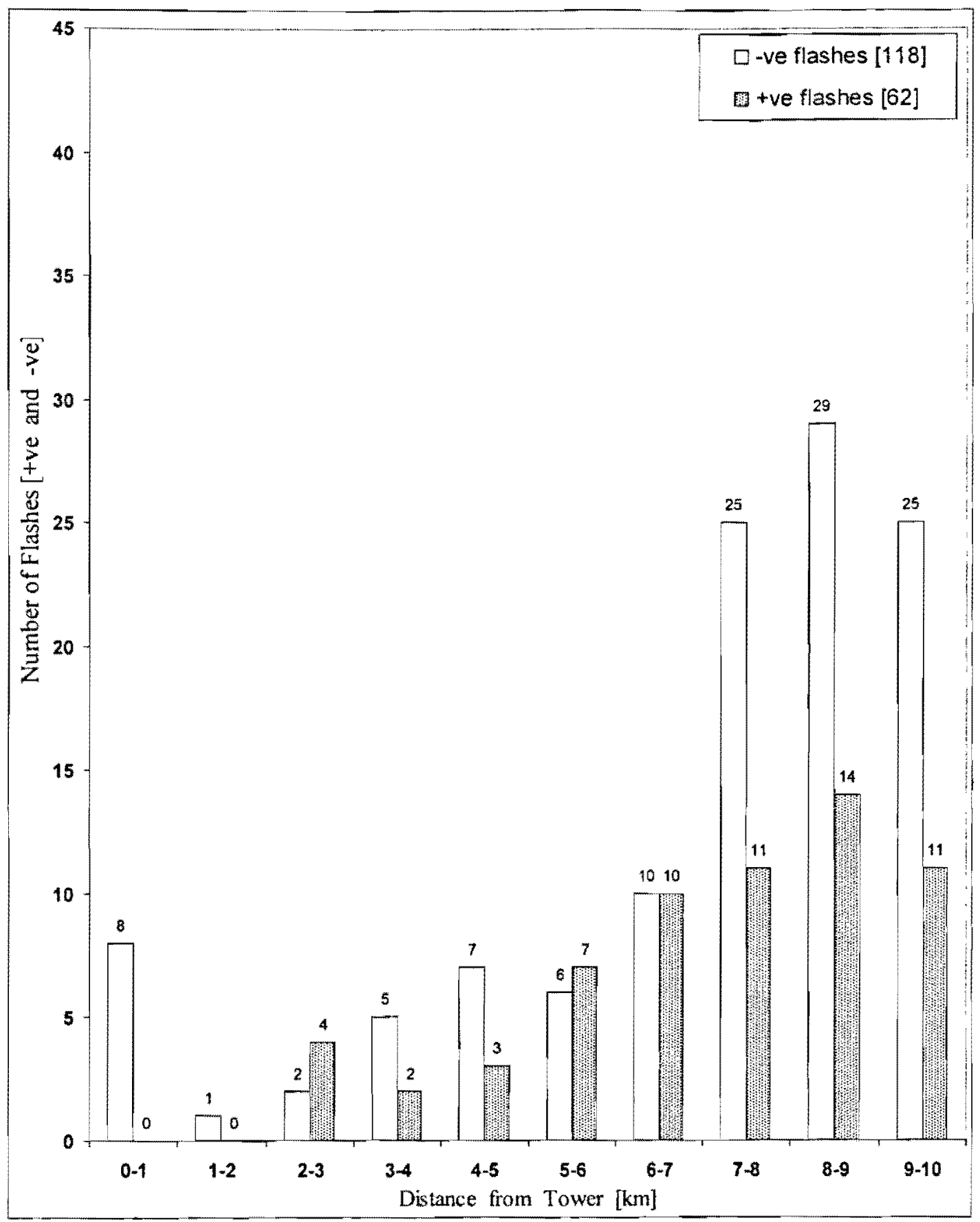

Figure 5.13: Number of - ve and +ve flashes vs distance from the CN Tower $(0-10 \mathrm{~km}$ radius) for August 19, 2005 lightning events 


\subsection{Flash Multiplicity}

A lightning flash must contain at least one, but may have several strokes. We define flash multiplicity (FM) by NALDN as the number of strokes per flash. In this section the positive and negative flashes are put together. The data once again comes from NALDN. The grouping of which strokes belonged to which flash was done using NALDN's data and the procedure of assigning strokes to a given flash if they occur within a time interval from the previous stroke of $500 \mathrm{~ms}$, with the maximum flash duration being 1 second. Hence, the FM for the whole year of 2005 (both negative and positive flashes together) for data within a $100 \mathrm{~km}$ radius of the $\mathrm{CN}$ Tower is \#strokes/\#flashes $=181949 / 74829=2.432$. The FM for only August 19, 2005 for the same $100 \mathrm{~km}$ radius (also for both negative and positive flashes together) is \#strokes/\#flashes = $30901 / 12559=2.460$. This shows that August 19,2005 data has a slightly higher number of strokes/flash than 2005 data. This small increase may be, at least partially, attributed to $\mathrm{CN}$ Tower flashes which usually have higher FM.

Now, when looking at figure 5.14, the average multiplicity versus distance from the tower (0$10 \mathrm{~km}$ ) for August 19,2005 (for both positive and negative flashes together), the tower flashes or the flashes in the immediate vicinity to the tower have the highest multiplicity. As shown, for flashes that the NALDN located up to $1 \mathrm{~km}$ around the tower (which are mostly tower flashes), the number of strokes per flash was 3 whereas $1^{+}-2 \mathrm{~km}$ away the value is 1 . This is a significant drop for locations exceeding $1 \mathrm{~km}$ from the tower. From $1-10 \mathrm{~km}$ the average values fluctuate between 1 and nearly 2 but no where near the amount at the tower or its immediate vicinity.

For the CN Tower flashes, according the NALDN for flash location, all flashes occurred within $0-1 \mathrm{~km}$ from the $\mathrm{CN}$ Tower. When comparing a severe storm like the one that occurred on August 19, 2005 to the rest of the whole year of 2005 its interesting to see that for a $10 \mathrm{~km}$ radius around the Tower, the number of flashes that occurred $2 \mathrm{~km}$ or more from the tower is $98.28 \%$ on August $19^{\text {th }}$ and the number of flashes that occurred $2 \mathrm{~km}$ or more from the tower is $96.13 \%$ for the whole year of 2005. The number of flashes that occurred $10 \mathrm{~km}$ or more from the tower is $2.29 \%$ for August $19^{\text {th }}$ and the number of flashes that occurred $10 \mathrm{~km}$ or more from the tower is $2.28 \%$ for the whole year. 


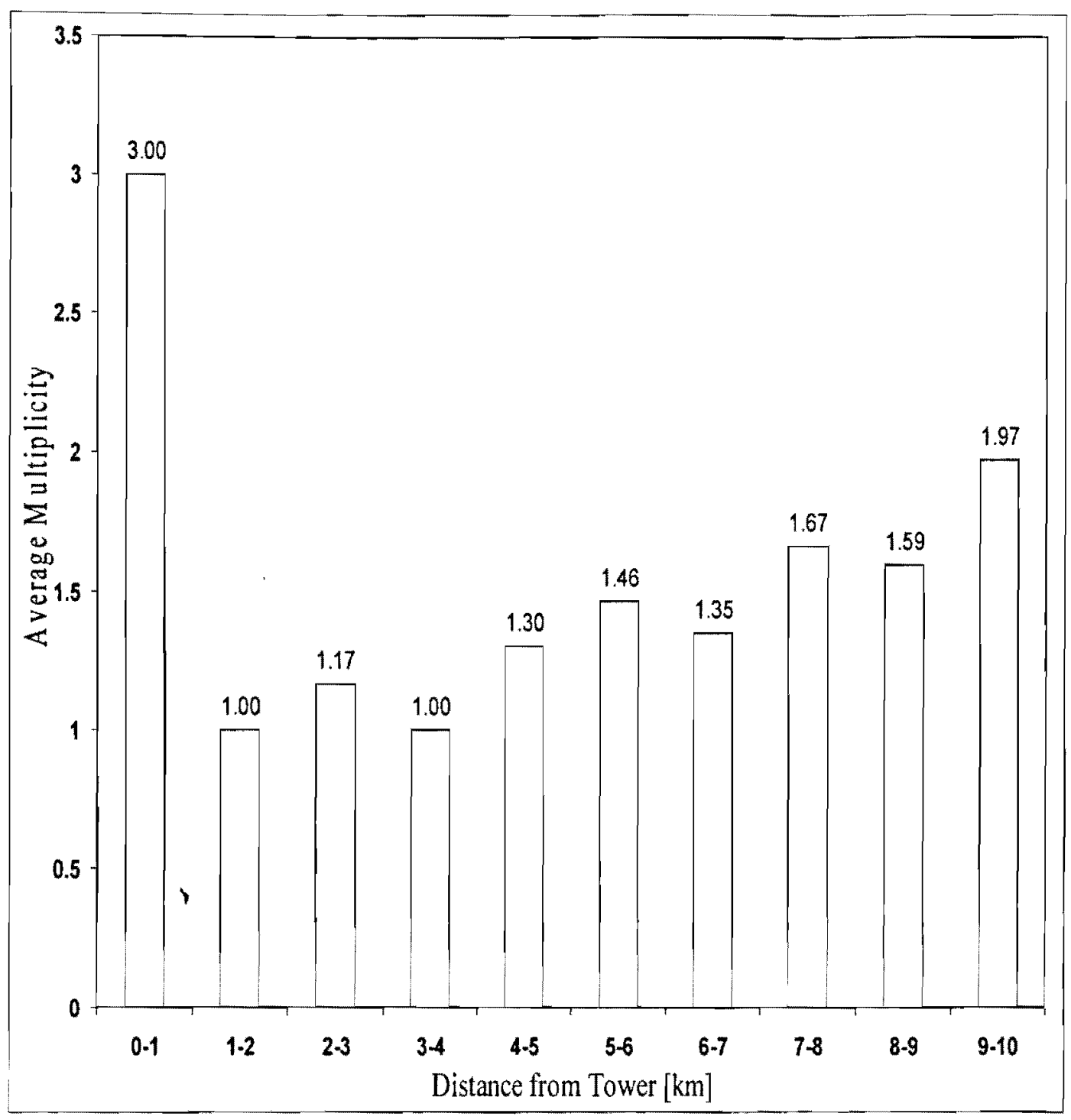

Figure 5.14: Average flash multiplicity vs distance from Tower (10 km radius) August 19, 2005

This analysis shows how important the August 19,2005 storms are in the study of lightning and severe storms to tall structures. The more strokes per flash the more damage caused as all those strokes hit the tower or immediate surrounding area which increases the electromagnetic radiation in the area. This is important as it supports the conclusions about not having radio/television and/communication towers within a close proximity to the tower. However, this is not possible when having such a tall structure in a very busy and crowded downtown core like the position of the $\mathrm{CN}$ Tower in Toronto. Therefore, protection systems need to protect against all these effects to protect not only the tower, but the surrounding area. 
Now, the flash multiplicity for both the positive and negative flashes should be looked at separately in order to distinguish between the two. The multiplicity determined from NALDN data is also compared to the multiplicity determined by the data obtained by the field (accurate stroke count methods), where for the CN Tower, is located $2 \mathrm{~km}$ north of the Tower.

The percentage of single stroke flashes and multiplicity are lightning characteristics that are clearly sensitive to the reliability of the stroke identification process [5]. Knowledge of the relative occurrence of single and multiple stroke flashes is needed in estimating the probability of successful circuit-breaker re-closure following a lightning-caused outage of a power line [5]. It is observed that negative flashes usually have $3-5$ strokes at least and positive flashes usually have only a single stroke followed by continuing current [5]. There is no consensus as of yet why this is the case.

For the whole year 2005 , for a $100 \mathrm{~km}$ radius around the CN Tower using NALDN data for a total of 74829 flashes, 10191 are positive and 64638 are negative. Therefore only $15.77 \%$ of the total flashes are positive.

For August 19, 2005 for a $100 \mathrm{~km}$ radius around the CN Tower using NALDN data for a total of 12559 flashes, 3122 are positive and 9437 are negative. Therefore, $33.08 \%$ of the total flashes on this day are positive. When looking at the multiplicity for negative and positive flashes for this day, the multiplicity is 2.84 and 1.31 , respectively. This shows that the multiplicity of negative flashes is more than twice the amount than the multiplicity for positive flashes. The comparison between the measured values (field data) and the estimated values (NALDN data) for August 19, 2005 is looked at in section 7.9 in more detail.

It is clear from the estimated data (NALDN) shows more single stroke flashes then the measured data. NALDN does not pick up smaller currents, which is the usual case for subsequent strokes of a multiple stroke flash [5]. The measured (field) data does show more multiple stroke flashes as the equipment, in this case for the $\mathrm{CN}$ Tower, is located $2 \mathrm{~km}$ North of the tower, therefore, it stands to reason that the data collected for the area surrounding the $\mathrm{CN}$ Tower will be more accurate than the NALDN system. 
For the $\mathrm{CN}$ Tower, it is clear that on average it has substantially more strokes per flash than flashes occurring elsewhere, as shown in Figure 5.15, which shows the cumulative distribution of the number of strokes per flash. Actually, the further you move away from the $\mathrm{CN}$ Tower the fewer strokes per flash. When looking at more data like the $100 \mathrm{~km}$ line and the $10 \mathrm{~km}$ line, as expected, when more data is considered, there are more strokes per flash.

There are 6 flashes total for the $\mathrm{CN}$ Tower line, 174 flashes total for the $10 \mathrm{~km}$ line (not including the $\mathrm{CN}$ Tower flashes), and 12553 flashes total for the $100 \mathrm{~km}$ line (not including the $\mathrm{CN}$ Tower flashes). For all three lines, at least 1 stroke is found in $100 \%$ of the data (there is at least 1 stroke per flash).

For $\mathrm{CN}$ Tower, $83.33 \%$ of the flashes have 2 or more strokes so only $16.67 \%$ of the flashes are single stroke. On this day the most strokes that hit the tower per flash was 6 and that contributed to $16.67 \%$ of the data (interestingly same as single stroke flashes).

For $100 \mathrm{~km}$ radius, $43.36 \%$ of the flashes have 2 or more strokes so a majority of $56.64 \%$ of the flashes is single stroke. Just to compare to the CN Tower flashes, for $100 \mathrm{~km}$ radius, $11.72 \%$ have 6 or more strokes with the highest number being 15 or more which is a mere $0.21 \%$ of the flashes.

For $10 \mathrm{~km}$ radius, $23.56 \%$ of the flashes have 2 or more strokes so a huge majority of $76.44 \%$ of the flashes is single stroke. Again for comparison, $3.45 \%$ have 6 or more strokes with the highest number being 10 or more which is again a mere $0.57 \%$.

This graph shows that when looking at the $\mathrm{CN}$ Tower, the $\mathrm{CN}$ Tower has a $253.69 \%$ increase in the number of strokes per flash that hit the $\mathrm{CN}$ Tower compared to strokes hitting anywhere within $10 \mathrm{~km}$ of the tower. 


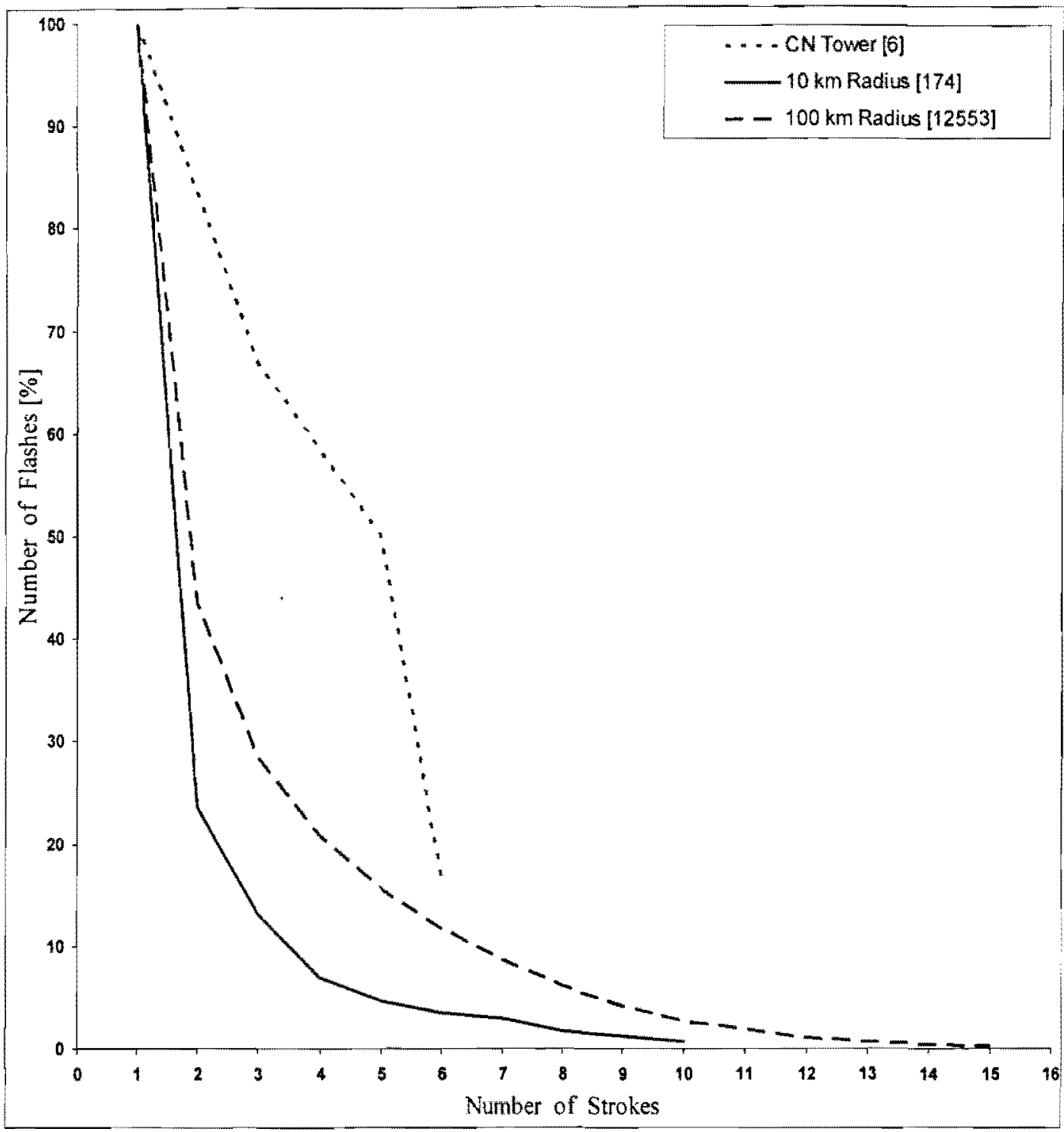

Figure 5.15: Cumulative distribution of the number of strokes per flash for August 19, 2005 


\subsection{Flash Duration}

The flash duration is defined as the time between the appearance of the first stroke in the flash and the disappearance of the last time of the last stroke in the flash. The interstroke time is the time between adjacent strokes. For example, if there are 3 strokes per flash, stroke 1, stroke 2 , and stroke 3 , then the flash duration would be stroke 3 time - stroke 1 time. In this case there are 2 interstroke times, interstroke 1 would be stroke 2 time - stroke 1 time and interstroke 2 would be stroke 3 time - stroke 2 time. Only multiple stroke flashes are considered here as it is difficult to determine the duration for single stroke flashes unless a sub $\mathrm{ms}$ time resolution is available. The given NALDN time resolution is $1 \mathrm{~ms}$. When looking at Figure 5.16, the average flash duration for multiple stroke flashes versus distance from the Tower $(0-10 \mathrm{~km})$ for August 19 , 2005 , the average flash duration for $0-1 \mathrm{~km}$ radius is 0.3476 seconds. For just slightly further at $1-2 \mathrm{~km}$ from the tower, the flash duration is 0 (since no multiple stroke flashes) and $2-3 \mathrm{~km}$ is 0.01 seconds. The flash duration is the highest $0-1 \mathrm{~km}$ then anywhere else within a $10 \mathrm{~km}$ radius of the tower expect for the area of 5-6 km radius where the flash duration is 0.412 seconds.

This shows that the flashes last longer for tower flashes (NALDN estimated locations are within $1 \mathrm{~km}$ from the tower) within $1 \mathrm{~km}$ of the tower which is very important in protection for this area.

Flashes with long durations and with a large number of strokes constitute a more severe threat to electrical power installations [1]. On average, the $\mathrm{CN}$ Tower flashes are substantially longer and do contain a larger number of strokes compared to all other flashes. 


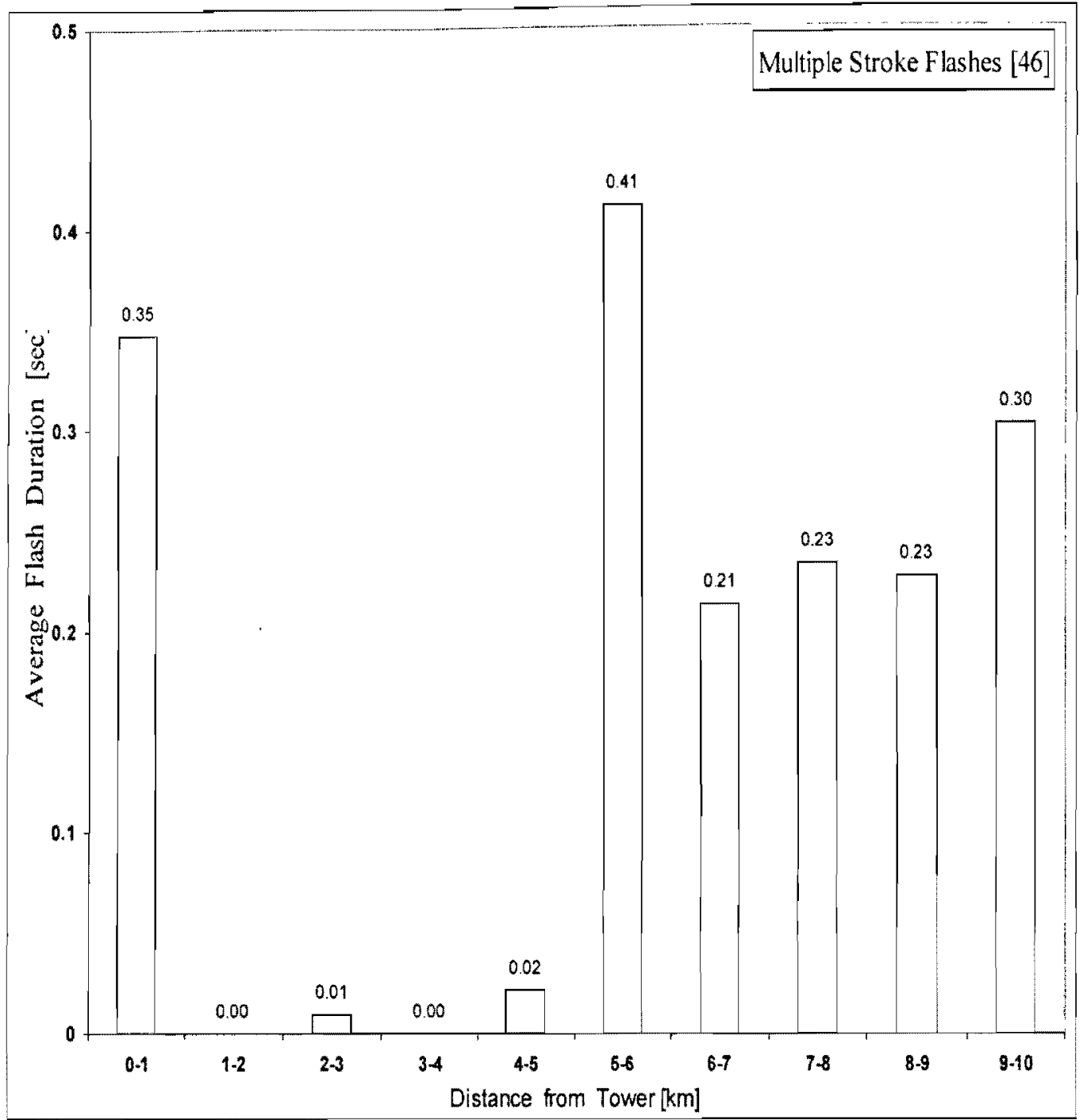

Figure 5.16: Average flash duration for multiple stroke flashes vs distance from the Tower (10 km radius) August 19,2005

The flash duration for the $\mathrm{CN}$ Tower flashes are longer when compared to the flashes occurring elsewhere within a $10 \mathrm{~km}$ radius of the tower. Since the flashes at the tower have more strokes to consider, then it is expected that the duration of the flashes would be longer. This is crucial in lightning protection as the need for protecting the $\mathrm{CN}$ Tower and the surrounding area grows with the length of the flash that is occurring there.

The cumulative distribution of flash duration for multiple stroke flashes for August 19, 2005 can be seen in figure 5.17. For the $\mathrm{CN}$ Tower flashes, 5 out of the 6 are multiple stroke flashes so 
those are the ones considered for this graph. All flashes last $100 \mathrm{~ms}$ or more for the longest time being $700 \mathrm{~ms}$ or more which occurs $20 \%$ of the time.

For $10 \mathrm{~km}$ around the $\mathrm{CN}$ Tower, all flashes last at least $0.0001 \mathrm{~ms}$ with only $66.67 \%$ of the flashes lasting longer than $100 \mathrm{~ms}$. The longest, being $900 \mathrm{~ms}$ account for only $2.2 \%$ of the time. $4.44 \%$ of the flashes last $700 \mathrm{~ms}$ or more. This shows that for the longest time of $700 \mathrm{~ms}$ for the $\mathrm{CN}$ Tower, the $\mathrm{CN}$ Tower flashes last $350.45 \%$ longer than for those hitting anywhere within 10 $\mathrm{km}$ of the $\mathrm{CN}$ Tower.

There is a very strong correlation between flash duration and the objects height, putting the tall structure more and more in danger due to length of flashes occurring.

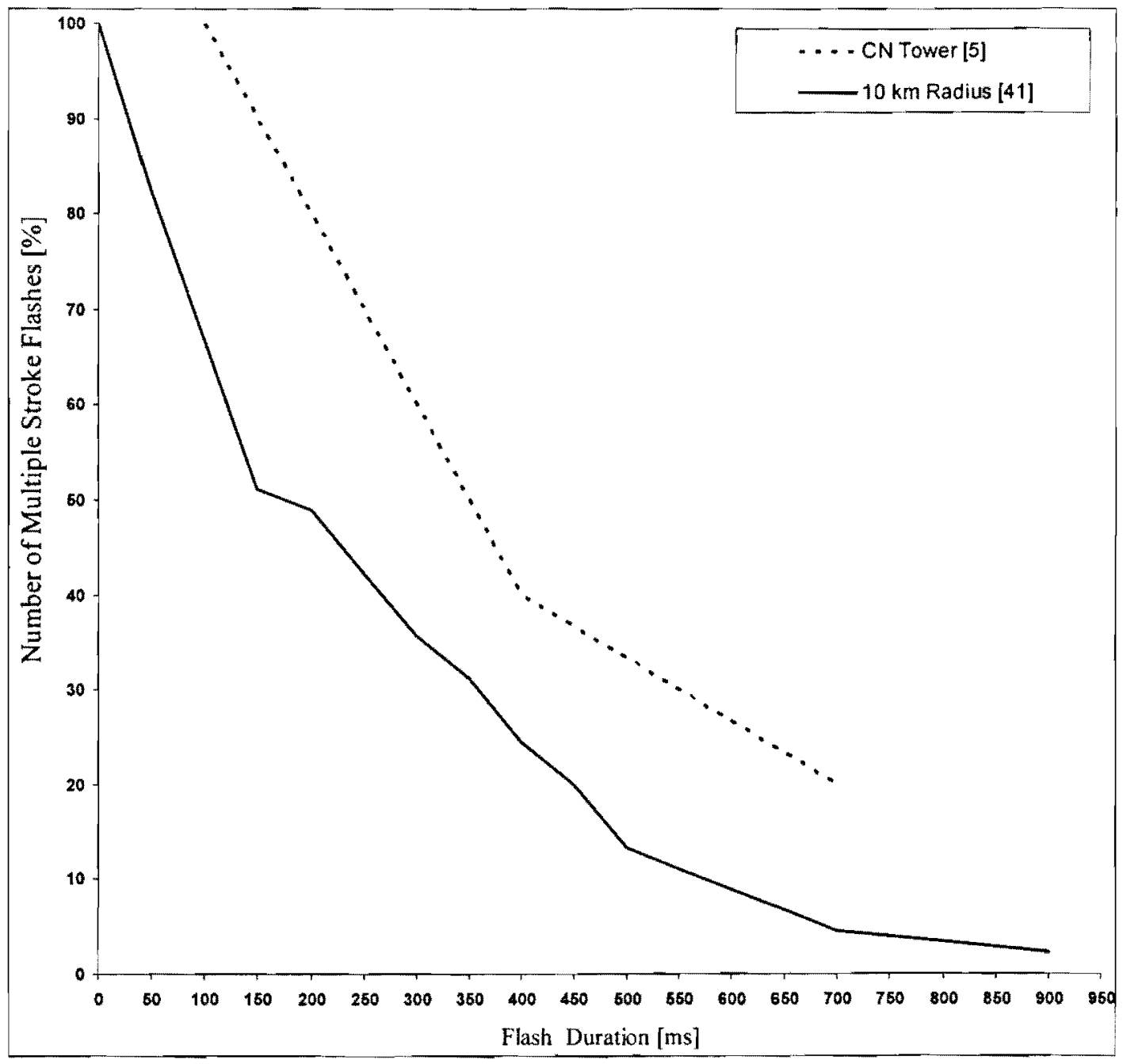

Figure 5.17: Cumulative Distribution of the Number of Multiple Stroke Flashes for August 19, 2005 


\subsection{Stroke Density}

Stroke density at and in the vicinity of the tower is also determined. Stroke density is defined as the total number of strokes per square $\mathrm{km}$ per year. For a $100 \mathrm{~km}$ radius around the $\mathrm{CN}$ Tower for 2005 , the stroke density for positive and negative strokes combined is $181949 / \Pi(100)^{2}=$ 5.792 strokes $/ \mathrm{km}^{2} /$ year. For August 19, 2005 the stroke density for both positive and negative strokes combined is $30901 / \pi(100)^{2}=0.984$ strokes $/ \mathrm{km}^{2}$. This means that relative to 2005 , $16.983 \%$ of the strokes $/ \mathrm{km}^{2}$ occurred on August 19, 2005.

For stroke data, August 192005 and the whole year of 2005 are both investigated separately for $\mathrm{CN}$ Tower strokes for $10 \mathrm{~km}$ radius around the tower, and also for $100 \mathrm{~km}$ radius around the tower. The $10 \mathrm{~km}$ and $100 \mathrm{~km}$ radius data excludes tower's strokes.

For August 19, 2005, as mentioned before, the total number of strokes detected by the NALDN and was confirmed to have hit the tower is 22 . The total number of strokes within 10 $\mathrm{km}$ is 281 and the total number of strokes within $100 \mathrm{~km}$ is 30,879 .

For the whole year of 2005, the total number of strokes confirmed by the $\mathrm{CN}$ Tower current measurement system to hit the tower is 24 . The total number of strokes within $10 \mathrm{~km}$ is 878 and the total number of strokes within $100 \mathrm{~km}$ is 181,925 . The additional 2 strokes for the whole year data that hit the tower both belong to the flash on June $15^{\text {th }}$.

Further, it is interesting to note that when comparing August 19, 2005 to the whole year of 2005 for $10 \mathrm{~km}$ radius around the tower, the number of strokes that occurred $10 \mathrm{~km}$ or more from the tower is $3.91 \%$ for August 19 and $3.30 \%$ for the whole year. These values are very close but once again, August $19^{\text {th }}$ is higher even though this day (within $10 \mathrm{~km}$ radius) only accounts for 281 out of 878 or $32 \%$ of the data. 


\subsection{The Current}

In most cases, as the height of the elevated struck object increases, the conducted statistical analysis shows a decrease in the current peak [20]. Higher height should result in a lower current peak value [20] but the flashes to the $\mathrm{CN}$ Tower show just the opposite. On average, the current is higher at the tower, then the surrounding area, during the summer months.

The higher the current the more damage it causes to a building and its surrounding area. When looking at Figure 5.18, the average current $(\mathrm{kA})$ versus distance from the tower $(0-10 \mathrm{~km})$ for all flashes (current in the first stroke of each flash represents the current for that flash) for August 19,2005, one can see that the closer the lightning is to the CN Tower, the higher the current, jeopardizing the surrounding area around the tower and showing the need for excellent lightning protection measures. At $0^{+}-1 \mathrm{~km}$ from the tower, the average current for-ve flashes is $20.89 \mathrm{kA}$ and from $1^{+}-2 \mathrm{~km}$ from the tower the average current for -ve flashes slightly decreases to $20.6 \mathrm{kA}$. There is then a dramatic drop from $2^{+}-3 \mathrm{~km}$ where the average current for-ve flashes is $13.7 \mathrm{kA}$. This shows that the average current for $-\mathrm{ve}$ flashes at $0^{+}-1 \mathrm{~km}$ is $78.27 \%$ higher here then just a few km's away in the $2^{+}-3 \mathrm{~km}$ range.

There are many more flashes away from the tower than at the tower, but the majority of those within a close proximity ( 6 out of 8 within $1 \mathrm{~km}$ ) hit the tower. The maximum peak current on August 19, 2005 is $109 \mathrm{kA}$, occurring $7.5-8 \mathrm{~km}$ from the $\mathrm{CN}$ Tower.

From looking at the $0^{+}-1 \mathrm{~km}$ radius around the CN Tower, 6 out of the 8 or $75 \%$ of the flashes in this region actually hit the tower (as verified by $\mathrm{CN}$ Tower current and video recording systems). The average value of the current for these 6 -ve flashes (which contained 22 strokes) is $23.93 \mathrm{kA}$ and the average value of the current for the remaining 2 non-CN Tower flashes is 9.65 $\mathrm{kA}$. This shows that $\mathrm{CN}$ Tower return strokes may have larger peak currents, than those occurring in its immediate vicinity. More data is needed to confirm this finding.

There are no positive return stroke currents within the first $2 \mathrm{~km}$ of the $\mathrm{CN}$ Tower. However, 4 out of the 6 flashes occurring at $2^{+}-3 \mathrm{~km}$ from the tower were +ve with an average peak current 
of $10.73 \mathrm{kA}$. The highest value of positive peak current was $27.73 \mathrm{kA}$, which occurred between $4^{+}-5 \mathrm{~km}$ radius of the tower.

The determination of return-stroke current peak values is quite important in lightning protection as the severity of the damage caused by lightning strikes is very dependant on the peak current. The analysis of the data shows that strikes to the $\mathrm{CN}$ Tower and objects in its immediate surrounding area feature higher return-stroke peak currents. Therefore, the need for more protection is obvious. 


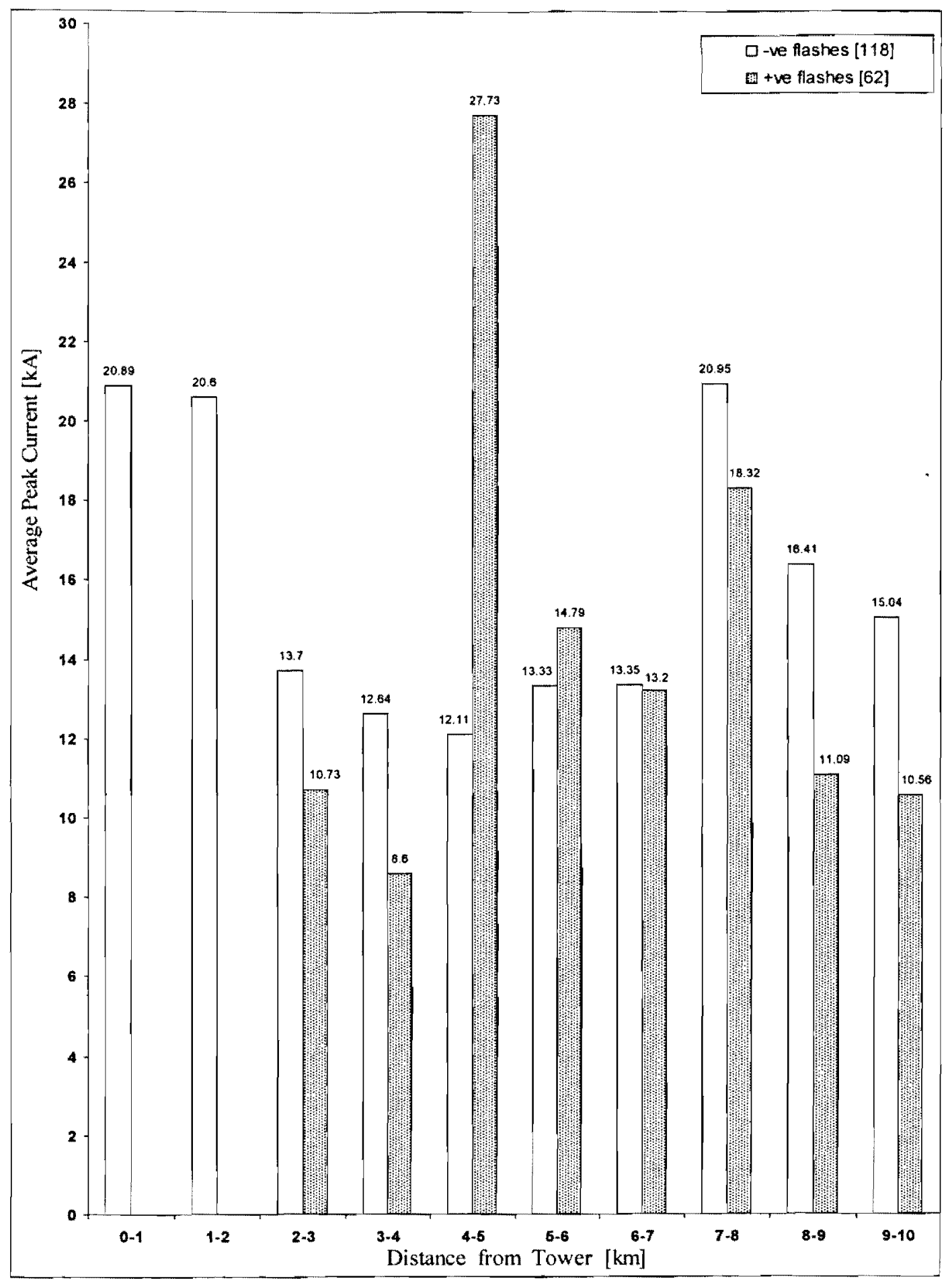

Figure 5.18: Average peak current ( $\mathrm{kA}$ ) vs distance from the $\mathrm{CN}$ Tower ( $10 \mathrm{~km}$ radius) August 19, 2005 lightning events (distance is defined as $0^{+}-1,1^{+} 2, \ldots, 9^{+}-10$ ) 
Figure 5.19 shows the cumulative distribution of the peak current for $\mathrm{CN}$ Tower stroke and ve and +ve non-CN Tower strokes occurring on August 19, 2005. The 22 strokes that hit the $\mathrm{CN}$ Tower are only -ve strokes. For up to $10 \mathrm{~km}$ radius around the tower (not including $\mathrm{CN}$ Tower strokes), there were 209 -ve strokes and 72 +ve strokes (for a total of 281 strokes). For CN Tower strokes, the peak current variation range is $5-40 \mathrm{kA}$. The $\mathrm{CN}$ Tower peak current median value at $50 \%$ probability level is almost double its median value for non-CN Tower strokes within $10 \mathrm{~km}$ from the tower. However the NALDN estimated peak current of CN Tower strokes was proved to be about 2.6 times the directly measured current [5].

The highest -ve stroke peak current recorded within $10 \mathrm{~km}$ of the tower was found to be 105 $\mathrm{kA}$ which only occurs $0.48 \%$ of the time and the highest +ve stroke peak current recorded within $10 \mathrm{~km}$ of the tower is $+95 \mathrm{kA}$ which occurs $1.39 \%$ of the time.

We are more concerned with -ve stroke peak current when looking at them separately as this one occurs more often and is the only one occurring at the CN Tower on August 19, 2005. That being said, it is interesting to note that of the total strokes of 209 within $10 \mathrm{~km}$ of the tower (not including the 22 tower strokes), 72 were +ve. This means that $35.45 \%$ of the strokes had +ve stroke peak currents. 


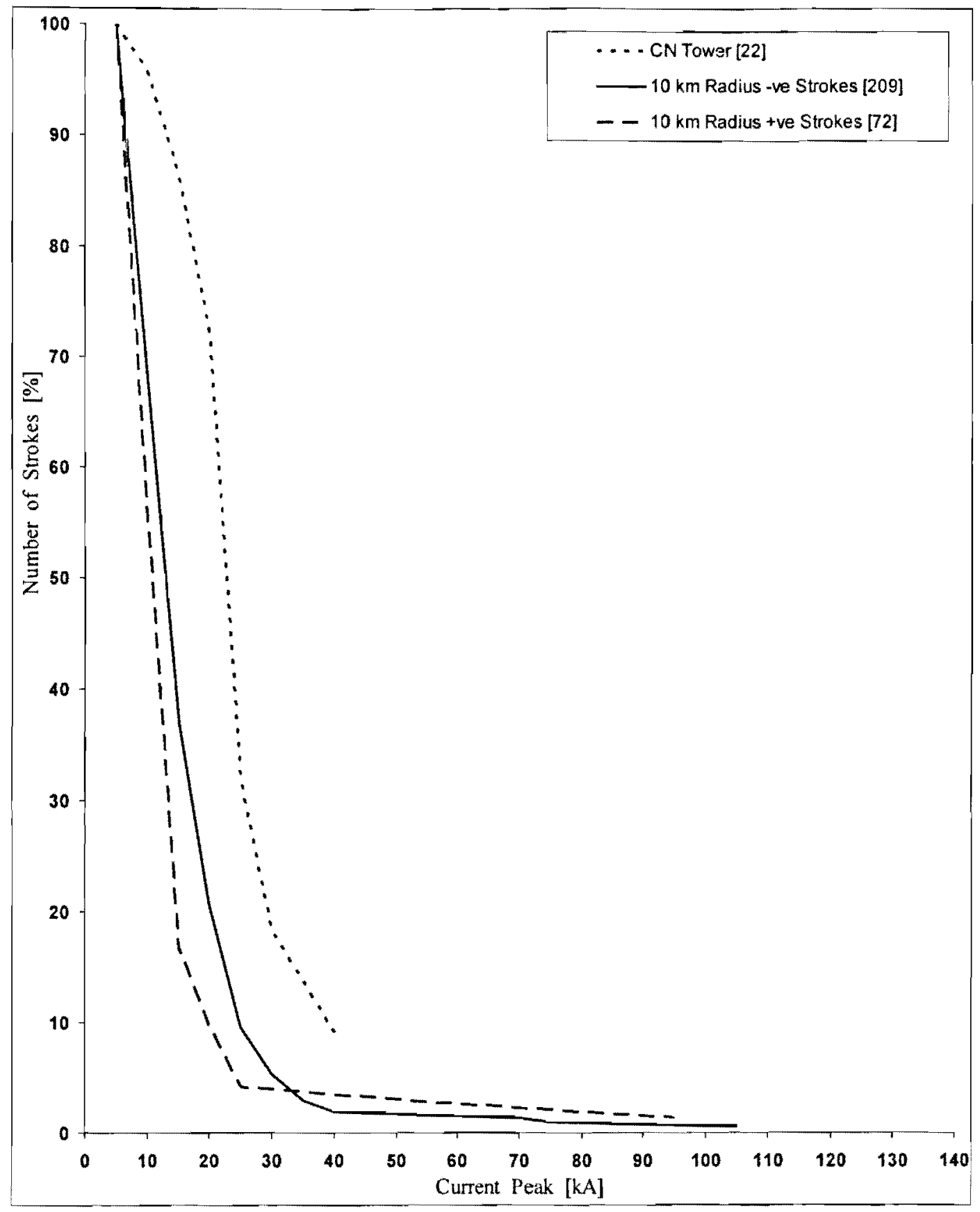

Figure 5.19: Cumulative distribution of the peak current for August 19, 2005 


\subsection{The Lightning Electromagnetic Pulse (LEMP)}

The electric and magnetic field waveforms generated by a $\mathrm{CN}$ Tower lightning return-strokes during the famous storm of August 19,2005 are previously shown in Figures 3.6 and 3.7, respectively. Figures 5.20 and 5.21 present the cumulative statistics of the electric field wavefront peak and the $10 \%$ to $90 \%$ risetime to the peak, respectively, for $\mathrm{CN}$ Tower and non$\mathrm{CN}$ Tower lightning return strokes during the August 19, 2005 lightning events. The total number of $\mathrm{CN}$ Tower and non-CN Tower strokes measured by the field sensors is 37 and 11 , respectively.

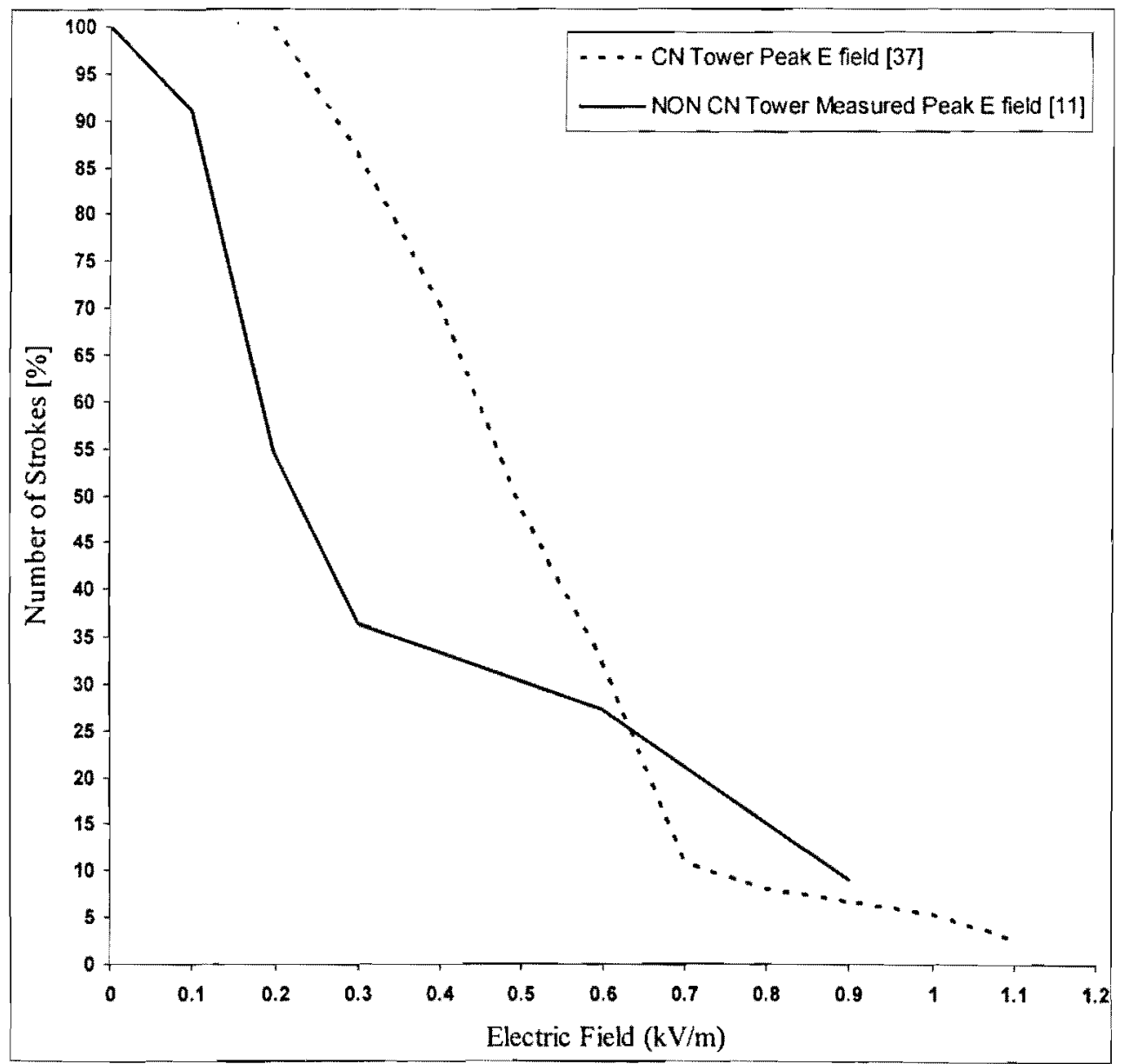

Figure 5.20: Cumulative distribution of the electric field peak for August 19, 2005 lightning events 


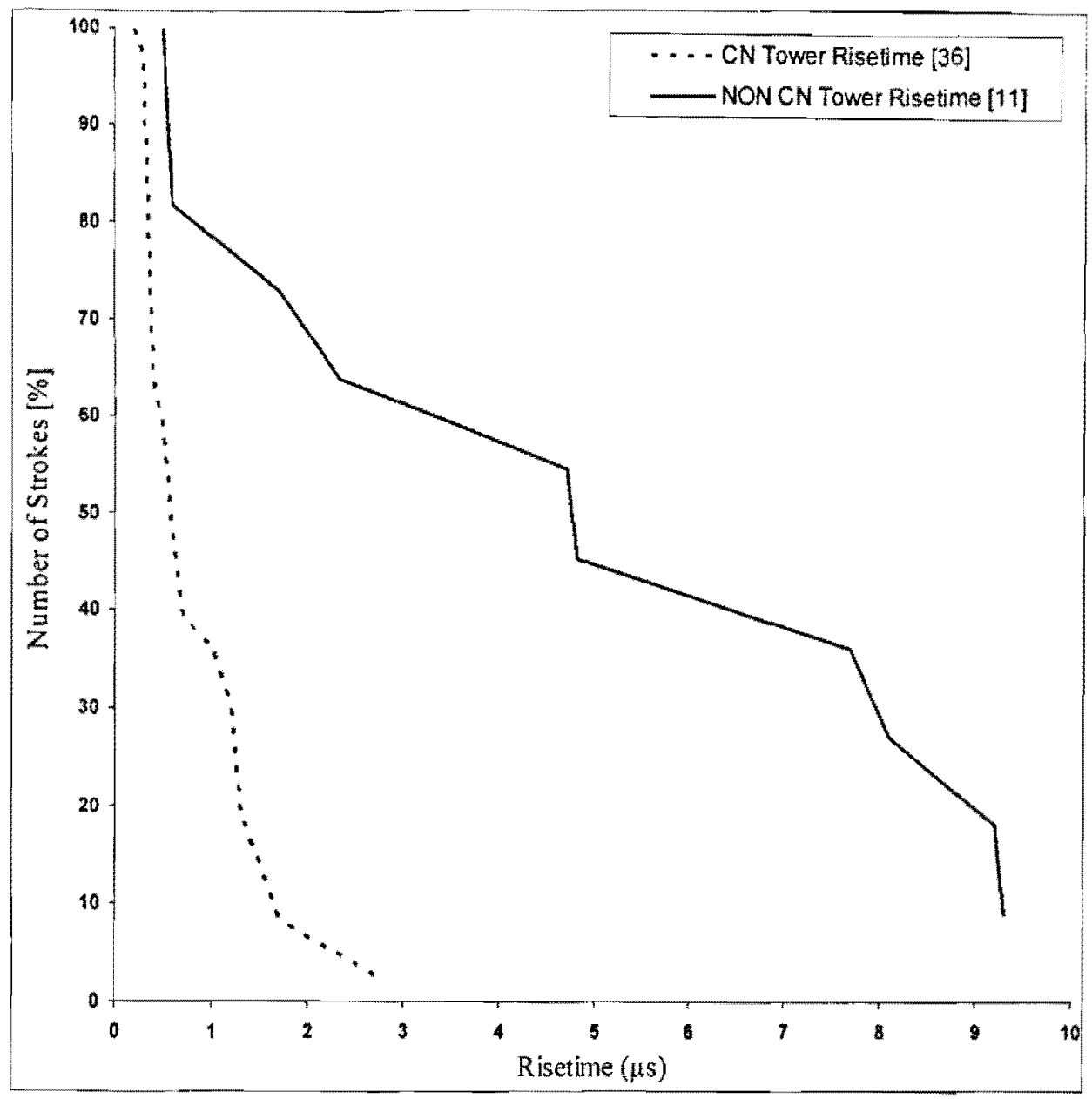

Figure 5.21: Cumulative distribution of the electric field risetime for August 19, 2005 lightning events

Although some of the locations of the non-CN Tower flashes are further away from the $\mathrm{CN}$ Tower in comparison to the location of field sensors, the results show a remarkable increase in the electromagnetic interference (EMI) near an extremely tall structure. This is evident since a substantial increase in the electric field peak, accompanied by a substantial decrease in the risetime, must result in a great increase in the field wavefront steepness. Furthermore, the frequency of lightning strikes to a structure rapidly increases as a function of its height. It can then be concluded that electronic and communication systems located in the vicinity of a very tall structure must be specially protected from the lightning-generated electromagnetic pulse (LEMP).

Ideally, there should not be any communications networks and/or power systems and/or businesses or homes in the close proximity of a tall structure like the CN Tower due to the high 
electromagnetic radiation and damaging current effects. This is quite difficult if not impossible for the $\mathrm{CN}$ Tower, due to its location in the heavily populated downtown core of a major city. Therefore, the presented statistical results will assist in the establishment of a more sophisticated approach in designing protective measures against of lightning, especially from lightning occurring at hazards tall structures or in mountainous areas. 


\section{Chapter 6}

\section{Conclusions and Future Research}

\subsection{Conclusions}

Although, extensive analysis have been performed concerning the characteristics of lightning strikes to the $\mathrm{CN}$ Tower, not much attention has been given to the characteristics of lightning strikes in the vicinity of the tower or the influence the tower has on the lightning environment around it. This thesis is believed to be the first to fill such a gap and tries to answer these questions.

Lightning research at the $\mathrm{CN}$ Tower is important in order to understand the physics of tallstructure lightning, which enables the establishment of more sophisticated lightning protection procedures, especially at tall structures and power lines routed through mountainous terrain. This research will also help in understanding the risk of electromagnetic interference resulting from LEMP to electronic and communication systems located in the vicinity of a tall structure.

The diurnal distribution of flashes for $10 \mathrm{~km}$ radius of the $\mathrm{CN}$ Tower for 2005 , July and August 2005, and August 19, 2005 show that the majority of flashes occurred in the mid afternoon for the summer months. Although more years of data could show further details concerning diurnal distribution, the analysis points out to the best time to do any repair or maintenance work in power utilities at or within a close proximity of the $\mathrm{CN}$ Tower would be during the morning hours and even better during the late evening hours, at least for the summer months. 
When looking at the flash locations for a maximum of $20 \mathrm{~km}$ radius of the $\mathrm{CN}$ Tower, most flashes are located in the region north-west of the tower. There are less flashes occurring northeast of the Tower. The CN Tower seems to provide a degree of protection to the area east of it. This may be due to the fact the storms start in the west and move east. It is also interesting to see that there is an area about $0-4 \mathrm{~km}$ radius from the tower that had very few flashes. This area seems to be protected by the tower.

Flash density is defined as the total number of flashes per square $\mathrm{km}$ per year. This factor is very important as it show the extent of the severity of lightning flashes and the effect of the $\mathrm{CN}$ Tower. The analysis of August 19, 2005 flash data shows that there was substantially lower flash density within about $4 \mathrm{~km}$ around the $\mathrm{CN}$ Tower in comparison with areas further away from the tower. This points out to the existence of a protection cone for the area within the immediate vicinity to the tower.

Flash multiplicity analysis shows that $\mathrm{CN}$ Tower flashes have on average more strokes per flash than flashes striking objects in the vicinity of the tower. Of course, the more strokes per flash the more damage caused.

Flash duration analysis shows that flashes to the $\mathrm{CN}$ Tower statistically last longer than flashes occurring in its vicinity. A flash with long duration and a large number of strokes presents a more severe threat to electrical power installations. On average, $\mathrm{CN}$ Tower flashes are substantially longer and do contain larger number of strokes compared to non-CN Tower flashes.

The determination of return-stroke current peak values is quite important in lightning protection as the severity of the damage caused by lightning strikes is very dependant on the peak current. The analysis of the data shows that on average strikes to the $\mathrm{CN}$ Tower feature higher return-stroke peak currents than strikes to objects around the tower. Therefore, the need for more protection to the tower is obvious.

The lightning-generated electromagnetic pulse is a very important factor is lightning studies. Although some of the locations of the non-CN Tower flashes are further away from the $\mathrm{CN}$ Tower in comparison of the location of field sensors, the results show a remarkable increase in 
the electromagnetic interference (EMI) near an extremely tall structure. This is evident since a substantial increase in the electric field peak, accompanied by a substantial decrease in the risetime, must result in a great increase in the field wavefront steepness. Furthermore, the frequency of lightning strikes to a structure rapidly increases as a function of its height. It can then be concluded that electronic and communication systems located in the vicinity of a very tall structure must be specially protected from the lightning-generated electromagnetic pulse.

\subsection{Future Research}

The studies of lightning at the $\mathrm{CN}$ Tower should be continued in order to account for a few details that have not yet been determined. For one, all the data, unless otherwise mentioned, comes from the North American Lightning Detection Network (NALDN). Due to the CN Tower's height and the effects of its presence shown in this paper, there should be more equipment set up around the $\mathrm{CN}$ Tower in order to record field data. A more extensive analysis is needed to confirm some of the findings related to the parameters of LEMP.

Further, it is observed that negative flashes usually have 3-5 strokes at least and positive flashes usually have only a single stroke followed by continuing current. There is no consensus as of yet why this is the case and this needs to be looked at in further detail.

More needs to be done to determine any further patterns concerning time of flashes. As it looks now, the best time to do any repair or maintenance work in power utilities at or within a close proximity of the $\mathrm{CN}$ Tower would be during the morning hours and even better during the late evening hours, at least for the summer months. During the summer months, the hottest time of day is during the mid afternoon so that may be a reason why the majority of flashes occur during 2-3 pm. More should be done to look into this.

Also the analysis of the data for 2005 shows that CN Tower return strokes may have larger peak currents, than those occurring in its immediate vicinity. More data is needed to confirm this finding. 


\section{References}

[1] A.M. Hussein, W. Janischewskyj, J.S. Chang, V. Shostak, W. Chisholm, P. Dzurevych and Z.I. Kawasaki, "Simultaneous Measurement of Lightning Parameters for Strokes to the Toronto CN Tower," Journal of Geophysical Research-Atmosphere, vol. 100, no. 5, pp. 8853-8861, May 1995.

[2] Environment Canada, "The Canadian Lightning Detection Network," December 2002 $<$ http://www.weatheroffice.ec.gc.ca/lightning/index_e.html $>$.

[3] Martin Uman, “All About Lightning,” Dover Publications, Inc., New York, 1986.

[4] Martin Uman, "The Lightning Discharge," Academic Press, 1987.

[5] A. Lafkovici and A.M. Hussein, W. Janischewskyj and K. Cummins, "Performance analysis of the North American Lightning Detection Network using CN Tower Lightning data," International Lightning Detection Conference, pp 1-32, Tucson, Arizona, April 24-25, 2006.

[6] A.M. Hussein, M. Milewski, A. Abdelraziq, W. Janischewskyj and F. Jabbar, "Visual Characteristics of CN Tower Lightning Flashes," Proceedings of the $28^{\text {th }}$ International Conference on Lightning Protection (ICLP), pp. 89-94, Kanazawa, Japan, September 18-22, 2006.

[7] A.M. Hussein, M. Milewski, W. Janischewskyj, F. Noor, and F. Jabbar, "Characteristics of lightning flashes striking the CN Tower below its tip," Journal of Electrostatics, vol. 56, no. 5-6, pp. 307-315, May 2007.

[8] A.M. Hussein, W. Janischewskyj, M. Milewski, V. Shostak, J.S. Chang and W. Chisholm, "Current waveform parameters of CN Tower lightning return strokes," Journal of Electrostatics, Vol. 60, Nos. 2-4, pp. 149-162, March 2004.

[9] A.M. Hussein, W. Janischewskyj and M. Milewski, "Waveform parameters of the electromagnetic pulse generated by first and subsequent lightning return strokes to the $\mathrm{CN}$ Tower," Proceedings of the $17^{\text {th }}$ International Symposium on Electromagnetic Compatibility, pp. 394-399, Wroclaw, Poland, June 29-July 1, 2004.

[10] K. Bitner and A.M. Hussein, "Modelling of the CN Tower Lightning Return-Stroke Current Derivative," Proceedings of the $28^{\text {th }}$ International Conference on Lightning Protection (ICLP), pp. 261-266, Kanazawa, Japan, September 18-22, 2006. 
[11] Vaisala, "Lightning Verification Report Frequency Asked Questions," 1998-2004 http://www.lightningstorm.com/tux/isp/cs/products/strikefax/îaq/index.jsp.

[12] M.J. Grogan, "Vaisala's U.S. National Lightning Detection Network: Report on the 20022003 U.S. NLDN System-wide Upgrade," June 2004, Online Brochure: http://www.lightningstorm.com/jsp/discover/nldn/VN_20022003_NLDN_Upgrade_Article June-2004.pdf.

[13] Vaisala, "Environment Canada's CLDN: Canadian Lightning Detection Network," January 2004. [Online Brochure]:

http://www.lightningstorm.com/jsp/discover/nldn/CLDN Brochure B210413ENa Jan2004.pdf.

[14] Richard E. Orville, Gary R. Huffines, William R. Burrows, Ronald L. Holle and Kenneth L. Cummins, "The North American Lightning Detection Network (NALDN) - First Results: 1998-2000," American Meteorological Society, Volume 130 (2002).

[15] R. Siikamaki, "Vaisala expands into lightning data services: Global Atmospherics Inc. joins Vaisala," June 2002. [News Release]:

http://www.vaisala.com/DynaGen_Attachements/Att18434/VN159_p04_05.pdf.

[16] K.L. Cummins and M.J. Murphy, "Overview of lightning detection in the VLF, LF, and VHF frequency ranges," $16^{\text {th }}$ International Lightning Detection Conference, Global Atmospherics, Inc., Tucson, Arizona, November 7-8, 2000.

[17] D.R. MacGorman and W.D. Rust, "The Electrical Nature of Storms," Oxford University Press, March 1998.

[18] V.A. Rakov and M.A. Uman, "Lightning: Physics and Effects," Cambridge Univeristy Press, 2003.

[19] Natural Resources Canada, "Canadian Spatial Reference System," (2006) http://www.geod.nrcan.gc.ca/apps/gsrug/geo e.php.

[20] A.M. Hussein, W. Janischewskyj, M. Milewski, V. Shostak, F. Rachidi and J.S. Chang, "Comparison of Current Characteristics of Lightning Strokes Measured at the CN Tower and at Other Elevated Objects," IEEE International Symposium, Vol. 2, Issue 18-22, pages 495-500, August 2003 


\section{Publications Related to this Research}

[1] V. Todorovski, A.M. Hussein, K.L. Cummins and W. Janischewskyj, "CN Tower: Does It Provide Lightning Protection to Toronto Downtown Area?" accepted for publication, Union Radio-Scintifique General Assembly (URSI), Ottawa, Ontario, Canada, July 22-26, 2007.

[2] V. Todorovski and A.M. Hussein, "CN Tower: Gift or nightmare for Toronto?" Abstract submitted for publication, International Conference for Upcoming Engineers, Ryerson University, Toronto, Ontario, Canada, May 28-29, 2007. 